\title{
Avaliação de fatores prognósticos em tumores de mama nos estádios IIA e IIIB e sua correlação com sobrevida
}

Tese apresentada à Faculdade de Medicina da Universidade de São Paulo para obtenção de título de Doutor em Ciências

Programa de: Oncologia

Orientador: Prof. Dr. Fernando Augusto Soares 


\section{Avaliação de fatores prognósticos em tumores de mama nos estádios IIA e IIIB e sua correlação com sobrevida}

Tese apresentada à Faculdade de Medicina da Universidade de São Paulo para obtenção de título de Doutor em Ciências

Programa de: Oncologia

Orientador: Prof. Dr. Fernando Augusto Soares 
Dados Internacionais de Catalogação na Publicação (CIP)

Preparada pela Biblioteca da

Faculdade de Medicina da Universidade de São Paulo

Creprodução autorizada pelo autor

\section{Carvalho, Solange Maria Torchia}

Avaliação dos fatores prognósticos em tumores de mama nos estádios IIA e IIIB e sua correlação com sobrevida / Solange Maria Torchia Carvalho. -- São Paulo, 2010.

Tese(doutorado)--Faculdade de Medicina da Universidade de São Paulo. Programa de Oncologia.

Orientador: Fernando Augusto Soares.

Descritores: 1.Neoplasias da mama 2.Carcinoma ductal 3.Estadiamento de neoplasias 4.Imunoistoquímica 5.Marcadores biológicos de tumor 6.Sobrevida

USP/FM/DBD-262/10 


\section{Dedico este trabalho}

Aos meus pais, Antônio e Norma, a quem simplesmente devo tudo o que sou.

Ao meu marido, Rodrigo, companheiro nesta e em todas as minhas empreitadas.

Aos meus filhos, Rafaela, Clara e Rodrigo, por existirem.

À minha irmã Nélia, sempre presente em minha vida.

Aos meus sogros, D. Cidinha (in memoriam) e Sr. Marco, cujas histórias médicas ainda me fazem parecer uma caloura e continuam me inspirando.

Ao Dr. Mário Mourão Netto, meu mestre e amigo, principal incentivador da minha carreira como mastologista e a quem devo a finalização de mais esta etapa da minha vida.

Ao meu orientador Prof. Dr. Fernando Augusto Soares, por me guiar neste caminho com tanta paciência e dedicação. 


\section{Agradecimentos}

Agradeço a todos que de alguma forma ajudaram na realização deste trabalho, em especial:

Às pacientes do Hospital do Câncer, sem as quais este trabalho não poderia ter sido realizado.

À Dra. Mitzi Brentani, por ser incansável no seu esforço de ensinar e por ser um exemplo de dedicação e fidelidade às boas idéias.

Aos médicos do Departamento de Mastologia, do Hospital do Câncer, Dr. André Perina, Dr. Carlos Eduardo M. Fontes, Dr. Juan B. Donoso Collins, Dra. Fabiana Baroni A. Makdissi, Dr. Hirofumi Iyeyasu, Dra. Maria do Socorro Maciel e Dr. Wesley Pereira de Andrade, pela participação direta ou indireta na realização deste trabalho.

Ao colega Dr. José Humberto Tavares Guerreiro Fregnani, pelo empenho na análise dos resultados e paciência para passá-los a mim.

Aos membros da banca de qualificação, Prof. Dr. Ademar Lopes, Prof. Dr. André Lopes de Carvalho e Dra Maria Dirlei F. S. Begnami, pelas críticas e sugestões que muito contribuíram para o aprimoramento deste trabalho.

Aos funcionários do Departamento de Anatomia Patológica, em particular ao Sr. Rômulo Akira Miyamura, Sra. Suely Nonogaki, Sr. Severino da Silva Ferreira e à Sra. Liliane C. Afonso, cujo empenho e dedicação tornaram este trabalho viável.

Ao Dr. Rafael Malagoli Rocha, pela ajuda fundamental.

Aos funcionários do SAME, em especial, D. Hirde Contesine e Sr. Luciano Feitosa da Silva.

À Sra. Suely Francisco, chefe da Biblioteca do Hospital do Câncer, pela atenção e colaboração, fundamentais para o bom êxito deste trabalho.

Às secretárias da pós-graduação da Disciplina de Oncologia da Universidade de São Paulo, Sra. Elizângela Dias, Sra. Maria José Gonçalves Benevides e Sra. Rose Arruda, pelo auxílio inestimável. 
Esta tese está de acordo com as normas em vigor no momento desta publicação:

Referências: adaptado de International Committee of Medical Journals Editors (Vancouver)

Universidade de São Paulo. Faculdade de Medicina. Serviço de Biblioteca e Documentação. Guia de apresentação de dissertações, teses e monografias. Elaborado por Anneliese Carneiro da Cunha, Maria Julia de A. L. Freddi, Maria F. Crestana, Marinalva de Souza Aragão, Suely Campos Cardoso, Valéria Vilhena. 2a ed. São Paulo: Serviço de Biblioteca e Documentação; 2005.

Abreviaturas dos títulos dos periódicos de acordo com List of Journals Indexed in Index Medicus. 


\section{SUMÁRIO}

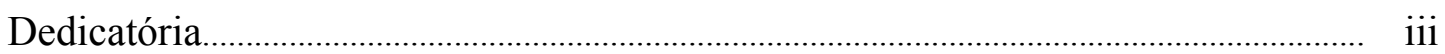

Agradecimentos................................................................................................................ iv

Lista de abreviaturas e siglas................................................................................................... viii

Lista de Tabelas........................................................................................................................ ix

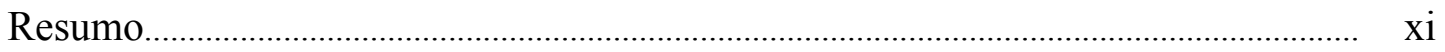

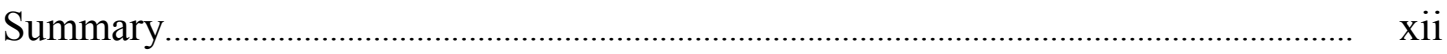

1. INTRODUÇ̃̃

1.1 Classificação molecular do carcinoma de mama.......................................................... 6

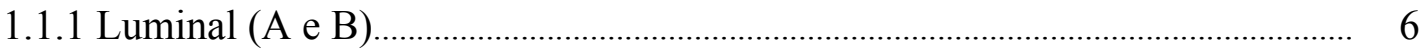

1.1.2 Super-expressores de HER-2 …………………………………………………... 7

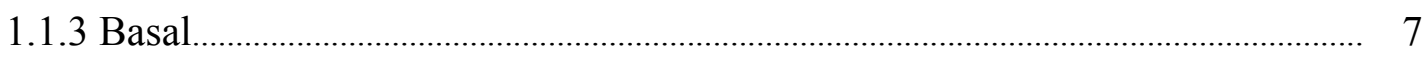

1.1.4 Triplo-negativo......................................................................................................... 10

1.1.5 Normal-like ou perfil similar à mama normal..................................................... $\quad 10$

1.2 Marcadores moleculares da transição epitélio-mesênquima...................................... 12

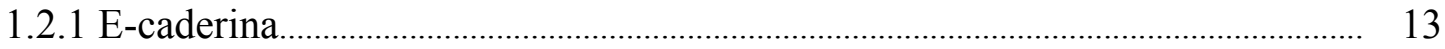

$1.2 .2 \mathrm{~N}$-caderina

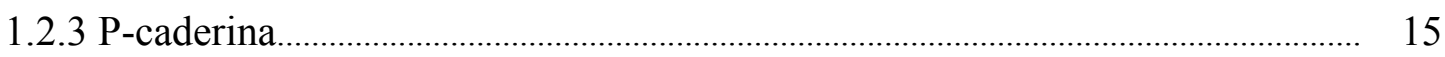

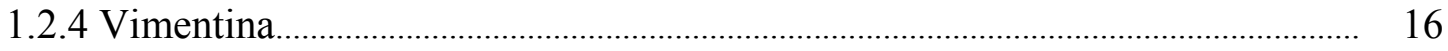

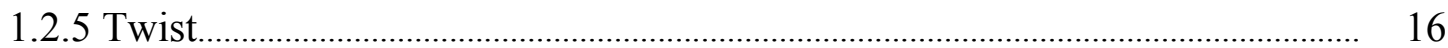

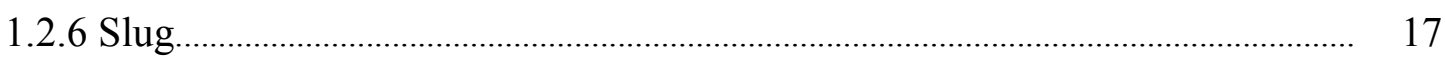

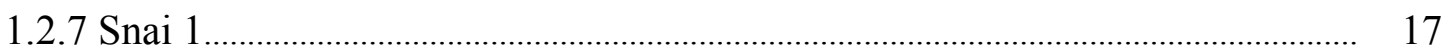

2. OBJETIVOS

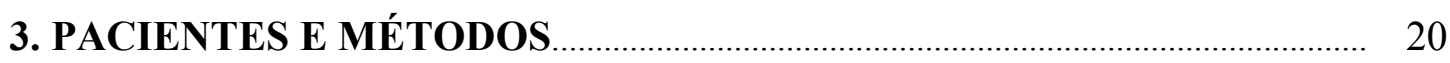

3.1 Pacientes.................................................................................................................... 20

3.1.1 Critérios de inclusão..................................................................................................... $\quad 20$

3.1.2 Critérios de exclusão...................................................................................................... 20 


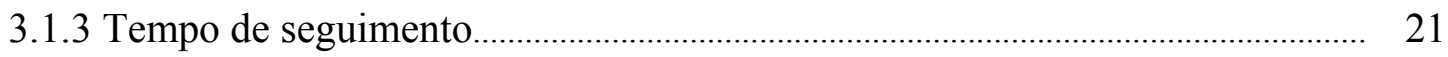

3.1.4 Definição dos estádios IIA e IIIB ............................................................................ 21

3.1.5 Coleta de dados e critérios de revisão das lâminas................................................. 21

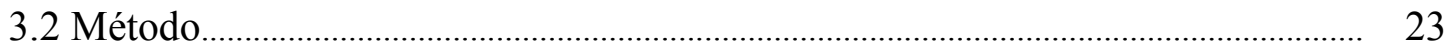

3.2.1 Confecção dos blocos e lâminas dos TMA............................................................... 23

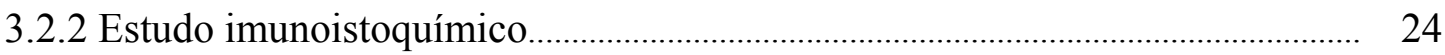

3.3 Definição dos subgrupos moleculares.......................................................................... 29

3.4 Análise estatística dos dados e resultados.................................................................. $\quad 30$

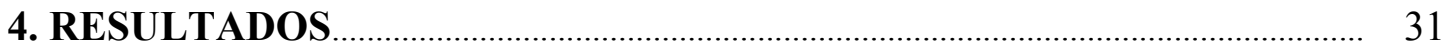

5. DISCUSS ÃO

6. CONCLUSÃO

7. ANEXOS

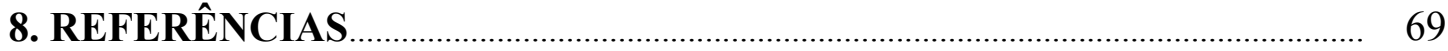

Apêndice 


\begin{tabular}{|c|c|}
\hline BRCA-1 & Breast Cancer Associated Gene -1 \\
\hline CGA & campos de grandes aumentos \\
\hline CDIS & carcinomas ductais in situ \\
\hline CDI & carcinomas ductais invasivos \\
\hline CDI SOE & carcinoma ductal invasivo sem outra especificação \\
\hline cDNA & Ácido desoxirribonucléico codificado \\
\hline $\mathrm{CISH}$ & hibridação in situ cromogênica \\
\hline CK & citoceratinas \\
\hline EGF & epidermal growth factor \\
\hline EGFR & epidermal growth factor receptor \\
\hline et al. & e outros \\
\hline FISH & hibridação in situ fluorescente \\
\hline $\mathrm{GH}$ & grau histológico \\
\hline GN & grau nuclear \\
\hline $\mathrm{HE}$ & hematoxilina/eosina \\
\hline IIQ & imunoistoquímica \\
\hline INCA & Instituto Nacional do Câncer \\
\hline IM & índice mitótico \\
\hline LPS & lipopolissacarídeos \\
\hline NOS-2 & nitric oxide synthase-2 \\
\hline HER-2 & proteina c-erbB-2 \\
\hline p53 & proteína p53 \\
\hline $\mathrm{RE}$ & receptores de estrógeno \\
\hline $\mathrm{RP}$ & receptor de progesterona \\
\hline EMT & epithelial-mesenchymal transition \\
\hline VEGF & vascular endothelial growth factor \\
\hline TMA & tissue microarray ("array de tecido") \\
\hline
\end{tabular}




\section{LISTA DE TABELAS}

Tabela 1 - Distribuição dos casos de acordo com as variáveis clínico-demográficas.........

Tabela 2 - Distribuição dos casos de acordo com as variáveis histopatológicas.

Tabela 3 - Distribuição dos casos de acordo com as variáveis relacionadas com os tratamentos adjuvante e neoadjuvante.

Tabela 4 - Distribuição dos casos de acordo com as variáveis biomoleculares.

Tabela 5 -

Distribuição dos casos de acordo com o perfil fenotípico biomolecular.

Tabela 6 -

Distribuição dos casos de acordo com as variáveis clínico-demográficas e a ocorrência ou não de óbito até 120 meses de seguimento* no grupo de mulheres estadiadas como IIA $(\mathrm{n}=82)$.

Tabela 7 - Distribuição dos casos de acordo com as variáveis relacionadas ao tratamento e a ocorrência ou não de óbito até 120 meses de seguimento* no grupo de mulheres estadiadas como IIA $(\mathrm{n}=82)$.

Tabela 8 - Distribuição dos casos de acordo com as variáveis histopatológicas e a ocorrência ou não de óbito até 120 meses de seguimento* no grupo de mulheres estadiadas como IIA $(n=82)$.

Tabela 9 - Distribuição dos casos de acordo com as variáveis biomoleculares e a ocorrência ou não de óbito até 120 meses de seguimento* no grupo de mulheres estadiadas como IIA $(\mathrm{n}=82)$.

Tabela 10 - Distribuição dos casos de acordo com o perfil biomolecular fenotípico e a ocorrência ou não de óbito até 120 meses de seguimento* no grupo de mulheres estadiadas como IIA $(\mathrm{n}=82)$.

Tabela 11 - Avaliação do risco de óbito em 120 meses* de acordo com o padrão fenotípico Luminal A em análise multivariada (regressão logística). Modelo ajustado por idade, realização de hormonioterapia e quimioterapia adjuvante (número de óbitos considerados no modelo $=21$ ).

Tabela 12 - Avaliação do risco de óbito em 120 meses* de acordo com o padrão fenotípico Luminal B em análise multivariada (regressão logística). Modelo ajustado por idade, realização de hormonioterapia e quimioterapia adjuvante (número de óbitos considerados no modelo $=21$ ).

Tabela 13 - Avaliação do risco de óbito em 120 meses* de acordo com o padrão fenotípico super-expressor de HER-2 em análise multivariada (regressão logística). Modelo ajustado por idade, realização de hormonioterapia e quimioterapia adjuvante (número de óbitos considerados no modelo $=21$ )....

Tabela 14 - Avaliação do risco de óbito em 120 meses* de acordo com o padrão fenotípico triplo-negativo em análise multivariada (regressão logística). Modelo B, ajustado por idade, realização de hormonioterapia e quimioterapia adjuvante (número de óbitos considerados no modelo $=21) \ldots$.

Tabela 15 - Avaliação do risco de óbito em 120 meses* de acordo com o padrão fenotípico Basal em análise multivariada (regressão logística). Modelo ajustado por idade, realização de hormonioterapia e quimioterapia adjuvante (número de óbitos considerados no modelo $=20$ ). 
Tabela 16 - Distribuição dos casos de acordo com as variáveis clínico-demográficas e a ocorrência ou não de óbito até 120 meses de seguimento* no grupo de mulheres estadiadas como IIIB $(\mathrm{n}=180)$.

Tabela 17 - Distribuição dos casos de acordo com as variáveis histopatológicas e a ocorrência ou não de óbito até 120 meses de seguimento* no grupo de mulheres estadiadas como IIIB $(\mathrm{n}=180)$

Tabela 18 - Distribuição dos casos de acordo com as variáveis relacionadas ao tratamento e a ocorrência ou não de óbito até 120 meses de seguimento* no grupo de mulheres estadiadas como IIIB $(\mathrm{n}=180)$.

Tabela 19 - Distribuição dos casos de acordo com as variáveis biomoleculares e a ocorrência ou não de óbito até 120 meses de seguimento* no grupo de mulheres estadiadas como IIIB $(\mathrm{n}=180)$.

Tabela 20 - Distribuição dos casos de acordo com o perfil biomolecular fenotípico e a ocorrência ou não de óbito até 120 meses de seguimento* no grupo de mulheres estadiadas como IIIB $(\mathrm{n}=180)$.

Tabela 21 - Avaliação do risco de óbito em 120 meses* de acordo com o padrão fenotípico Luminal A em análise multivariada (regressão logística). Modelo ajustado por idade, realização de hormonioterapia, quimioterapia adjuvante, quimioterapia neoadjuvante e status linfonodal (número de óbitos considerados no modelo $=96$ )

Tabela 22 - Avaliação do risco de óbito em 120 meses* de acordo com o padrão fenotípico Luminal B em análise multivariada (regressão logística). Modelo ajustado por idade, realização de hormonioterapia, quimioterapia adjuvante, quimioterapia neoadjuvante e status linfonodal (número de óbitos considerados no modelo $=96$ ).

Tabela 23 - Avaliação do risco de óbito em 120 meses* de acordo com o padrão fenotípico super-expressão de HER-2 em análise multivariada (regressão logística). Modelo ajustado por idade, realização de hormonioterapia, quimioterapia adjuvante, quimioterapia neoadjuvante e status linfonodal $\left(\mathrm{n}^{\circ}\right.$ de óbitos considerados no modelo $=96$ ).

Tabela 24 - Avaliação do risco de óbito em 120 meses* de acordo com o padrão fenotípico Triplo-negativo em análise multivariada (regressão logística). Modelo ajustado por idade, realização de hormonioterapia, quimioterapia adjuvante, quimioterapia neoadjuvante e status linfonodal (número de óbitos considerados no modelo $=96$ )...

Tabela 25 - Avaliação do risco de óbito em 120 meses* de acordo com o padrão fenotípico Basal em análise multivariada (regressão logística). Modelo ajustado por idade, realização de hormonioterapia, quimioterapia adjuvante, quimioterapia neoadjuvante e status linfonodal (número de óbitos considerados no modelo $=86$ ) 


\section{RESUMO}

Carvalho, SMT. Avaliação de fatores prognósticos em tumores de mama nos estádios IIA e IIIB e sua correlação com sobrevida [Tese]. São Paulo: Faculdade de Medicina da Universidade de São Paulo; 2010. 76p.

Introdução: Os tumores de mama apresentam uma grande heterogeneidade molecular e clínica. Uma das classificações mais utilizadas no carcinoma de mama, baseia-se em seus aspectos moleculares e subdivide o câncer de mama em cinco grandes grupos baseados na expressão de alguns genes: luminais (A e B), super-expressor de HER-2, tipo basal e aqueles semelhantes à mama normal. Para melhor definirmos estes subgrupos de carcinomas mamários, analisamos diferentes marcadores imunoistoquímicos em dois estádios de pacientes: IIA e IIIB. Objetivo: O objetivo de nosso estudo foi avaliar quais fatores seriam importantes na determinação do prognóstico, tanto nas pacientes estadiadas como IIA quanto nas IIIB, com um período de seguimento de 120 meses, levando em conta dados clínicos e demográficos, características tumorais, tipos de tratamento, diferentes marcadores moleculares da transição epitélio-mesênquima (e-caderina, pcaderina, n-caderina, vimentina, twist, snai 1, slug), o EGFR, a NOS-2 e os diferentes fenótipos (Luminal A, Luminal B, super-expressor de HER-2, basal e triplo-negativo) em câncer de mama. Pacientes e Métodos: A casuística deste estudo é constituída por 268 pacientes portadoras de tumor de mama operadas no Hospital A C Camargo, no período de 1980 a 1999. Foi realizado estudo imunoistoquímico para análise de nove marcadores moleculares e cada tumor foi classificado de acordo com a expressão do receptor de estrogênio, progesterona e expressão do HER-2 em uma das categorias luminais, basal, triplo-negativo e super-expressor de HER-2. Resultados: Observamos que a maioria dos tumores media de 2,1 a 5,0 cm $(57,8 \%)$, pertenciam ao grau histológico $2(57,1 \%)$, eram grau nuclear $3(61,6 \%)$, possuíam de 0 a 9 mitoses por campo de grande aumento (CGA) e $59 \%$ apresentavam metástase linfonodal. As pacientes analisadas pertenciam a dois subgrupos de estadiamento, sendo que 86 casos pertenciam ao EC IIA $(32,1 \%)$ e 182 ao EC IIIB (67,9\%). Na análise multivariada, observamos em nosso estudo que a presença de diversos fatores clínicos e demográficos, de variáveis histopatológicas, formas de tratamento, os diversos marcadores moleculares não parecem conferir um pior prognóstico às pacientes do grupo IIA. Neste grupo, os fatores que mostraram estar associados a um pior prognóstico foram o fato destas pacientes pertencerem ao padrão fenotípico triplo negativo ou ao padrão basal. Quando realizamos a análise multivariada para avaliação do risco de óbito em 120 meses, observamos que no estádio IIIB, o padrão fenotípico luminal A, luminal B, super-expressor de HER-2 e triplo-negativo, não esteve relacionado com óbito. O risco de óbito esteve associado com a presença de metástase linfonodal e a não realização de quimioterapia adjuvante. Conclusão: Com estes achados podemos concluir que os padrões fenotípicos basal e triplo-negativo estão relacionados com uma pior sobrevida nas pacientes IIA. Entretanto, os subtipos de câncer de mama não estão relacionados com o prognóstico no grupo de mulheres do estádio IIIB. A presença de metástase nos linfonodos e a não realização de quimioterapia adjuvante são fatores de risco para estas mulheres.

Descritores: 1. Neoplasias da mama; 2. Carcinoma ductal; 3. Estadiamento de neoplasias; 4. Imunoistoquímica; 5. Marcadores biológicos de tumor; 6. Sobrevida. 


\section{SUMMARY}

Carvalho, SMT. Prognostic evaluation of clinical stage IIA and IIIB breast cancers and the relationship with survive [Thesis]. São Paulo: "Faculdade de Medicina da Universidade de São Paulo"; 2010. 76p.

Introduction: The breast cancer is a great molecular and clinical heterogeneous disease. One of the most used breast cancer classification involves molecular events and classify breast cancer into distinct groups based on gene expression patterns: luminal (A and B), overexpression of HER-2, basal and and normal breast like. Once the breast subgroups have been identified, we used a large panel of different tumour markers, to differenciated to groups of patients: IIA and IIIB. Objectives: The aim of our study was to identify which factors could be necessary to determine the prognosis, in both patients group (IIA and IIIB), until 10 years of follow-up, when we consider clinical and demographics aspects, histopathologic characteristics of the tumour, treatment, molecular markers of the epithelial-mesenchymal transition (e-cadherin, $\mathrm{p}$-cadherin, n-cadherin, vimentin, twist, snai 1, slug), EGFR and NOS 2 and molecular subgroups (luminal A, luminal B, basal, triplenegative and overexpressor of HER-2), in breast cancer. Patients and Methods: Cases for this study were selected from Hospital A C Camargo, and included 268 patients with diagnosis of breast cancer submitted to surgery between 1980 and 1999. We applied immunohistochemical to analyse nine different molecular markers and each tumour was classified according to estrogen receptor, progesterone receptor and HER-2 expression in one of the molecular cathegories. Results: We observed that the size of most tumours varied 2.1 to $5.0 \mathrm{~cm}(57.8 \%)$, that they had histologic grade $2(57.1 \%)$, nuclear grade 3 (61.6\%), they showed 0 to $9 \mathrm{~m}$ mitoses and 59\% had dissemination to lymph nodes. Eighty six patients were staged as IIA (32.1\%) and 182 were staged as IIIB (67.9\%). The multivarieted analysis showed that different clinical and demographics factors, histopathologic characteristics of the tumour, different treatment and some molecular markers didn't confer a worse prognostic to patients staged as IIA. The factors that showed an association with a worse prognosis were: tumor belongs to triple-negative or basal phenotype. When we realize the multivarieted analysis in stage IIIB, to look for the death risk in ten years, we observed that luminal A or B, over expression of HER-2 and triplenegative phenotype, didn't had any relation with death. The death risk was associated with dissemination to lymph nodes and with no adjuvant chemotherapy. Conclusion: We concluded that in stage IIA, the factors that showed an association with a worse prognosis were triple-negative or basal phenotype. And that the phenotype subgroups were not related to prognoses in stage IIIB and that the presence of lymph node dissemination and no adjuvant chemotherapy were risk factors for these patients.

Descriptors: 1. Breast cancer; 2. Ductal carcinoma; 3. Staging; 4.Immunohistochemistry;

5. Biological cancer markers; 6. Survival. 


\section{INTRODUÇÃO}

O câncer de mama é a neoplasia maligna mais frequente entre as mulheres no Brasil, ficando atrás apenas dos tumores de pele do tipo não melanoma (Ministério da Saúde, 2009). Segundo dados do INCA, estima-se no Brasil, a ocorrência de 49.240 casos, para o ano de 2010 (Ministério da Saúde, 2009). Apesar do aumento da incidência no Brasil e em outros países, os grandes estudos internacionais mostram que a maior eficiência nos programas de rastreamento, a melhor definição das imagens ao diagnóstico e o uso adequado de terapias medicamentosas adjuvantes, melhoraram a sobrevida das pacientes nas últimas décadas (EBCTCG, 2005; Smigal et al., 2006).

Define-se como paciente com longa sobrevida, aquela que ainda continua viva, cinco anos depois do diagnóstico de câncer (ACS, 2005). A sobrevida das pacientes com câncer de mama aos 5 e 10 anos é de respectivamente $88 \%$ e $77 \%$, ambas bastante elevadas quando comparadas à sobrevida em cinco anos de todos os outros tipos de câncer juntos (ACS, 2005; Soerjomataram et al., 2008). Com estes dados em mão, nos parece lógico que a procura por fatores prognósticos que possam predizer quais pacientes terão uma sobrevida livre de doença longa, após 10 anos de diagnóstico, seja considerada.

Dentre os fatores clássicos determinantes de sobrevida, em câncer de mama, destacamos:

Idade ao diagnóstico, aonde se observa que as pacientes com idades que variam de 30 a 35 anos, apresentam uma pior sobrevida quando comparadas àquelas com 70 anos ou mais (Soerjomataram et al., 2008). 
Tamanho do tumor: é um dos fatores prognósticos mais importantes, principalmente, por se reconhecer que tumores maiores costumam estar associados à maior presença de linfonodos comprometidos (Warwick et al., 2004). Independente desta associação, observamos que tumores medindo de 2 a $5 \mathrm{~cm}$ apresentam uma sobrevida global de $66 \%$ contra os $79 \%$ dos tumores que medem até 1,0 cm (Chia et al., 2004).

Tipo histológico: De forma geral, pode ser classificado em quatro grupos: excelente prognóstico (cribiforme invasivo, tubular, túbulo-alveolar e mucinoso) com uma sobrevida em 10 anos maior de 80\% (Fisher et al., 2001; Greene, 2002), bom prognóstico (medular atípico e carcinoma lóbulo-alveolar) com uma sobrevida em 10 anos entre 60 a 80\% (Fisher et al., 2001), prognóstico ruim (papilar invasivo, lobular clássico e medular) com uma sobrevida em 10 anos entre 50 a 60\% (Fisher et al., 2001) e os de prognóstico muito ruim com uma sobrevida em 10 anos inferior a 50\% (carcinoma ductal e lobular, ductal e lobular sólido) (Soerjomataram et al., 2008). Porém vale lembrar que o valor prognóstico desta informação, hoje está em questionamento, pois encontramos tumores historicamente de bom prognóstico, com comportamentos agressivos.

Grau histológico e grau nuclear: o sistema de graduação histológica mais utilizado é a classificação de Scarff- Bloom-Richardson, que leva em consideração o grau nuclear, a arquitetura tumoral e o número de mitoses. Observamos que os tumores graduados como de alto grau apresentam pior sobrevida (Soerjomataram et al., 2008).

Atividade mitótica: é um indicador de atividade proliferativa da neoplasia em uma determinada área do tumor. Combinado com outros fatores prognósticos, pode ser uma ferramenta bastante precisa para determinar a sobrevida a longo prazo. Pacientes com tumores medindo até $5 \mathrm{~cm}$, axila negativa e índice mitótico exibindo mais de 10 mitoses por campo de grande aumento (CGA), apresentam uma sobrevida em 10 anos de 80\%, 
comparada com 90\% de sobrevida em 10 anos, nas pacientes com menos de 10 CGA (Louwman et al., 2006).

Envolvimento linfonodal axilar: é o fator prognóstico mais importante. Os pacientes com linfonodos comprometidos por tumor apresentam uma taxa de mortalidade de 4 a 8 vezes maior do que aqueles sem envolvimento linfonodal (Fisher et al., 2001; Arriagada et al., 2006).

Outros fatores importantes na determinação do prognóstico em câncer de mama são: os receptores hormonais e a expressão de HER-2. Entre as décadas de 1960 e 1970, foi feita a primeira distinção molecular no câncer de mama, ao se identificar e caracterizar a expressão dos receptores de estrógeno (RE) e de progesterona (RP) nas células tumorais. Esta descoberta logo levou ao desenvolvimento de terapias antiestrogênicas (Fisher et al., 1983). A seguir observou-se que 25 a 30\% dos tumores de mama apresentavam ampliação do oncogene HER-2/neu e que esta alteração genômica cursava com um pior prognóstico. Este achado acabou por levar ao desenvolvimento de terapias alvo e mostrou um impacto significante na sobrevida das mulheres que expressavam HER-2 em seus tumores (Slamon et al., 1987; Romond et al., 2005).

O estadiamento do câncer de mama também é uma maneira muito objetiva de se analisar a sobrevida. Ele se baseia no sistema TNM (Tumor, Linfonodo, Metástase) e vem sendo utilizado desde 1942. É composto por três informações: tamanho do tumor, doença com disseminação para os linfonodos regionais e presença de metástase à distância (Singletary, Connoly, 2006). Os tumores de mama pertencentes ao estádio IIA são, por definição, considerados iniciais e incluem os tumores T0N1M0, T1N1M0 e T2N0M0. Neste estádio, os pacientes apresentam uma sobrevida livre de doença em cinco anos, em torno de 85\% (Gloeckler Ries et al., 2003). Os tumores de mama pertencentes ao estádio 
IIIB são, por definição, considerados localmente avançados e incluem os tumores T4N0M0, T4N1M0 e T4N2M0. Neste grupo coexistem grandes tumores considerados operáveis e tumores considerados inoperáveis, porém sem a detecção de metástases para órgãos distantes. Os pacientes deste estádio apresentam uma taxa de $58 \%$ de sobrevida livre de doença em cinco anos (Gloeckler Ries et al., 2003).

Devemos levar em conta não só os fatores reconhecidos como de valor prognóstico no câncer de mama, como também novos marcadores moleculares que mostrem ter seu valor na determinação prognóstica do câncer de mama. Com a evolução das técnicas genômicas e consequentemente dos marcadores moleculares, a informação prognóstica pode ser cada vez mais refinada. Porém, estes achados ainda não foram suficientes para o mastologista e o oncologista clínico, frente a um laudo padrão de anatomopatológico, determinarem a melhor conduta em alguns casos específicos. Há uma necessidade crescente, por exemplo, em identificar-se pacientes com câncer de mama e axila negativa, que apresentarão uma baixa probabilidade de recorrer, para quem o tratamento quimioterápico poderia ser evitado, juntamente com seus possíveis efeitos deletérios. Ou então, identificar quais pacientes com câncer de mama e axila negativa teriam alta probabilidade de recorrer, e para as quais o tratamento quimioterápico seria necessário, senão fundamental.

Dados da literatura mostram que pacientes classificadas no estádio IIA, definido como tumores apresentando doença local ou disseminada para linfonodos axilares homolaterais apresentarão $80 \%$ de sobrevida livre de doença em cinco anos e $20 \%$ irão falecer no mesmo intervalo, a despeito do bom prognóstico associado a estes casos (Gloecker Ries et al. 2003). Da mesma maneira, aproximadamente 60\% das pacientes no estádio IIIB, definido como doença localmente extensa ou disseminada para linfonodos 
axilares, morrerão nos primeiros 10 anos após o diagnóstico (Singletary, Connoly, 2006), havendo um pequeno grupo de pacientes que não morrerão doença conforme esperado.

Alguns grupos no início deste século estudaram a assinatura molecular dos carcinomas ductais invasivos (CDI) (Perou et al., 2000; Sorlie et al., 2001). Perou et al., (2000) analisaram 65 amostras de 42 pacientes, utilizando a técnica de expressão gênica de microarrays de DNA complementar (cDNA), representando 8.102 genes humanos. Eles demonstraram que a diversidade fenotípica dos tumores de mama estava associada a uma diversidade na expressão gênica. Em complemento a este trabalho, Sorlie et al. (2001) analisaram 85 experimentos com 78 carcinomas, três fibroadenomas e quatro tecidos mamários normais, com a mesma estratégia para validar os primeiros achados. Estes experimentos definiram o que hoje reconhecemos como a classificação molecular do carcinoma de mama, dividindo os tipos em cinco grandes grupos baseados na expressão de poucos genes. Mais importante do que isto foi que esta classificação se mostrou de valor prognóstico e validava comportamentos clínicos bem conhecidos demonstrados pela literatura pertinente. Estes tipos foram chamados de luminais (A e B), super-expressor de HER-2, basal e aqueles semelhantes à mama normal. Desde então, diversos estudos tentaram caracterizar melhor estes subgrupos, em especial o subtipo basal, que apresenta expressão negativa do RE, RP e HER-2. Inicialmente, ele foi identificado como sendo triplo-negativo, porém com a melhor caracterização dos subtipos, observou-se que apesar da negatividade da expressão dos receptores, os termos basal e triplo-negativo não eram equivalentes, conforme veremos a seguir. 


\subsection{Classificação molecular do carcinoma de mama}

\subsubsection{Luminal (A e B)}

Os tumores luminais representam $45 \%$ dos tumores de mama e menos de $20 \%$ deles apresentam TP53 mutado (Sorlie et al., 2001; Sotiriou et al., 2003). Os luminais A são aqueles carcinomas que, além da expressão de RE, podem ou não apresentar positividade do RP, expressam as citoceratinas (CK) 7/8 e 18/19 e têm expressão negativa de HER-2 (Nielsen et al., 2004). São tumores que costumam apresentar baixa expressão de ki67 e um baixo índice mitótico. Além disso, expressam genes que são ativados pela ligação hormonal, tais como o gene $B C L-2$, que regula negativamente a apoptose, e o fator de transcrição GATA-3. São tumores usualmente de baixo grau histológico, bem diferenciados e com poucas mitoses. O grupo luminal $\mathrm{B}$ tem também o mesmo padrão de expressão de RE e do RP, de CK, mas co-expressam os genes ligados à proliferação celular, podendo apresentar alta expressão de ki67 e alto índice mitótico. Podem apresentar a expressão de HER-2, embora ocorram casos com expressão negativa (Brenton et al., 2005). São tumores histologicamente menos diferenciados, com maior índice proliferativo e que respondem pior ao tratamento com anti-estrogênios. Em geral os subtipos luminais apresentam um bom prognóstico, entretanto há uma clara diferença na sobrevida, sendo que o luminal B carrega significativamente um pior prognóstico, quando comparado ao luminal A. Em parte estas diferenças na sobrevida ocorrem devido à variação na resposta ao tratamento. Os tumores tipo luminal A, em geral, são adequadamente tratados com hormonioterapia enquanto o subtipo luminal B, por ter maior expressão de genes proliferativos, parece se beneficiar mais do que o subtipo luminal A, de quimioterapia associada com hormonioterapia (Sorlie et al., 2003). 


\subsubsection{Super-expressores de HER-2}

Os tumores super-expressores de HER-2 são aqueles que invariavelmente têm a expressão imunoistoquímica (IIQ) positiva para HER-2 e que, ao ter seu estado gênico avaliado por testes de hibridação in situ fluorescente (FISH) ou cromogênica (CISH) apresentam amplificação do número de cópias deste gene. Apresentam expressão negativa do RE e do RP (Brenton et al., 2005). Correspondem a cerca de $20-25 \%$ dos carcinomas de mama. Não há associação entre este subtipo com idade, raça ou outros fatores de risco (Carey et al., 2006).

Há uma grande proporção de tumores com mutação do TP53 (40 a 80\%) (Sorlie et al., 2001). O estudo de Calza et al. (2006), mostrou que a média de tamanho tumoral variou entre os subtipos, com exceção do grupo HER-2, aonde o tamanho do tumor tendia a ser maior. Este subtipo apresenta sensibilidade às antraciclinas e taxanos neoadjuvantes, com uma significativa resposta clínica quando comparada à resposta do subtipo Luminal A (Rouzier et al., 2005). Os carcinomas mamários que super-expressam HER-2 têm um comportamento biológico agressivo, o que resulta em uma taxa de recorrência após o tratamento inicial, uma sobrevida livre de doença curta e um pior prognóstico (Brenton et al., 2005). Outro dado importante é o de que este grupo de tumores costuma apresentar maior probabilidade de metástase cerebral (Brenton et al., 2005).

\subsubsection{Basal}

O subtipo basal representa $15 \%$ dos tumores de mama. Não expressa ou tem baixa expressão de receptores hormonais (RE/RP) e HER-2 e expressa proteínas comumente presentes nas células progenitoras ou células basais/luminais. Esta negatividade fez com que estes tumores fossem conhecidos coloquialmente como "triplo-negativos". Embora 
seja verdade que estes tumores sejam realmente negativos para os três marcadores (RE/RP/HER-2), a premissa inversa não é verdadeira. Há tipos histológicos que são triplonegativos, mas não são basais (Haupt et al., 2010). São exceções, é verdade, mas cerca de 5-9\% dos tumores triplo-negativos não são do tipo basal. Nem todos os tumores basais são de alto grau histológico ou agressivos. Existem tipos histológicos especiais que são raros e são de baixo grau histológico como o carcinoma secretório e adenóide-cístico.

Deixando claras as exceções acima, podemos definir alguns padrões de reconhecimento dos carcinomas do tipo basal. São tumores que apresentam massa tumoral bem delimitada, de bordas expansivas, com necrose e/ou fibrose central, alto grau histológico, alto índice mitótico e frequentes elementos metaplásicos. A grande maioria são carcinomas ductais invasivos sem outra especificação (CDI SOE), mas dentre os tipos especiais, os carcinomas medulares, medulares atípicos e metaplásicos são quase que invariavelmente do tipo basal (Reis-Filho et al., 2006). Os carcinomas lobulares invasores podem apresentar este fenótipo em cerca de $5 \%$ dos casos e mesmo cerca de $20 \%$ dos carcinomas mucinosos podem ser de padrão imunofenotípico basal. Demonstrou-se a associação destes tumores com a expressão de proteína p53 (Ferrini et al., 2001).

São tumores que apresentam maior disseminação para órgãos sólidos, como fígado e pulmão, e em séries mais recentes observa-se maior incidência de metástases cerebrais (Ibrahim et al., 2008).

Os carcinomas basais expressam um padrão característico de CK, as CK5 e CK14 (De Brot et al., 2009). Utilizando este tipo de marcador somente, podemos identificar cerca de $40 \%$ dos casos, o que nos obriga a acrescentar outros marcadores. Matos et al. (2005) recomendaram o uso de p63, p-caderina e CK5, o que realmente aumenta bastante a chance de identificarmos estes tumores. O maior problema é que, em nosso meio, a p-caderina é 
pouco específica e é extremamente frequente a sua expressão em tumores não-basais. Aparentemente, o uso de marcação para o receptor do fator de crescimento epidérmico, (EGFR, do inglês epidermal growth factor receptor) traz grande especificidade para o painel e Vialle e Bottiglieri (2009) sugerem a avaliação IIQ do EGFR, de rotina.

O EGFR é uma glicoproteína da membrana plasmática e funciona como um receptor do tipo tirosina-quinase. Está envolvido na regulação do crescimento e diferenciação celular e é específico para o fator de crescimento epidérmico (EGF, do inglês, epidermal growth factor). Os quatro membros da família destes receptores são o EGFR (HER1/c-erbB-1), HER2/neu (c-erbB-2), HER3 (c-erbB-3) e HER4 (c-erbB-4), caracterizados por um sítio de ligação extracelular, uma região transmembrana e um domínio tirosino-quinase citoplasmático (Hynes, Lane, 2005).

A ativação do EGFR cria sítios de ligação para proteínas adaptadoras e enzimas ligadas à proliferação celular, angiogênese, invasão, metástases e inibição da apoptose (Hutcheson et al., 2006). A amplificação do gene EGFR tem sido descrita em vários tumores, inclusive no câncer de mama (Reis-Filho et al., 2005).

A sinalização aberrante do EGFR tem sido considerada uma das principais causas da progressão tumoral e da formação de metástases, porém a mecanismo desta sinalização ainda não está bem esclarecido, inclusive acredita-se que ele favoreça a transição epitéliomesênquima, via EGF/EGFR (Lo et al., 2007). O fenótipo basal se caracteriza entre outros, pela positividade da expressão IIQ do EGFR (Nielsen et al., 2004).

O uso de um painel de RE, HER-2, CK5/CK14 e EGFR, teria uma especificidade de $100 \%$ e uma sensibilidade em torno de $75 \%$ (Vialle e Bottiglieri, 2009). 


\subsubsection{Triplo-negativo}

O câncer de mama triplo-negativo apresenta características patológicas e moleculares únicas. Este termo refere-se à classificação IIQ dos tumores de mama aonde não se observa a expressão de RE, RP e HER-2 (Nielsen et al., 2004). A maioria dos estudos publicados mostra, além dos dados acima, que este grupo de tumores apresenta expressão negativa de p-caderina e de p63, expressão positiva de HER 1 (EGFR), expressão positiva das $\mathrm{CK}$ 5/6, expressão positiva de c-kit e da vimentina (Nielsen et al., 2004; Rakha et al., 2009). Carey et al. (2006) mostraram que os tumores triplo-negativos se associam a um perfil tumoral mais agressivo. Quando comparado aos outros tipos moleculares apresenta uma elevada taxa de mutação do gene TP53, maior índice mitótico, um acentuado pleomorfismo nuclear e maior grau histológico. Em um grande estudo realizado, aonde se avaliaram 1.600 pacientes diagnosticadas e tratadas com câncer de mama em Toronto, no período de 1987 a 1997, observou-se que os tumores que não eram triplo-negativos apresentavam menor probabilidade de metástase à distância e morte nos primeiros cinco anos após o diagnóstico (Dent et al., 2007).

Os tumores triplo-negativos constituem um dos grupos de câncer de mama que mais apresentam resposta às antraciclinas associadas aos taxanos neoadjuvantes, muito embora se observe, que as pacientes que não apresentaram resposta patológica total ainda mostrem significativamente um pior prognóstico (Carey et al., 2007; Reis-Filho, Tutt, 2008) .

\subsubsection{Normal-like ou perfil similar à mama normal}

O último grupo identificado pela assinatura gênica de Perou et al. (2000) foi o que chamamos "normal-like", ou seja, aquele de perfil similar à mama normal. Este é o grupo que mais carece de definição precisa. Eles expressam genes dos tecidos mesenquimais da 
mama e são frequentemente triplo-negativos. São raros os trabalhos individualizando este grupo e sobre o seu comportamento biológico. Este grupo precisa ainda ser melhor definido, para que saibamos se realmente se trata de um grupo especial.

A pesquisa sobre o câncer de mama se tornou uma das áreas mais importantes de pesquisa no Brasil e em todo o mundo. Em decorrência disto, observamos um crescente interesse na busca de novos marcadores moleculares que sejam específicos para os tumores de mama. Atualmente, diversos marcadores moleculares são úteis na prática clínica, principalmente, direcionando o uso de drogas alvo-específicas. Espera-se cada vez mais que novos marcadores sejam descobertos e com eles um arsenal terapêutico mais específico, e que possam servir também como marcadores prognósticos. Entretanto, ainda existem muitos obstáculos ao desenvolvimento de novos testes biomoleculares para a prática clínica. Isto se deve em parte à falta de especificidade de alguns marcadores tumorais e pouca sensibilidade dos testes, limitando seu uso clínico. A identificação de marcadores moleculares através da técnica de IIQ se apresenta como uma alternativa factível e viável. Apresentaremos aqui alguns marcadores imunoistoquímicos com potencial para melhorar a definição dos diferentes subtipos moleculares de câncer de mama. Foram escolhidos alguns marcadores moleculares da transição epitélio-mesênquima (TEM) para correlacionarmos com a sobrevida, pois sabemos sua expressão parece estar associada a um fenótipo mais agressivo e mais invasivo com maior diferenciação mesenquimal, piorando a sobrevida (Thiery, 2002). 


\subsection{Marcadores moleculares da transição epitélio-mesênquima}

A transição epitélio-mesênquima (TEM) é um fenômeno onde as células epiteliais desdiferenciam e passam a expressar marcadores mesenquimais e pode estar relacionada com o processo de transformação tumoral (mama normal, carcinoma ductal in situ, carcinoma invasor) e capacidade de metastatização. Nele, um epitélio primitivo, origina células mesenquimais com uma morfologia apropriada para a migração para linfonodos. Um dos melhores marcadores moleculares do processo de TEM no carcinoma de mama é a perda da expressão de e-caderina, relacionada com a adesão célula-célula nos tecidos epiteliais. Outras moléculas de adesão também participam deste processo como a ncaderina e a p-caderina (Thiery, 2002). Na mama, assim como no modelo embrionário, o critério para a definição de TEM envolve a perda da polaridade celular, a separação em células individuais, aquisição da mobilidade e posterior dispersão. Depois da perda da polaridade celular, o citoesqueleto é remodelado, ocorrendo uma mudança do filamento intermediário de citoqueratina para vimentina que passa a ser um importante marcador. Ocorre a aquisição de morfologia similar aos fibroblastos com reorganização do citoesqueleto, aumento da motilidade, invasão e maior capacidade de se metastatizar (Thompson et al., 2005; Thiery, Sleeman, 2006).

A TEM gera células com características de células-tronco (Mani et al., 2008). Estes aspectos são bem documentados no CDI da mama (Prasad et al., 2009) e são geralmente associados com o fenótipo basal, incluindo os carcinomas metaplásicos (Sarrió et al., 2008).

As mudanças genéticas necessárias para completar as mudanças fenotípicas associadas à TEM são em menor parte mediadas por um número específico de fatores transcricionais ou indutores do TEM. Estes fatores transcricionais incluem Snai 1, Slug 
(Snail2), Twist (Cano et al., 2000; Yang et al., 2004), entre outros. Este processo de transição tem sido reconhecido como um potente mecanismo para a progressão de carcinomas, já que diversas vias de sinalização da TEM também são comuns à progressão tumoral (Thiery, 2002).

Também observamos que estudos com os marcadores de adesão celular são bastante frequentes na mensuração do prognóstico no carcinoma de mama. A adesão entre as células epiteliais normais (e as tumorais) se fez por sistemas moleculares distintos, incluindo a adesão célula a célula ou a adesão célula à matriz extracelular.

As caderinas são glicoproteínas e são as principais moléculas de adesão celular, sendo responsáveis pela adesão célula-célula nos tecidos dos vertebrados, aonde elas irão mediar o contato homofílico entre células vizinhas e por manterem as células unidas nos tecidos embrionários iniciais (Takeichi et al., 1988).

As três primeiras caderinas descobertas foram denominadas de acordo com os principais tecidos aonde foram encontradas: a e-caderina está presente em muitos tipos de células epiteliais, a n-caderina, no nervo, no músculo e nas células do cristalino e a pcaderina, nas células da placenta e da epiderme (Cavallaro, Christofori, 2004) e são também encontradas em outros tecidos.

De maneira sintética, relacionaremos os marcadores citados: e-caderina, n-caderina, p-caderina, vimentina, Snai1, Slug e Twist.

\subsubsection{E-caderina}

É a caderina mais bem caracterizada e é abundante nas junções aderentes de células epiteliais maduras. Sua importância no desenvolvimento e na função normal do tecido é 
bem demonstrada pela letalidade no camundongo sem o gene da e-caderina nos estágios iniciais da embriogênese (Larue et al., 1994).

Uma característica básica da célula tumoral é a perda da adesão entre as células (Nelson, 2008), o que ocorre durante a progressão do câncer, e é um evento importante desde o seu início até a formação da metástase (Baranwal, Alahari, 2009). A e-caderina é uma proteína supressora de tumor e um potente inibidor da invasão (Heimann, Hellman, 2000). Sua expressão anormal foi descrita em diferentes tumores humanos, inclusive no câncer de mama e está associada à progressão tumoral (Shiozaki et al., 1996).

Em geral a expressão de e-caderina se correlaciona com características não invasivas e bem diferenciadas (Berx, Van Roy, 2001). Porém, a expressão de e-caderina está mantida no carcinoma inflamatório de mama (Charafe-Jauffret et al., 2004). Também metástases costumam mostrar uma forte expressão de e-caderina (Kowalski et al., 2003).

Os fatores de transcrição Snai 1, Slug e Twist, se ligam à e-caderina, cuja perda da expressão induz o processo da transformação do epitélio-mesênquima em diversos tipos de tumor (Hajra et al., 2002; Yang et al., 2004).

\subsubsection{N-caderina}

A célula epitelial normal expressa e-caderina. Entretanto, as células tumorais que sofreram uma EMT começam a expressar de maneira inapropriada a n-caderina (Cavallaro et al., 2002). Um evento importante na progressão do câncer é a transformação da e-caderina em n-caderina (Hazan et al., 2000). Através de vários mecanismos a n-caderina promove um comportamento mais agressivo às células tumorais, por exemplo, através da interação com o receptor de tirosina-quinase na superfície da célula (Wheelock et al., 2008). 
A n-caderina está super-expressa em várias linhagens de tumores de mama (Agiostratidou et al., 2007). Ela induz a formação de metástase devido à sua habilidade em se ligar e por potencializar a sinalização para o receptor FGF (Nieman et al., 1999).

\subsubsection{P-caderina}

Esta foi a terceira caderina a ser identificada. Ao contrário da e-caderina que apresenta uma ampla distribuição nos tecidos epiteliais, a p-caderina apresenta uma distribuição singular, localizando-se parcialmente com a e-caderina e ficando restrita à camada basal proliferativa na maioria dos epitélios estratificados, o que poderia estar correlacionado com indiferenciação celular e proliferação neste tecido (Paredes et al., 2007).

Os ductos mamários e os alvéolos terminais são formados por duas camadas de ectoderma derivados do epitélio. A IIQ mostra uma abundante expressão de e-caderina na membrana lateral no alvéolo terminal e nas células ductais luminais, porém não mostram expressão de p-caderina. Já as células basais que representam o ponto de crescimento para o desenvolvimento ductal da glândula mamária e para seus descendentes, exibem uma forte expressão de p-caderina (Radice et al., 2003). Fêmeas de camundongos que não expressavam p-caderina exibiram uma diferenciação precoce da glândula mamária e desenvolveram hiperplasia e displasia conforme foram envelhecendo. Isto mostra que a adesão mediada pela p-caderina ou os sinais derivados das interações celulares, ainda são importantes determinantes do crescimento celular mamário e na manutenção de um estado indiferenciado durante um período de tempo específico (Radice et al., 1997).

Na glândula mamária normal, a expressão espacial seletiva tanto da p-caderina, quanto da e-caderina parece ser importante para a diferenciação glandular (Palacios et al., 1995). A p-caderina se encontra alterada em diversos tipos de tumor, porém seu 
significado ainda permanece incerto. No câncer de mama, ela promove a invasão celular, uma maior agressividade tumoral, indicando um pior prognóstico para o paciente (Paredes et al., 2007), além de estar mais expressa no subtipo basal (Perou et al., 2000).

\subsubsection{Vimentina}

A vimentina é uma proteína que forma o filamento intermediário do citoesqueleto. Sua expressão foi descrita em tumores de mama (Kokkinos et al., 2007) e é expressa de maneira seletiva em linhagens de células cancerosas mamárias agressivas (Gilles et al., 2003). A expressão elevada de vimentina se correlaciona com maior migração e invasão de células cancerosas (Korsching et al., 2005). Outros dados mostram que linhagens de células de câncer de mama mais agressivas, expressam vimentina, sugerindo a sua utilidade na identificação de casos de pior prognóstico (Zajchowski et al., 2001). Observou-se que nos carcinomas de mama de padrão basal há uma maior expressão da vimentina (Van De Rijn et al., 2002).

\subsubsection{Twist}

O fator transcricional Twist apresenta funções bem definidas no crescimento celular e diferenciação tanto em vertebrados quanto invertebrados (Desprez et al., 2003). Ele funciona como regulador fundamental no processo de formação das metástases, aonde ele tem um papel crucial através da inibição da regulação da e-caderina e $\beta$-catenina, promovendo a TEM, além de mediar a motilidade celular e a favorecer a invasão (Yang et al., 2004; Kwok et al., 2005). A expressão elevada de Twist leva a uma maior expressão do fator de crescimento endotelial vascular, VEGF (do inglês, vascular endothelial growth factor), promove a angiogênese e se correlaciona com a instabilidade cromossômica no 
câncer de mama (Mironchik et al., 2005). Encontramos a expressão de twist aumentada nos câncer de mama (Watanabe et al., 2004). Esta expressão aumentada se correlaciona positivamente com maior agressividade do tumor e pior taxa de sobrevida em pacientes com câncer de mama (Yang et al., 2004; Kwok et al., 2005).

\subsubsection{Slug}

Está proteína pertence à super-família dos reguladores transcricionais, implicados na formação do mesoderma e da crista neural, bem como na progressão patológica dos tumores epiteliais (Nieto, 2002). A super-expressão desta proteína nas células epiteliais promove a perda da expressão da adesão molecular entre as células (Cano et al., 2000). O gene $S L U G$ pertence à família $S N A I$, sendo bastante efetivo em induzir a inibição da

regulação de marcadores como a e-caderina e permitir a aquisição de um fenótipo migratório em uma variedade de células tumorais (Nieto, 2002). Trabalhos recentes mostram que a expressão do gene SLUG estava associada a um comportamento biológico mais agressivo do melanoma, do câncer de pulmão, cólon e ovário (Elloul et al., 2005; Shih et al., 2005; Shioiri et al., 2006).

No câncer de mama, a expressão do gene $S L U G$ se correlaciona com o número de linfonodos comprometidos por tumor ou com doença metastática (Côme et al., 2006). Segundo Storci et al. (2008) a expressão do gene $S L U G$ confere ao câncer de mama um fenótipo mais agressivo, do tipo padrão basal.

\subsubsection{Snai 1}

A família Snai de fatores transcricionais faz a mediação de eventos no mesoderma, neuroectoderma e outros órgãos em desenvolvimento no embrião (Hemavathy et al., 2000). Há relatos de que a super-expressão do gene SNAIL é um indutor da EMT, repressor da 
e-caderina, além de ser um forte indicador de fenótipo tumoral mais agressivo (Cano et al., 2000). No câncer de mama observa-se que o aumento da expressão de Snai 1 está associado com a repressão da e-caderina, envolvimento linfonodal, maior potencial de invasão e de metastatização, além de um decréscimo na sobrevida livre de doença (Blanco et al., 2002). Kurrey et al. (2005), publicaram um estudo aonde mostrava que a expressão ectópica de Snai 1 ou de Slug resultava em indução da EMT em uma linhagem de células de carcinoma de ovário, com aumento da motilidade e da invasibilidade, perda da expressão de marcadores epiteliais e aumento da expressão de vimentina. Outros trabalhos com diversas linhagens celulares transformadas mostraram uma correlação negativa entre Snai 1 e Slug com a expressão de e-caderina (Cano et al., 2000). Além disso, em uma série de amostras de câncer de mama, a expressão de Snai 1 foi observada em todos aqueles associados à presença de linfonodos acometidos, sugerindo que este poderia ser um marcador de potencial metastático (Blanco et al., 2002).

Ainda estudamos, a NOS-2 (do inglês nitric oxide synthase-2) ou sintase do óxido nítrico 2, que é uma das isoformas das sintases do óxido nítrico e foi isolada a partir de macrófagos de ratos (Hevel et al., 1991). Sua localização é citoplasmática, e não se encontra normalmente presente nas células, sendo sua expressão induzida por estímulos inflamatórios ou por lipopolissacarídeos (LPS) bacterianos. Diferentes tipos celulares produzem a NOS-2, além das células epiteliais do tecido mamário normal (Tschugguel et al., 1999).

Estudos mostram a expressão das isoformas da NOS em vários tumores humanos, incluindo mama (Thomsen et al., 1994). Carvalho et al. (2010), mostraram que o tecido tumoral apresenta maior expressão de NOS-2 quando comparado ao tecido mamário normal. $\mathrm{O}$ estudo sugere que as células neoplásicas adquiriram a capacidade de expressar a NOS-2, sugerindo ser este um fenômeno precoce na progressão tumoral e que quanto mais indiferenciado o tumor, menor a capacidade de expressar NOS-2. 


\section{OBJETIVOS}

O objetivo de nosso estudo foi avaliar quais fatores seriam importantes na determinação do prognóstico, tanto nas pacientes estadiadas como IIA quanto nas IIIB, com um período de seguimento de 120 meses, levando em conta dados clínicos e demográficos, características tumorais, tipos de tratamento, diferentes marcadores moleculares da transição epitélio-mesênquima e moléculas de adesão (e-caderina, pcaderina, n-caderina, vimentina, twist, snai 1, slug), o EGFR, a NOS-2 e os diferentes fenótipos tumorais (Luminal A, Luminal B, super-expressor de HER-2, basal e triplonegativo) em câncer de mama. 


\section{PACIENTES E MÉTODOS}

\subsection{Pacientes}

A casuística deste estudo é constituída por 268 pacientes portadoras de tumor de mama operadas no Hospital A. C. Camargo, no período de 1980 a 1999, previamente identificadas a partir de levantamento no arquivo do departamento de Anatomia Patológica deste hospital. O protocolo do estudo foi aprovado pela Comissão de Ética em Pesquisa do Centro de Tratamento e Pesquisa do Hospital do Câncer - A. C. Camargo (Processo no 949/07) e da Comissão de Ética da Universidade de São Paulo (Processo no 0763/07) (Anexos 1 e 2).

\subsubsection{Critérios de inclusão}

Os critérios de inclusão foram pacientes do sexo feminino, independente da raça ou do status hormonal, com o diagnóstico de CDI de mama operado, pertencentes ao estádio clínico IIA ou IIIB e com material representativo do tumor suficiente para o estudo.

\subsubsection{Critérios de exclusão}

Os critérios de exclusão incluem tratamentos quimioterápico ou radioterápico prévios, outros estádios clínicos que não IIA e IIIB, outros tipos de neoplasias associadas e pacientes com material representativo do tumor insuficientes para o estudo. 


\subsubsection{Tempo de seguimento}

Para o nosso estudo, selecionamos pacientes com um tempo de seguimento mínimo de cinco anos (60 meses), ou seja, todas as pacientes vivas e com menos de 60 meses de seguimento foram excluídas da análise. O tempo de seguimento máximo foi de até 10 anos ou 120 meses, sendo considerado o óbito durante qualquer momento do seguimento.

O seguimento clínico teve início considerando-se como a data inicial, a data da primeira consulta no Departamento de Mastologia do Hospital do Câncer - A. C. Camargo e a data final registrada, a data da última consulta ou do óbito. Foram considerados como perda de seguimento clínico aqueles casos de pacientes que não retornaram em consulta, e que após tentativa de contato telefônico ou por telegrama, não obtivemos resposta.

\subsubsection{Definição dos estádios IIA e IIIB}

O estadiamento utilizado se baseou na classificação TNM do sistema da UICC (Sobin, Wittenkind, 2006) (Anexo 3). Todos os casos do presente estudo estão agrupados em dois estádios, a saber:

- EC IIA: que incluem os casos T0N1M0; T1N1M0; T2N0M0, num total de 86 pacientes;

- EC IIIB: que incluem os casos T4N0M0, T4N1M0, T4N2M0, num total de 182 pacientes

\subsubsection{Coleta de dados e critérios de revisão das lâminas}

Os prontuários clínicos foram revistos, anotando-se em ficha de dados (Anexo 3) as informações clínico-patológicas relevantes (dados clínico-demográficos, estadiamento 
anatomopatológico, terapêutica adjuvante, seguimento, recidiva, sobrevida), e a seguir repassadas para uma planilha Excel (Anexo 4).

De todos os casos selecionados, resgatamos as lâminas originais coradas por hematoxilina/eosina (HE) e os blocos correspondentes de material incluído em parafina, dos quais foram feitos novos cortes histológicos. Os dados referentes ao tipo histológico, grau histológico, grau nuclear, índice mitótico, foram obtidos a partir do banco de dados do Departamento de Anatomia Patológica. O tamanho tumoral foi obtido segundo os laudos originais dos exames anatomopatológicos, uma vez que esta informação é colhida durante o exame.

Com relação à graduação histológica, adotamos em nosso trabalho a graduação de Notthingham (Ellis, Elston, 1998), que leva em consideração a extensão da formação de túbulos, o grau de pleomorfismo nuclear e a contagem mitótica. A cada uma dessas variáveis é atribuído um escore de 1, 2 ou 3, e os escores são somados para a obtenção de uma graduação final (Anexo 5). O escore mitótico é determinado pelo número de mitoses encontradas em 10 campos de grandes aumentos (CGA) nas áreas com maior atividade mitótica do tumor. Os tumores foram agrupados em tumores com índice mitótico de 1 a 9 mitoses/CGA (escore $=1)$, 10 a 19 mitoses/CGA(escore $=2)$ e mais que 19 mitoses/CGA $($ escore $=3)$. 


\subsection{Método}

\subsubsection{Confecção dos blocos e lâminas dos TMA}

Nas lâminas convencionais foram marcadas áreas representativas do componente invasor para orientar as perfurações e obtenção dos cilindros para a confecção dos TMA. A partir de cada bloco original de tumor, foi obtido um cilindro, utilizando-se um instrumento de precisão especial para confecção dos TMA (Beecher Instruments ${ }^{\circledR}$, Silver Spring, Maryland), conforme descrito em protocolos da literatura (Kononen et al., 1998).

O diâmetro de cada cilindro dos blocos de TMA confeccionados para este estudo foi de 1,0 mm; a distância entre os cilindros no bloco receptor foi de 0,2 mm. Cada bloco possui um total de 320 cilindros de tecido, dispostos em coordenadas correspondentes a 16 colunas e 20 linhas (designações das linhas de 1 a 20; designações das colunas de A a P). Do total de 320 cilindros, um corresponde a um fragmento de tecido hepático usado como marcador das coordenadas "A-1" dos TMA, utilizados para a orientação da leitura de lâminas e identificação dos casos.

Os cortes histológicos obtidos dos blocos de TMA, com espessura média de $4 \mu$, foram dispostos em lâminas especiais eletricamente carregadas (Instrumedics Inc. ${ }^{\circledR}$ ) para facilitar sua orientação após a microtomia.

Os blocos de TMA foram submetidos a cortes seriados, com uma média de 100 cortadas para cada um, numeradas sequencialmente de acordo com nível de corte (de 1 a 100), restando ainda material suficiente para novas secções histológicas nos blocos de arrays. Aquelas lâminas que não foram utilizadas para as reações deste estudo IIQ tiveram suas superfícies parafinizadas e foram mantidas em freezer a $-70^{\circ} \mathrm{C}$ para melhor preservação da antigenicidade dos marcadores. Foi realizada coloração pela 
hematoxilina/eosina de uma lâmina a cada 20 níveis de cada um dos blocos para controle histológico da representação do tumor de cada caso nas diferentes áreas do tumor nos cilindros (níveis 1, 20, 40, 60, 80 e 100).

\subsubsection{Estudo imunoistoquímico (IIQ)}

O estudo IIQ foi realizado com anticorpos que reconhecem os diferentes marcadores utilizados. As reações para cada marcador foram realizadas em duplicata, simultaneamente, utilizando-se níveis distantes da amostra dos blocos, dispostos em duas lâminas separadas (62 ou 63 níveis de diferença entre as secções utilizadas nas reações que, com a espessura média de $4 \mu$, resultam numa distância de cerca de $250 \mu$ ), para que houvesse representação de diferentes células ou áreas de cada tumor/amostra. As reações de IIQ seguiram os protocolos padronizados específicos preconizados pelos fabricantes, conforme descrito em literatura para cada marcador. Todas as reações tiveram controles positivos e negativos corridos paralelamente às lâminas do estudo. $\mathrm{O}$ quadro 1 , mostra a lista completa dos nove anticorpos utilizados com os respectivos clones, diluições e fabricantes. Os controles positivos das reações foram realizados nas mesmas condições, com um corte de tecido que sabidamente expressava o antígeno pesquisado. Os controles negativos incluíram a simples retirada do anticorpo primário que foi substituído por BSA. 
Quadro 1 - Anticorpos e protocolos de reações utilizados

\begin{tabular}{|l|l|l|l|}
\hline Anticorpos & Clones & Diluições & Fabricantes \\
\hline Receptor de estrógeno & Monoclonal em coelho SP1 & $1: 400$ & Neomarkers, CA, EUA \\
\hline Receptor de progesterona & PgR636 & $1: 300$ & Dako, Carpinteria, CA, EUA \\
\hline HER2 & Policlonal em coelho & RTU* & Dako \\
\hline NOS-2 & 16 & $1: 100$ & BD Transduction \\
\hline EGFR & EGFR-25 & $1: 100$ & Novocastra, UK \\
\hline TWIST 2 & $3 \mathrm{C} 8$ & $1: 250$ & Novus Biologicals \\
\hline SLUG & Policlonal & $1: 100$ & Abcam \\
\hline SNAI-1 & E18 & $1: 500$ & Santa Cruz \\
\hline Vimentina & Vim3B4 & $1: 400$ & DAKO \\
\hline E caderina & 36 & $1: 600$ & BD Transduction, San Jose, \\
& & & CA, EUA \\
\hline N Caderina & $6 G-11$ & $1: 50$ & Dako \\
\hline P Caderina & $56 \mathrm{C} 1$ & $1: 100$ & NeoMarkers \\
\hline
\end{tabular}

*RTU - ready to use (anticorpo pronto para uso)

A leitura de todas as lâminas de cada anticorpo foi realizada num só dia para diminuir a variabilidade de interpretação intraobservador. Nos casos onde ocorreu descolamento do tecido em uma das lâminas durante o processamento ou onde não mais houvesse representação de células neoplásicas, considerou-se apenas o resultado do disco presente (ou adequado) para a análise. Quando não havia amostragem celular adequada em nenhum dos cortes dos dois cilindros, o caso foi excluído da análise para o respectivo marcador. $\mathrm{O}$ fato das reações terem sido feitas simultaneamente para cada anticorpo uniformizou eventuais variações da intensidade de marcação.

A avaliação das reações IIQ levou em conta apenas o número percentual de células marcadas e classificadas em relação ao padrão específico de expressão para cada anticorpo e ao número de células positivas (Allred et al., 1998). Para os marcadores nucleares considerou-se positivo quando o percentual de núcleos marcados foi maior do que $1 \%$ e 
negativo quando esta marcação foi menor do que $1 \%$ ou negativa. Para os marcadores citoplasmáticos considerou-se positivo aqueles casos com mais de $10 \%$ das células marcadas. A leitura das lâminas de IIQ foi realizada em microscópio óptico comum. Exemplos de casos positivos e negativos são demonstrados nas figuras 1 a 3 .

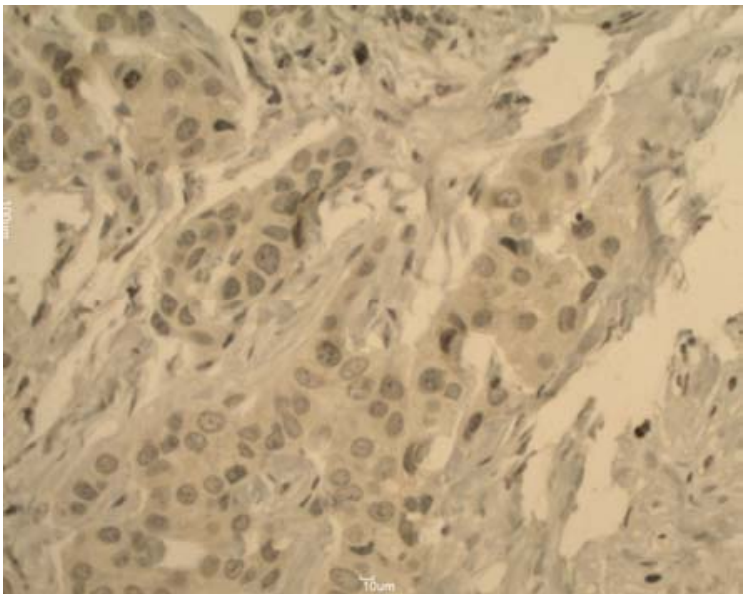

EGFR (negativo)

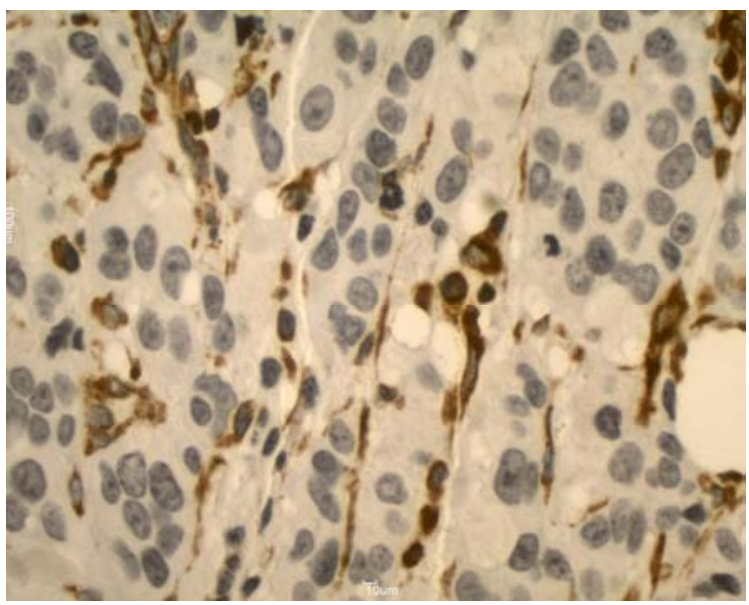

Vimentina (negativo)

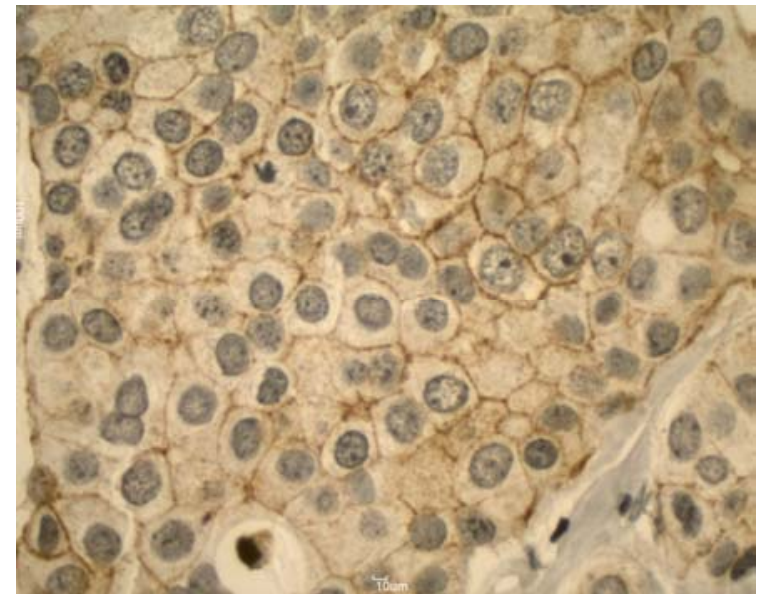

EGFR (positivo)

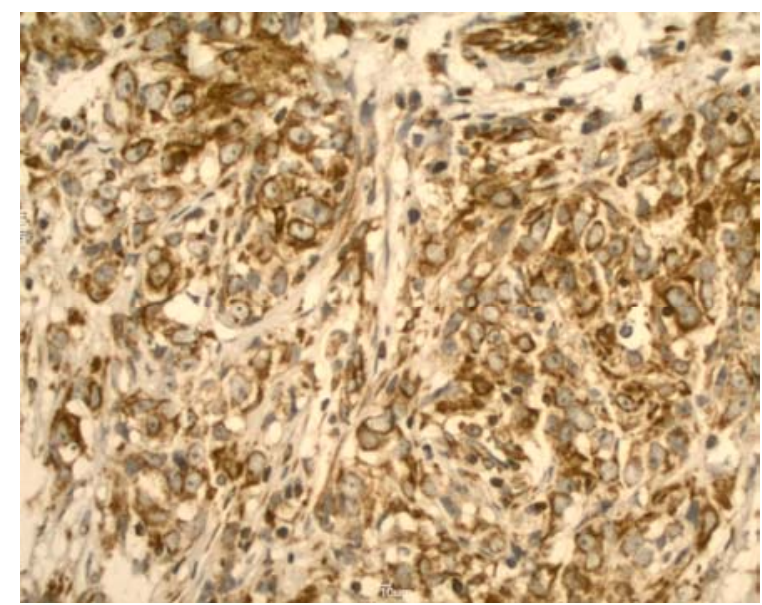

Vimentina (positivo)

Figura 1 - Padrões de expressão dos marcadores IIQ (EGFR, vimentina). Aumento 400x. 


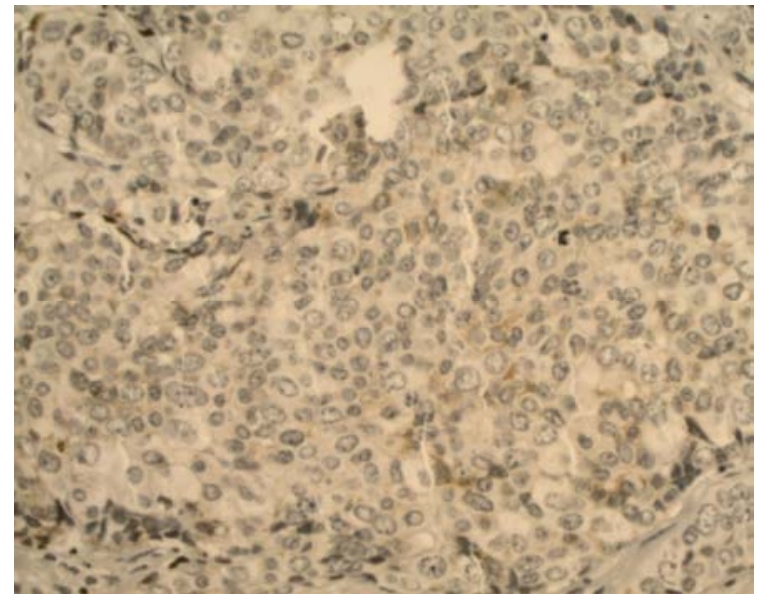

e-caderina (negativo)

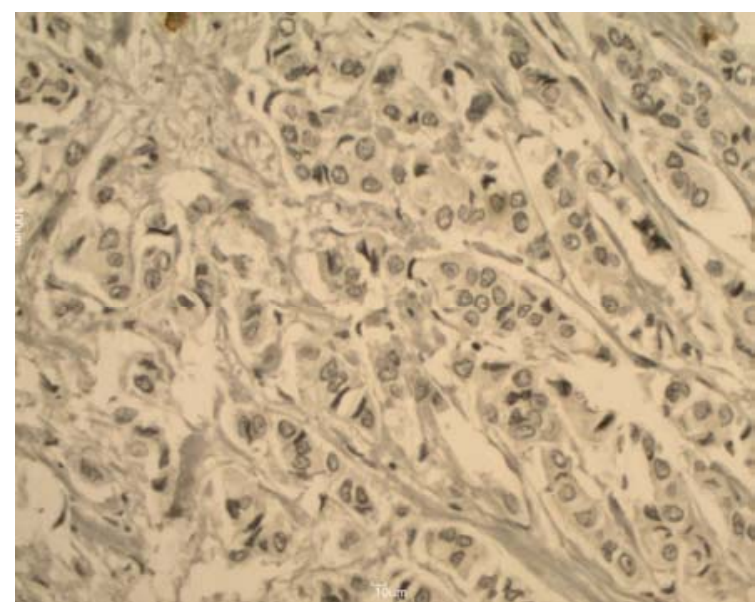

n-caderina (negativo)

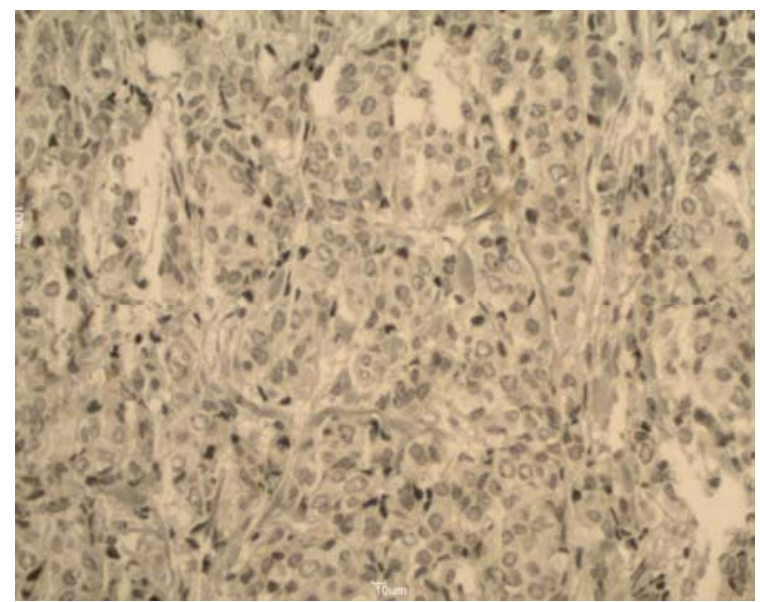

p-caderina (negativo)

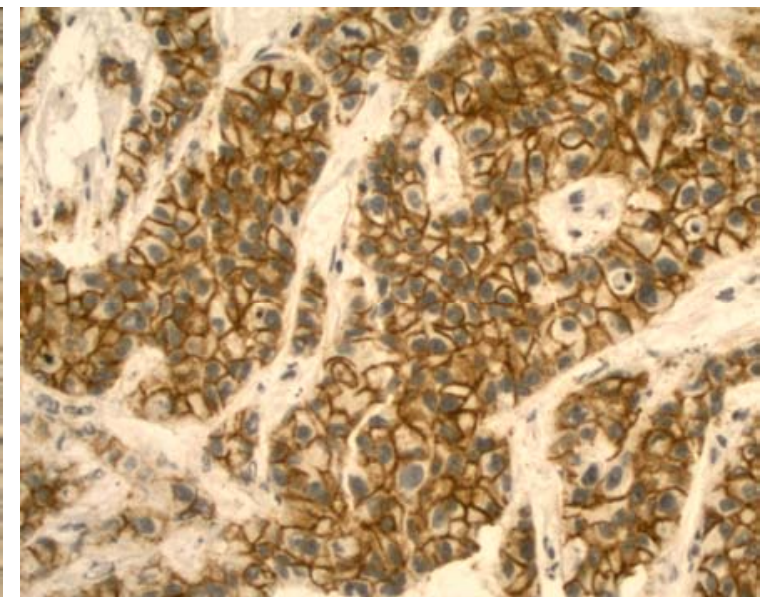

e-caderina (positivo)

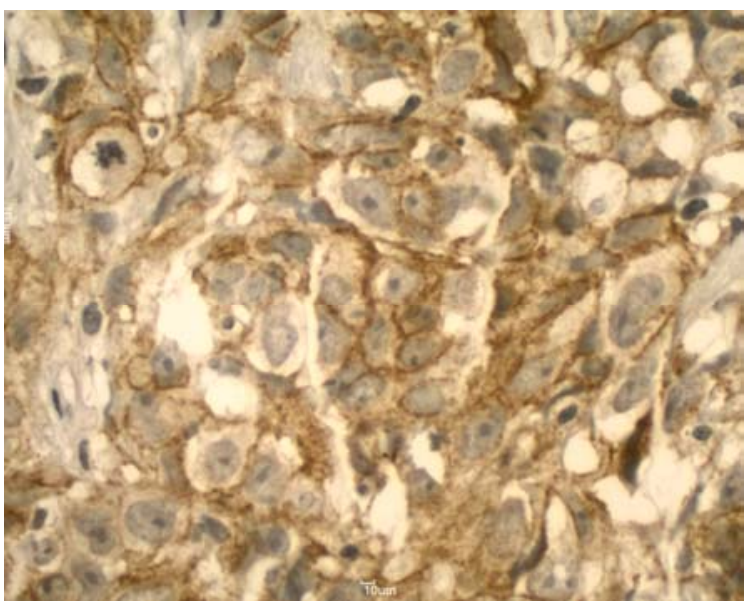

n-caderina (positivo)

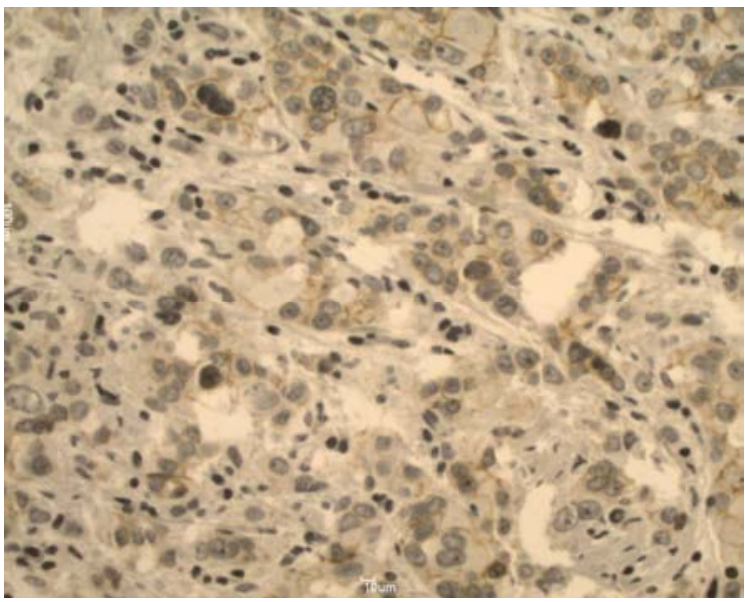

n-caderina (positivo)

Figura 2 - Padrões de expressão dos marcadores IIQ (e-caderina, n-caderina, p-caderina). Aumento 400x. 


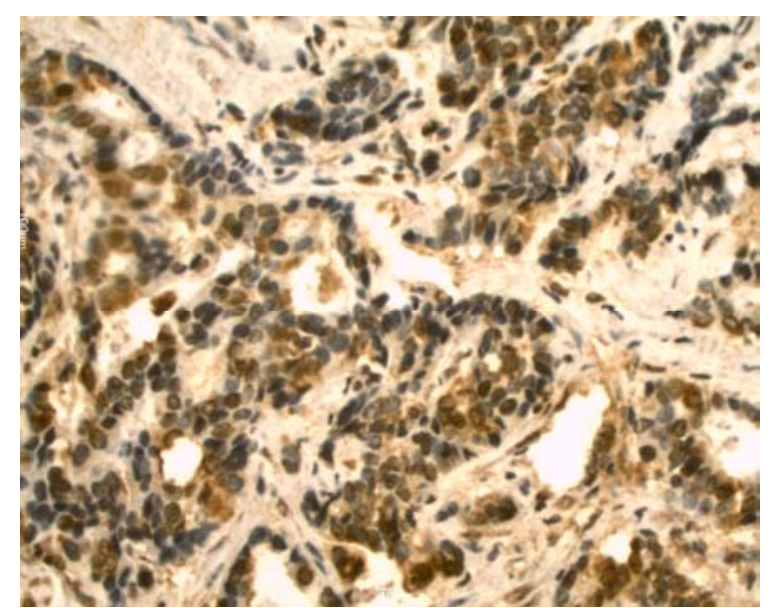

Snail (parcialmente positivo)

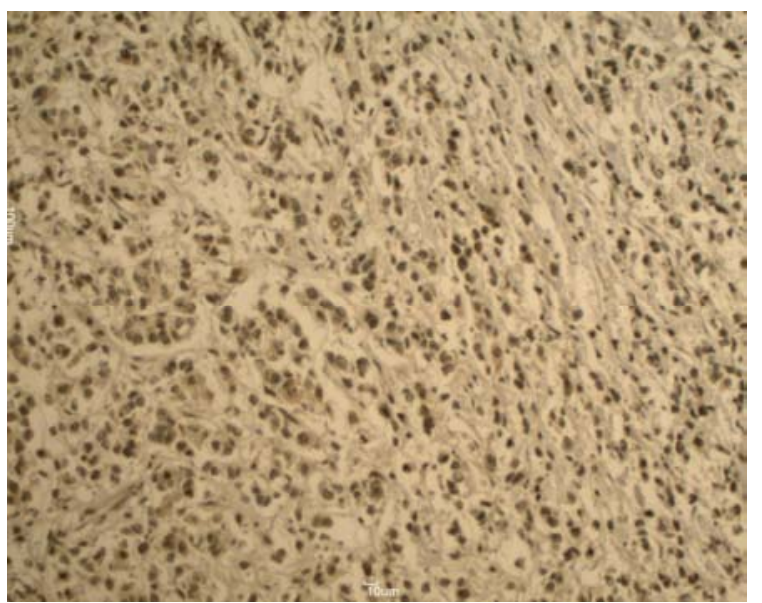

Slug (negativo)

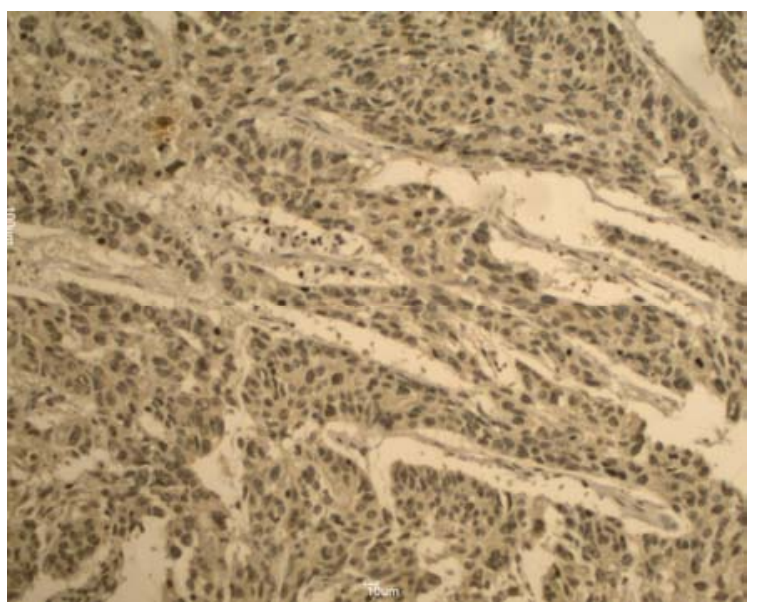

Twist (negativo)

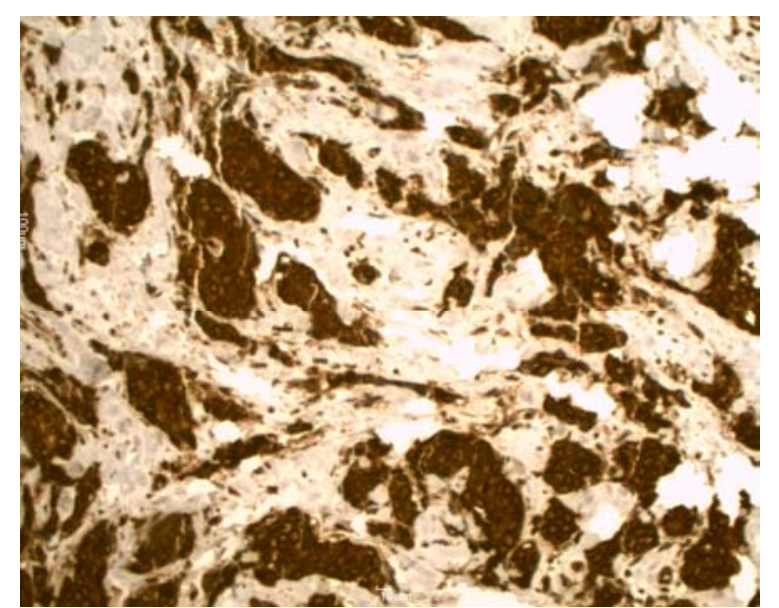

Snail (positivo)

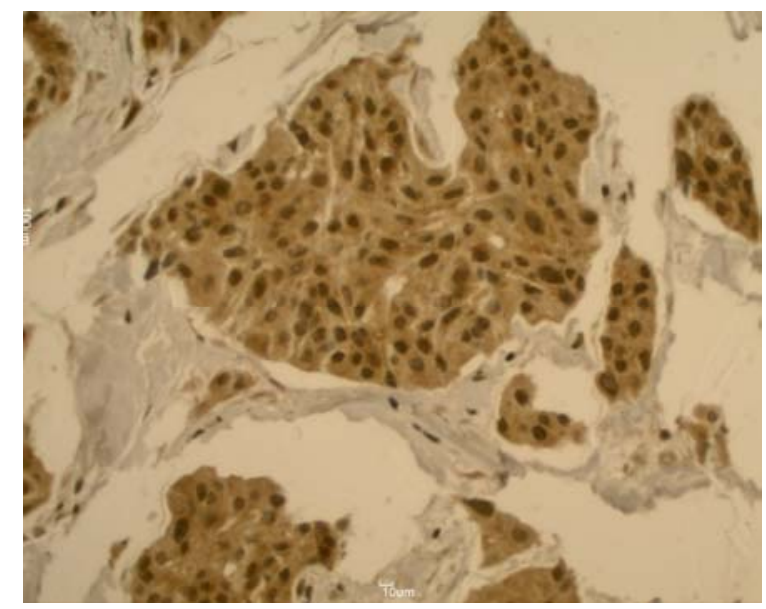

Slug (positivo)

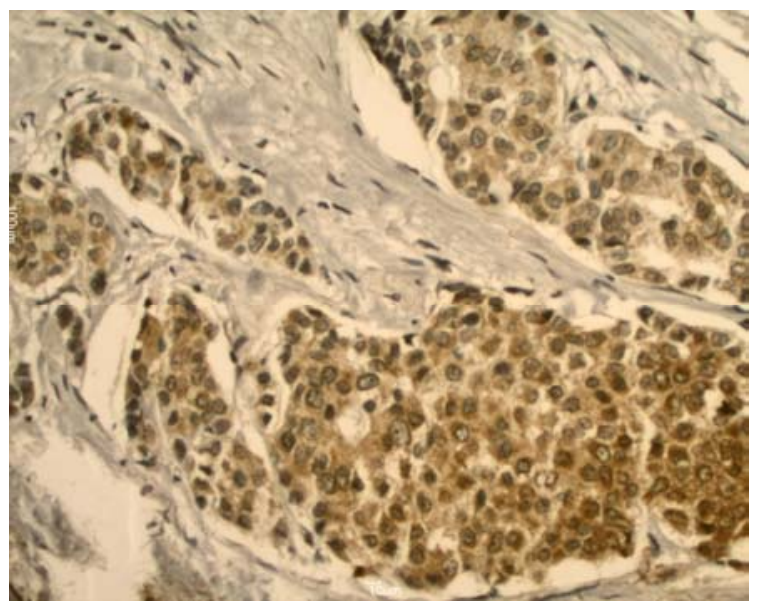

Twist (positivo)

Figura 3 - Padrões de expressão dos marcadores IIQ (snai1, slug, twist). Aumento 400x. 


\subsection{Definição dos subgrupos moleculares}

Estes tumores foram analisados previamente com relação a diversos marcadores, e estes dados foram utilizados para definirmos os subgrupos dos tumores de mama (Stiepich, 2007). Os dados utilizados incluíram RE, RP, HER-2, CK 8/18, ki67, índice mitótico, ck5/14, p63. De acordo com os resultados das reações IIQ, foram identificados cinco subgrupos caracterizados pela presença ou ausência de expressão de alguns dos marcadores, conforme especificado abaixo:

1. Luminal A: Receptores hormonais positivos (RE/RP +), HER-2(-); expressão das CK 8/18; positividade para expressão do Bcl-2 e Gata-3 (estes não mostrados na tese).

2. Luminal B: Receptores hormonais positivos (RE/RP +), HER-2(+); expressão das CK 8/18; alto índice de proliferação celular (ki67 e índice mitótico) .

3. Super-expressor de HER-2: Receptores hormonais negativos (RE/RP -), HER-2(+); FISH amplificado.

4. Triplo-negativo: Receptores hormonais negativos (RE/RP -), HER-2(-);

5. Padrão Basal: Receptores hormonais negativos (RE/RP -), HER-2(-); positividade de citoceratinas basais $(\mathrm{CK}$ 5/CK 14) ou EGFR + ou p63+ ou p-caderina + ou caveolina- $1+$ ou ativação Wnt (estes não mostrados na tese). 


\subsection{Análise estatística dos dados e resultados}

Os resultados obtidos foram analisados utilizando-se os programas de computador SPSS v13 (SPSS Inc. USA, 2004) e GraphPad Prism v.4.02 (Graphpad Software Inc. USA, 2000). Caracterizou-se a amostra por meio da estatística descritiva. Realizou-se a análise de associação entre as variáveis categóricas através do teste do qui-quadrado ou do teste exato de Fisher, dependendo dos valores observados nas tabelas de contingência. A regressão logística foi empregada para a identificação dos fatores de risco independentes associados ao óbito. Para a análise dos óbitos, truncou-se o tempo de seguimento em 120 meses e optou-se por uma avaliação transversal dos dados. Em todos os testes o nível de significância considerado foi de 5\%. 


\section{RESULTADOS}

Foram analisados neste estudo 268 pacientes ( 86 pertencentes ao EC IIA e 182 pertencentes ao EC IIIB) com diagnóstico de carcinoma ductal invasivo (CDI). Na tabela 1, observamos a distribuição dos casos de acordo com as variáveis clínico-demográficas (idade, cor de pele, número de gestações, status hormonal e história familiar).

Tabela 1 - Distribuição dos casos de acordo com as variáveis clínico-demográficas

\begin{tabular}{llrc}
\hline VARIÁVEL & CATEGORIAS & n & \% \\
\hline \multirow{3}{*}{ Idade } & Até 50 anos & 100 & 37,3 \\
& $>50$ anos & 165 & 61,6 \\
& Inconclusivo & 3 & 1,1 \\
\hline \multirow{3}{*}{ Cor de pele } & Branca & 208 & 77,6 \\
& Não branca & 39 & 14,6 \\
& Inconclusivo & 21 & 7,8 \\
\hline \multirow{3}{*}{ Número de gestações } & Nenhuma & 36 & 13,4 \\
& Uma ou mais & 205 & 76,5 \\
& Inconclusivo & 27 & 10,1 \\
\hline \multirow{3}{*}{ Status hormonal } & Pré-menopausa & 110 & 41,0 \\
& Pós-menopausa & 156 & 58,2 \\
& Inconclusivo & 2 & 0,2 \\
\hline \multirow{3}{*}{ História familiar } & Não & 192 & 71,6 \\
& Sim & 49 & 18,3 \\
& Inconclusivo & 27 & 10,1 \\
\hline
\end{tabular}


Na tabela 2, observamos a distribuição dos casos de acordo com as variáveis histopatológicas (tamanho do tumor, grau histológico, grau nuclear, índice mitótico e presença de metástase linfonodal) e o estadiamento patológico. As pacientes analisadas pertenciam a dois subgrupos de estadiamento, sendo que 86 casos pertenciam ao EC IIA $(32,1 \%)$ e 182 ao EC IIIB (67,9\%).

Tabela 2 - Distribuição dos casos de acordo com as variáveis histopatológicas

\begin{tabular}{|c|c|c|c|}
\hline VARIÁVEL & CATEGORIAS & $\mathbf{n}$ & $\%$ \\
\hline \multirow{4}{*}{ Tamanho do tumor } & Até $2,0 \mathrm{~cm}$ & 29 & 10,8 \\
\hline & $2,1-5,0 \mathrm{~cm}$ & 155 & 57,8 \\
\hline & $>5,0 \mathrm{~cm}$ & 71 & 26,5 \\
\hline & Inconclusivo & 13 & 4,9 \\
\hline \multirow{4}{*}{ Scarff-Bloom-Richardson } & Grau 1 & 41 & 15,3 \\
\hline & Grau 2 & 153 & 57,1 \\
\hline & Grau 3 & 73 & 27,2 \\
\hline & Inconclusivo & 1 & 0,4 \\
\hline \multirow{4}{*}{ Grau nuclear } & Grau 1 & 3 & 1,1 \\
\hline & Grau 2 & 98 & 36,6 \\
\hline & Grau 3 & 165 & 61,6 \\
\hline & Inconclusivo & 2 & 0,7 \\
\hline \multirow{4}{*}{ Índice mitótico } & 0 a 9 & 136 & 50,7 \\
\hline & 10 a 19 & 65 & 24,3 \\
\hline & 20 ou mais & 3 & 1,1 \\
\hline & Inconclusivo & 64 & 23,9 \\
\hline \multirow{3}{*}{ Metástase linfonodal } & Não & 104 & 38,8 \\
\hline & Sim & 158 & 59,0 \\
\hline & Inconclusivo & 6 & 2,2 \\
\hline \multirow{2}{*}{ Estadiamento } & Estádio IIA & 86 & 32,1 \\
\hline & Estádio IIB & 182 & 67,9 \\
\hline
\end{tabular}


A análise da distribuição dos casos de acordo com as variáveis relacionadas com os tratamentos adjuvantes e neoadjuvantes, se encontra na tabela 3.

Tabela 3 - Distribuição dos casos de acordo com as variáveis relacionadas com os tratamentos adjuvante e neoadjuvante

\begin{tabular}{llrc}
\hline VARIÁVEL & CATEGORIAS & n & \% \\
\hline \multirow{3}{*}{ Quimioterapia neoadjuvante } & Não & 137 & 51,1 \\
& Sim & 104 & 38,8 \\
& Inconclusivo & 27 & 10,1 \\
\hline \multirow{2}{*}{ Radioterapia neoadjuvante } & Não & 230 & 85,8 \\
& Sim & 11 & 4,1 \\
& Inconclusivo & 27 & 10,1 \\
\hline \multirow{3}{*}{ Quimioterapia adjuvante } & Não & 94 & 35,1 \\
& Sim & 146 & 54,5 \\
& Inconclusivo & 28 & 10,4 \\
\hline \multirow{3}{*}{ Radioterapia adjuvante } & Não & 49 & 18,3 \\
& Sim & 192 & 71,6 \\
& Inconclusivo & 27 & 10,1 \\
\hline \multirow{2}{*}{ Hormonioterapia } & Não & 135 & 50,4 \\
& Sim & 106 & 39,6 \\
& Inconclusivo & 27 & 10,1 \\
\hline
\end{tabular}


$\mathrm{Na}$ análise das reações IIQ, observamos perdas de alguns cortes de cilindros em decorrência de descolamento do tecido durante o preparo técnico. Na tabela 4 estão relacionados os resultados das reações IIQ para todos os anticorpos realizados.

Tabela 4 - Distribuição dos casos de acordo com as variáveis biomoleculares

\begin{tabular}{|c|c|c|c|}
\hline VARIÁVEL & CATEGORIAS & $\mathbf{n}$ & $\%$ \\
\hline & Negativo & 89 & 33,2 \\
\hline \multirow[t]{3}{*}{ ER } & Positivo & 178 & 66,4 \\
\hline & Inconclusivo & 1 & 0,4 \\
\hline & Negativo & 141 & 52,6 \\
\hline \multirow[t]{3}{*}{ PR } & Positivo & 125 & 46,6 \\
\hline & Inconclusivo & 2 & 0,7 \\
\hline & Negativo & 220 & 82,1 \\
\hline \multirow[t]{3}{*}{ HER-2 } & Positivo & 48 & 17,9 \\
\hline & Ignorado & 0 & 0,0 \\
\hline & Negativo & 17 & 6,3 \\
\hline \multirow[t]{3}{*}{ P53 } & Positivo & 245 & 91,4 \\
\hline & Inconclusivo & 6 & 2,2 \\
\hline & Negativo & 226 & 84,3 \\
\hline \multirow[t]{3}{*}{ CK 5/6 } & Positivo & 38 & 14,2 \\
\hline & Inconclusivo & 4 & 1,5 \\
\hline & Negativo & 249 & 92,9 \\
\hline \multirow[t]{3}{*}{ CK 14} & Positivo & 13 & 4,9 \\
\hline & Inconclusivo & 6 & 2,2 \\
\hline & Negativo & 3 & 1,1 \\
\hline \multirow[t]{3}{*}{ CK 8} & Positivo & 254 & 94,8 \\
\hline & Inconclusivo & 11 & 4,1 \\
\hline & Negativo & 39 & 14,6 \\
\hline \multirow[t]{3}{*}{ CK 18} & Positivo & 216 & 80,6 \\
\hline & Ignorado & 13 & 4,9 \\
\hline & Negativo & 236 & 88,1 \\
\hline \multirow[t]{3}{*}{ P63 n } & Positivo & 17 & 6,3 \\
\hline & Inconclusivo & 15 & 5,6 \\
\hline & Negativo & 88 & 32,8 \\
\hline \multirow[t]{2}{*}{ NOS-2 } & Positivo & 159 & 59,3 \\
\hline & Inconclusivo & 21 & 7,8 \\
\hline
\end{tabular}




\begin{tabular}{|c|c|c|c|}
\hline VARIÁVEL & CATEGORIAS & $\mathbf{n}$ & $\%$ \\
\hline \multirow{3}{*}{ E caderina } & Negativo & 89 & 33,2 \\
\hline & Positivo & 150 & 56,0 \\
\hline & Inconclusivo & 29 & 10,8 \\
\hline \multirow{3}{*}{$\mathrm{N}$ caderina } & Negativo & 214 & 79,9 \\
\hline & Positivo & 11 & 4,1 \\
\hline & Inconclusivo & 43 & 16,0 \\
\hline \multirow{3}{*}{$\mathrm{P}$ caderina } & Negativo & 166 & 61,9 \\
\hline & Positivo & 64 & 23,9 \\
\hline & Inconclusivo & 38 & 14,2 \\
\hline \multirow{3}{*}{ Vimentina } & Negativo & 224 & 83,6 \\
\hline & Positivo & 11 & 4,1 \\
\hline & Inconclusivo & 33 & 12,3 \\
\hline \multirow{3}{*}{ Twist } & Negativo & 140 & 52,2 \\
\hline & Positivo & 85 & 31,7 \\
\hline & Inconclusivo & 43 & 16,0 \\
\hline \multirow{3}{*}{ Snai 1} & Negativo & 0 & 0,0 \\
\hline & Positivo & 233 & 86,9 \\
\hline & Inconclusivo & 35 & 13,1 \\
\hline \multirow{3}{*}{ EGFR } & Negativo & 232 & 86,6 \\
\hline & Positivo & 1 & 0,4 \\
\hline & Inconclusivo & 35 & 13,1 \\
\hline \multirow{3}{*}{ Slug } & Negativo & 45 & 16,8 \\
\hline & Positivo & 181 & 67,5 \\
\hline & Inconclusivo & 42 & 15,7 \\
\hline
\end{tabular}


Na tabela 5 observamos a distribuição dos casos de acordo com o perfil fenotípico dos tumores (luminal A, luminal B, super-expressor de HER-2, triplo negativo e basal).

Tabela 5 - Distribuição dos casos de acordo com o perfil fenotípico biomolecular

\begin{tabular}{llcr}
\hline VARIÁVEL & CATEGORIAS & n & \% \\
\hline \multirow{3}{*}{ Luminal A* } & Não & 100 & 37,3 \\
& Sim & 166 & 61,9 \\
& Indeterminado & 2 & 0,7 \\
\hline \multirow{3}{*}{ Luminal B* } & Não & 249 & 92,9 \\
& Sim & 19 & 7,1 \\
& Indeterminado & 0 & 0,0 \\
\hline \multirow{3}{*}{ Super-expressão HER-2* } & Não & 239 & 89,2 \\
& Sim & 29 & 10,8 \\
& Indeterminado & 0 & 0,0 \\
\hline \multirow{3}{*}{ Triplo-negativo* } & Não & 214 & 79,9 \\
& Sim & 52 & 19,4 \\
& Indeterminado & 2 & 0,7 \\
\hline \multirow{2}{*}{ Basal* } & Não & 228 & 85,1 \\
& Sim & 22 & 8,2 \\
\hline
\end{tabular}

* Determinação dos grupos:

Luminal A: $\quad($ ER + ou PR +$)$ e HER-2 -

Luminal B: $\quad($ ER + ou PR + ) e HER-2 +

Super-expressor HER-2: ER- e PR- e HER-2+

Triplo negativo: ER- e PR- e HER-2-

Basal: Triplo-negativo e (EGFR+ ou CK5/6+ ou P63n+ ou p-caderina+ ou CK14+) 


\section{Análise comparativa no estádio IIA}

Ao analisarmos as pacientes do estádio IIA, que tiveram um seguimento de 120 meses, observamos que não houve diferença estatisticamente significante, quando analisamos todas as variáveis clínico-demográficas e as relacionadas ao tratamento (Tabelas 6 e 7).

Tabela 6 - Distribuição dos casos de acordo com as variáveis clínico-demográficas e a ocorrência ou não de óbito até 120 meses de seguimento* no grupo de mulheres estadiadas como IIA $(\mathrm{n}=82)$

\begin{tabular}{|c|c|c|c|c|c|c|}
\hline \multirow{3}{*}{ VARIÁVEL } & \multirow{3}{*}{ CATEGORIAS } & \multicolumn{4}{|c|}{ Óbito até 120 meses } & \multirow{3}{*}{$\mathbf{p}^{* *}$} \\
\hline & & \multicolumn{2}{|c|}{ Não } & \multicolumn{2}{|c|}{ Sim } & \\
\hline & & n & $\%$ & $\mathbf{n}$ & $\%$ & \\
\hline \multirow{2}{*}{ Idade } & Até 50 anos & 24 & 72,7 & 9 & 27,3 & \multirow{2}{*}{0,807} \\
\hline & $>50$ anos & 33 & 70,2 & 14 & 29,8 & \\
\hline \multirow{2}{*}{ Cor de pele } & Branca & 44 & 68,8 & 20 & 31,3 & \multirow{2}{*}{0,264} \\
\hline & Não branca & 9 & 90,0 & 1 & 10,0 & \\
\hline \multirow{2}{*}{ Número de gestações } & Nenhuma & 10 & 71,4 & 4 & 28,6 & \multirow{2}{*}{1,000} \\
\hline & Uma ou mais & 41 & 70,7 & 17 & 29,3 & \\
\hline \multirow{2}{*}{ Status hormonal } & Pré-menopausa & 26 & 72,2 & 10 & 27,8 & \multirow{2}{*}{0,744} \\
\hline & Pós-menopausa & 31 & 68,9 & 14 & 31,1 & \\
\hline \multirow{2}{*}{ História familiar } & Não & 42 & 71,2 & 17 & 28,8 & \multirow{2}{*}{1,000} \\
\hline & Sim & 10 & 71,4 & 4 & 28,6 & \\
\hline
\end{tabular}

* Pacientes vivas e com menos de 60 meses de seguimento foram excluídas da análise.

** Teste de qui-quadrado ou teste exato de Fisher. 
Tabela 7 - Distribuição dos casos de acordo com as variáveis relacionadas ao tratamento e a ocorrência ou não de óbito até 120 meses de seguimento* no grupo de mulheres estadiadas como IIA $(\mathrm{n}=82)$

\begin{tabular}{|c|c|c|c|c|c|c|}
\hline \multirow{3}{*}{ VARIÁVEL } & \multirow{3}{*}{ CATEGORIAS } & \multicolumn{4}{|c|}{ Óbito até 120 meses } & \multirow{3}{*}{$\mathbf{p}^{* *}$} \\
\hline & & \multicolumn{2}{|c|}{ Não } & \multicolumn{2}{|c|}{ Sim } & \\
\hline & & $\mathbf{n}$ & $\%$ & $\mathbf{n}$ & $\%$ & \\
\hline \multirow{2}{*}{ Quimioterapia neoadjuvante } & Não & 49 & 73,1 & 18 & 26,9 & \multirow{2}{*}{0,345} \\
\hline & Sim & 3 & 50,0 & 3 & 50,0 & \\
\hline \multirow{2}{*}{ Radioterapia neoadjuvante } & Não & 50 & 72,5 & 19 & 27,5 & \multirow{2}{*}{0,574} \\
\hline & Sim & 2 & 50,0 & 2 & 50,0 & \\
\hline \multirow{2}{*}{ Quimioterapia adjuvante } & Não & 21 & 70,0 & 9 & 30,0 & \multirow{2}{*}{0,846} \\
\hline & Sim & 31 & 72,1 & 12 & 27,9 & \\
\hline \multirow{2}{*}{ Radioterapia adjuvante } & Não & 15 & 68,2 & 7 & 31,8 & \multirow{2}{*}{0,705} \\
\hline & Sim & 37 & 72,5 & 14 & 27,5 & \\
\hline \multirow{2}{*}{ Hormonioterapia } & Não & 27 & 79,4 & 7 & 20,6 & \multirow{2}{*}{0,149} \\
\hline & Sim & 45 & 64,1 & 14 & 35,9 & \\
\hline
\end{tabular}

* Pacientes vivas e com menos de 60 meses de seguimento foram excluídas da análise.

** Teste de qui-quadrado ou teste exato de Fisher. 
Quando analisamos as variáveis histopatológicas, observamos que não houve diferença estatisticamente significante entre o grupo de pacientes que morreram e as que não morreram, com exceção da variável grau nuclear, no qual observamos que a maioria das pacientes que morreram pertenciam ao grau $3(\mathrm{p}=0,008)$ (Tabela 8$)$.

Tabela 8 - Distribuição dos casos de acordo com as variáveis histopatológicas e a ocorrência ou não de óbito até 120 meses de seguimento* no grupo de mulheres estadiadas como IIA $(n=82)$

\begin{tabular}{|c|c|c|c|c|c|c|}
\hline \multirow{3}{*}{ VARIÁVEL } & \multirow{3}{*}{ CATEGORIAS } & \multicolumn{4}{|c|}{ Óbito até 120 meses } & \multirow{3}{*}{$\mathbf{p}^{* *}$} \\
\hline & & \multicolumn{2}{|c|}{ Não } & \multicolumn{2}{|c|}{ Sim } & \\
\hline & & $\mathbf{n}$ & $\%$ & $\mathbf{n}$ & $\%$ & \\
\hline \multirow{2}{*}{ Tamanho do tumor } & Até $2,0 \mathrm{~cm}$ & 14 & 87,5 & 2 & 12,5 & \multirow{2}{*}{0,127} \\
\hline & $2,1-5,0 \mathrm{~cm}$ & 41 & 65,1 & 22 & 34,9 & \\
\hline \multirow{2}{*}{ Scarff-Bloom-Richardson } & Graus 1 e 2 & 50 & 73,5 & 18 & 26,5 & \multirow{2}{*}{0,332} \\
\hline & Grau 3 & 8 & 57,1 & 6 & 42,9 & \\
\hline \multirow{2}{*}{ Grau nuclear } & Graus 1 e 2 & 28 & 87,5 & 4 & 12,5 & \multirow{2}{*}{0,008} \\
\hline & Grau 3 & 30 & 60,0 & 20 & 40,0 & \\
\hline \multirow{2}{*}{ Índice mitótico } & 0 a 9 & 37 & 78,7 & 10 & 21,3 & \multirow{2}{*}{0,106} \\
\hline & 10 ou mais & 9 & 56,3 & 7 & 43,8 & \\
\hline \multirow{2}{*}{ Metástase linfonodal } & Não & 45 & 68,2 & 21 & 31,8 & \multirow{2}{*}{0,329} \\
\hline & Sim & 12 & 86,7 & 2 & 14,3 & \\
\hline
\end{tabular}

* Pacientes vivas e com menos de 60 meses de seguimento foram excluídas da análise.

** Teste de qui-quadrado ou teste exato de Fisher.

Já com relação às variáveis biomoleculares e a ocorrência ou não de óbito, observamos que a expressão do receptor de estrogênio foi positiva nas pacientes que não morreram e esta diferença foi estatisticamente significante $(p=0,021)$ (Tabela 9). 
Tabela 9 - Distribuição dos casos de acordo com as variáveis biomoleculares e a ocorrência ou não de óbito até 120 meses de seguimento* no grupo de mulheres estadiadas como IIA $(\mathrm{n}=82)$

\begin{tabular}{|c|c|c|c|c|c|c|}
\hline \multirow{3}{*}{ VARIÁVEL } & \multirow{3}{*}{ CATEGORIAS } & \multicolumn{4}{|c|}{ Óbito até 120 meses } & \multirow{3}{*}{$\mathbf{p}^{* *}$} \\
\hline & & \multicolumn{2}{|c|}{ Não } & \multicolumn{2}{|c|}{ Sim } & \\
\hline & & $\mathbf{n}$ & $\%$ & $\mathbf{n}$ & $\%$ & \\
\hline \multirow{2}{*}{ ER } & Negativo & 6 & 42,9 & 8 & 57,1 & \multirow{2}{*}{0,021} \\
\hline & Positivo & 52 & 76,5 & 16 & 23,5 & \\
\hline \multirow{2}{*}{ PR } & Negativo & 19 & 59,4 & 13 & 40,6 & \multirow{2}{*}{0,071} \\
\hline & Positivo & 39 & 78,0 & 11 & 22,0 & \\
\hline \multirow{2}{*}{ HER-2 } & Negativo & 53 & 72,6 & 20 & 27,4 & \multirow{2}{*}{0,437} \\
\hline & Positivo & 5 & 55,6 & 4 & 44,4 & \\
\hline \multirow{2}{*}{ P53 } & Negativo & 2 & 50,0 & 2 & 50,0 & \multirow{2}{*}{0,574} \\
\hline & Positivo & 55 & 72,4 & 21 & 27,6 & \\
\hline \multirow{2}{*}{ CK 5/6 } & Negativo & 49 & 72,1 & 19 & 27,9 & \multirow{2}{*}{0,736} \\
\hline & Positivo & 8 & 66,7 & 4 & 33,3 & \\
\hline \multirow{2}{*}{ CK 14} & Negativo & 55 & 74,3 & 19 & 25,7 & \multirow{2}{*}{0,129} \\
\hline & Positivo & 2 & 40,0 & 3 & 60,0 & \\
\hline \multirow{2}{*}{ CK 8} & Negativo & 0 & 0,0 & 1 & 100,0 & \multirow{2}{*}{ NA } \\
\hline & Positivo & 58 & 72,5 & 22 & 27,5 & \\
\hline \multirow{2}{*}{ CK 18} & Negativo & 8 & 72,7 & 3 & 27,3 & \multirow{2}{*}{1,000} \\
\hline & Positivo & 48 & 70,6 & 20 & 29,4 & \\
\hline \multirow{2}{*}{ P63 n } & Negativo & 50 & 71,4 & 20 & 28,6 & \multirow{2}{*}{1,000} \\
\hline & Positivo & 4 & 66,70 & 2 & 33,3 & \\
\hline \multirow{2}{*}{ NOS-2 } & Negativo & 18 & 64,3 & 10 & 35,7 & \multirow{2}{*}{0,320} \\
\hline & Positivo & 36 & 75,0 & 12 & 25,0 & \\
\hline & Negativo & 22 & 62,9 & 13 & 37,1 & \\
\hline E caderina & Positivo & 32 & 78,0 & 9 & 22,0 & 0,146 \\
\hline & Negativo & 53 & 73,6 & 19 & 26,4 & \\
\hline $\mathrm{N}$ caderina & Positivo & 2 & 33,3 & 4 & 66,7 & 0,059 \\
\hline & Negativo & 30 & 68,2 & 14 & 31,8 & \\
\hline P caderina & Positivo & 24 & 75,0 & 8 & 25,0 & 0,518 \\
\hline & Negativo & 53 & 72,6 & 20 & 27,4 & \\
\hline Vimentina & Positivo & 1 & 33,3 & 2 & 66,7 & 0,199 \\
\hline & Negativo & 22 & 64,7 & 12 & 35,3 & \\
\hline Twist & Positivo & 29 & 74,4 & 10 & 25,6 & 0,370 \\
\hline & Negativo & 0 & - & 0 & - & \\
\hline Snai 1 & Positivo & 55 & 71,4 & 22 & 28,6 & NA \\
\hline & Negativo & 55 & 71,4 & 22 & 28,6 & \\
\hline EGFR & Positivo & 0 & 0,0 & 1 & 100,0 & NA \\
\hline & Negativo & 8 & 66,7 & 4 & 33,3 & \\
\hline Slug & Positivo & 43 & 70,5 & 18 & 29,5 & 0,745 \\
\hline
\end{tabular}

* Pacientes vivas e com menos de 60 meses de seguimento foram excluídas da análise.

** Teste de qui-quadrado ou teste exato de Fisher.

NA: Não avaliável em virtude do reduzido número de casos em uma das categorias. 
Quando analisamos a distribuição dos casos de acordo com o perfil fenotípico e o risco para óbito, observamos um maior número de pacientes luminais $\mathrm{A}$ entre as pacientes que não morreram $(\mathrm{p}=0,006)$, e um maior número de pacientes que morreram nos subgrupos triplo negativo( $\mathrm{p}=0,016)$ e no subgrupo basal $(\mathrm{p}=0,018)$ (Tabela 10$)$.

Tabela 10 - Distribuição dos casos de acordo com o perfil biomolecular fenotípico e a ocorrência ou não de óbito até 120 meses de seguimento* no grupo de mulheres estadiadas como IIA $(n=82)$

\begin{tabular}{|c|c|c|c|c|c|c|}
\hline \multirow{3}{*}{ VARIÁVEL } & \multirow{3}{*}{ CATEGORIAS } & \multicolumn{4}{|c|}{ Óbito até 120 meses } & \multirow{3}{*}{$p^{* *}$} \\
\hline & & \multicolumn{2}{|c|}{ Não } & \multicolumn{2}{|c|}{ Sim } & \\
\hline & & $\mathbf{n}$ & $\%$ & $\mathrm{n}$ & $\%$ & \\
\hline \multirow{2}{*}{ Luminal A*** } & Não & 8 & 44,4 & 10 & 55,6 & \multirow{2}{*}{0,006} \\
\hline & Sim & 50 & 78,1 & 14 & 21,9 & \\
\hline \multirow{2}{*}{ Luminal $\mathrm{B}^{* * *}$} & Não & 56 & 71,8 & 22 & 28,2 & \multirow{2}{*}{0,577} \\
\hline & Sim & 2 & 50,0 & 2 & 50,0 & \\
\hline \multirow{2}{*}{ Super-expressor HER $2 * * *$} & Não & 55 & 71,4 & 22 & 28,6 & \multirow{2}{*}{0,627} \\
\hline & Sim & 3 & 60,0 & 2 & 40,0 & \\
\hline \multirow{2}{*}{ Triplo-negativo*** } & Não & 55 & 75,3 & 18 & 24,7 & \multirow{2}{*}{0,016} \\
\hline & Sim & 3 & 33,3 & 6 & 66,7 & \\
\hline \multirow{2}{*}{ Basal*** } & Não & 56 & 75,7 & 18 & 24,3 & \multirow{2}{*}{0,018} \\
\hline & Sim & 2 & 28,6 & 5 & 71,4 & \\
\hline
\end{tabular}

\footnotetext{
* Pacientes vivas e com menos de 60 meses de seguimento foram excluídas da análise.

** Teste de qui-quadrado ou teste exato de Fisher.

*** Determinação dos grupos:

Luminal A: $\quad($ ER+ ou PR+) e HER-2 -

Luminal B: $\quad$ (ER+ ou PR+) e HER-2 +

Super-expressor HER- 2: ER- e PR- e HER-2+

Triplo-negativo: ER- e PR- e HER-2-

Basal: Triplo-negativo e (EGFR+ ou CK5/6+ ou P63n+ ou p-caderina+ ou CK14+)
} 
Usando-se regressões logísticas, foram testadas individualmente as variáveis luminal A, triplo-negativo e basal, (modelos), ajustadas por idade, realização de quimioterapia e hormonioterapia. O ajuste por idade, realização de quimioterapia e hormonioterapia, foi baseado num maior potencial de interferência com o desfecho (óbito). Em todos os modelos as variáveis de controle não foram significantes. Quando avaliamos o risco de óbito em 120 meses de acordo com o padrão fenotípico luminal A, observamos que no estádio IIA, as pacientes com padrão fenotípico diferente do luminal A têm risco aumentado de morrer $(\mathrm{OR}=6.3,95 \% \mathrm{CI}=1.7$ a $22.6, \mathrm{P}=0.005)($ Tabela 11$)$.

Tabela 11 - Avaliação do risco de óbito em 120 meses* de acordo com o padrão fenotípico Luminal A em análise multivariada (regressão logística). Modelo ajustado por idade, realização de hormonioterapia e quimioterapia adjuvante (número de óbitos considerados no modelo $=21$ )

\begin{tabular}{lccccc}
\hline VARIÁVEL & CATEGORIA & $\mathbf{n}$ & OR & IC95\% (OR) & p \\
\hline \multirow{2}{*}{ Luminal A } & Não & 16 & 6,3 & $1,7-22,6$ & \multirow{2}{*}{0,005} \\
& Sim & 57 & 1,0 & Referência & \\
\multirow{2}{*}{ Hormonioterapia } & Não & 34 & 0,3 & $0,1-1,2$ & 0,085 \\
& Sim & 39 & 1,0 & Referência & \\
\hline \multirow{2}{*}{ Quimioterapia } & Não & 30 & 0,9 & $0,3-3,3$ & 0,908 \\
\hline Idjuade & Sim & 43 & 1,0 & Referência & \\
\hline
\end{tabular}

* Pacientes vivas e com menos de 60 meses de seguimento foram excluídas da análise. 
Ao analisarmos o risco de óbito em 120 meses de acordo com o padrão fenotípico luminal B, super-expressor de HER-2 em análise multivariada, (modelo ajustado por idade, realização de hormonioterapia e quimioterapia adjuvantes), observamos que no estádio IIA, estes padrões não tiveram relação com o risco de óbito (Tabelas 12 e 13).

Tabela 12 - Avaliação do risco de óbito em 120 meses* de acordo com o padrão fenotípico Luminal B em análise multivariada (regressão logística). Modelo ajustado por idade, realização de hormonioterapia e quimioterapia adjuvante (número de óbitos considerados no modelo $=21$ )

\begin{tabular}{lccccc}
\hline VARIÁVEL & CATEGORIA & $\mathbf{n}$ & OR & IC95\% (OR) & p \\
\hline \multirow{2}{*}{ Luminal B } & Não & 70 & 0,9 & $0,1-12,3$ & \multirow{2}{*}{0,921} \\
& Sim & 3 & 1,0 & Referência & \\
\hline \multirow{2}{*}{ Hormonioterapia } & Não & 34 & 0,5 & $0,2-1,4$ & \multirow{2}{*}{0,168} \\
& Sim & 39 & 1,0 & Referência & \\
Quimioterapia & Não & 30 & 1,2 & $0,3-3,9$ & \multirow{2}{*}{0,804} \\
adjuvante & Sim & 43 & 1,0 & Referência & \\
\hline Idade & (variável contínua) & 73 & 1,0 & $0,96-1,05$ & 0,896 \\
\hline
\end{tabular}

* Pacientes vivas e com menos de 60 meses de seguimento foram excluídas da análise.

Tabela 13 - Avaliação do risco de óbito em 120 meses* de acordo com o padrão fenotípico super-expressor de HER-2 em análise multivariada (regressão logística). Modelo ajustado por idade, realização de hormonioterapia e quimioterapia adjuvante (número de óbitos considerados no modelo $=21$ )

\begin{tabular}{lccccc}
\hline VARIÁVEL & CATEGORIA & n & OR & IC95\% (OR) & p \\
\hline \multirow{2}{*}{ Super-expressor HER-2 } & Não & 68 & 0,4 & $0,1-2,8$ & \multirow{2}{*}{0,342} \\
& Sim & 5 & 1,0 & Referência & \\
\hline \multirow{2}{*}{ Hormonioterapia } & Não & 34 & 0,4 & $0,1-1,3$ & \multirow{2}{*}{0,118} \\
& Sim & 39 & 1,0 & Referência & \\
\hline \multirow{2}{*}{ Quimioterapia adjuvante } & Não & 30 & 1,3 & $0,4-4,4$ & \multirow{2}{*}{0,656} \\
& Sim & 43 & 1,0 & Referência & \\
\hline Idade & (variável contínua) & 73 & 1,0 & $0,96-1,04$ & 0,997 \\
\hline
\end{tabular}

* Pacientes vivas e com menos de 60 meses de seguimento foram excluídas da análise. 
Já ao analisarmos o risco de óbito de acordo com o padrão triplo negativo, observamos que as pacientes deste padrão têm risco aumentado de morrer em 120 meses, independentemente do efeito da hormonioterapia, da quimioterapia adjuvante e da idade $(\mathrm{OR}=11.8,95 \% \mathrm{CI}=2.0$ a $70.3, \mathrm{P}=0.007)($ Tabela 14$)$

Tabela 14 - Avaliação do risco de óbito em 120 meses* de acordo com o padrão fenotípico triplo-negativo em análise multivariada (regressão logística). Modelo ajustado por idade, realização de hormonioterapia e quimioterapia adjuvante (número de óbitos considerados no modelo $=21$ )

\begin{tabular}{lccccc}
\hline VARIÁVEL & CATEGORIA & $\mathbf{n}$ & OR & IC95\% (OR) & p \\
\hline \multirow{2}{*}{ Triplo-negativo } & Não & 30 & 1,0 & Referência & \multirow{2}{*}{0,007} \\
& Sim & 43 & 11,8 & $2,0-70,3$ & \\
\multirow{2}{*}{ Hormonioterapia } & Não & 34 & 0,4 & $0,1-1,3$ & 0,127 \\
& Sim & 39 & 1,0 & Referência & \\
\hline \multirow{2}{*}{ Quimioterapia } & Não & 30 & 0,9 & $0,2-3,3$ & 0,879 \\
\hline Idjuvante & Sim & 43 & 1,0 & Referência & \\
\hline
\end{tabular}

* Pacientes vivas e com menos de 60 meses de seguimento foram excluídas da análise. 
O mesmo observamos com relação à avaliação do risco de óbito no padrão basal, aonde as pacientes com este padrão têm risco aumentado de morrer em 120 meses, independentemente do efeito da hormonioterapia, da quimioterapia adjuvante e da idade $(\mathrm{OR}=18.4,95 \% \mathrm{CI}=1.8$ a $184,7, \mathrm{P}=0.013)($ Tabela 15$)$.

Tabela 15 - Avaliação do risco de óbito em 120 meses* de acordo com o padrão fenotípico Basal em análise multivariada (regressão logística). Modelo ajustado por idade, realização de hormonioterapia e quimioterapia adjuvante (número de óbitos considerados no modelo $=20$ )

\begin{tabular}{lccccc}
\hline VARIÁVEL & CATEGORIA & n & OR & IC95\% (OR) & p \\
\hline \multirow{2}{*}{ Basal } & Não & 66 & 1,0 & Referência & \multirow{2}{*}{0,013} \\
& Sim & 6 & 18,4 & $1,8-184,7$ & \\
\multirow{2}{*}{ Hormonioterapia } & Não & 33 & 0,4 & $0,1-1,4$ & \multirow{2}{*}{0,156} \\
& Sim & 39 & 1,0 & Referência & \\
\multirow{2}{*}{ Quimioterapia adjuvante } & Não & 29 & 0,8 & $0,2-2,9$ & \multirow{2}{*}{0,679} \\
& Sim & 43 & 1,0 & Referência & \\
\hline Idade & (variável contínua) & 73 & 1,0 & $0,96-1,05$ & 0,948 \\
\hline
\end{tabular}

* Pacientes vivas e com menos de 60 meses de seguimento foram excluídas da análise. 


\section{Análise comparativa no estádio IIIB}

Ao analisarmos as pacientes do estádio IIIB, com relação à ocorrência ou não de óbito, levando-se em conta as variáveis clínico-demográficas, histopatológicas e aquelas relacionadas ao tratamento, observamos que os únicos fatores diferentes entre os grupos estudados foram a presença de metástase linfonodal $(p=0,002)$ e a realização de quimioterapia adjuvante $(\mathrm{p}=0,005)$ (Tabelas 16,17 e 18).

Já com relação às variáveis biomoleculares e a ocorrência ou não de óbito, não observamos diferença estatisticamente significante entre os grupos (Tabela 19).

Tabela 16 - Distribuição dos casos de acordo com as variáveis clínico-demográficas e a ocorrência ou não de óbito até 120 meses de seguimento* no grupo de mulheres estadiadas como IIIB $(\mathrm{n}=180)$

\begin{tabular}{|c|c|c|c|c|c|c|}
\hline \multirow{3}{*}{ VARIÁVEL } & \multirow{3}{*}{ CATEGORIAS } & \multicolumn{4}{|c|}{ Óbito até 120 meses } & \multirow{3}{*}{$\mathbf{p}^{* *}$} \\
\hline & & \multicolumn{2}{|c|}{ Não } & \multicolumn{2}{|c|}{ Sim } & \\
\hline & & $\mathbf{n}$ & $\%$ & $\mathbf{n}$ & $\%$ & \\
\hline \multirow{2}{*}{ Idade } & Até 50 anos & 30 & 46,9 & 34 & 53,1 & \multirow{2}{*}{0,141} \\
\hline & $>50$ anos & 41 & 35,7 & 74 & 64,3 & \\
\hline \multirow{2}{*}{ Cor de pele } & Branca & 54 & 38,3 & 87 & 61,7 & \multirow{2}{*}{0,512} \\
\hline & Não branca & 13 & 44,8 & 16 & 55,2 & \\
\hline \multirow{2}{*}{ Número de gestações } & Nenhuma & 9 & 40,9 & 13 & 59,1 & \multirow{2}{*}{0,906} \\
\hline & Uma ou mais & 57 & 39,6 & 87 & 60,4 & \\
\hline \multirow{2}{*}{ Status hormonal } & Pré-menopausa & 32 & 45,1 & 39 & 54,9 & \multirow{2}{*}{0,262} \\
\hline & Pós-menopausa & 40 & 36,7 & 69 & 63,3 & \\
\hline \multirow{2}{*}{ História familiar } & Não & 53 & 40,8 & 77 & 59,2 & \multirow{2}{*}{0,486} \\
\hline & Sim & 12 & 34,3 & 23 & 65,7 & \\
\hline
\end{tabular}

\footnotetext{
* Pacientes vivas e com menos de 60 meses de seguimento foram excluídas da análise.
}

** Teste de qui-quadrado ou teste exato de Fisher. 
Tabela 17 - Distribuição dos casos de acordo com as variáveis histopatológicas e a ocorrência ou não de óbito até 120 meses de seguimento* no grupo de mulheres estadiadas como IIIB $(\mathrm{n}=180)$

\begin{tabular}{|c|c|c|c|c|c|c|}
\hline \multirow{3}{*}{ VARIÁVEL } & \multirow{3}{*}{ CATEGORIAS } & \multicolumn{4}{|c|}{ Óbito até 120 meses } & \multirow{3}{*}{$\mathbf{p}^{* *}$} \\
\hline & & \multicolumn{2}{|c|}{ Não } & \multicolumn{2}{|c|}{ Sim } & \\
\hline & & $\mathbf{n}$ & $\%$ & $\mathbf{n}$ & $\%$ & \\
\hline \multirow{3}{*}{ Tamanho do tumor } & Até $2,0 \mathrm{~cm}$ & 5 & 45,5 & 6 & 54,5 & \multirow{3}{*}{0,641} \\
\hline & $2,1-5,0 \mathrm{~cm}$ & 36 & 40,4 & 53 & 59,6 & \\
\hline & $>5 \mathrm{~cm}$ & 24 & 34,3 & 46 & 65,7 & \\
\hline \multirow{2}{*}{ Scarff-Bloom-Richardson } & Graus 1 e 2 & 50 & 41,0 & 72 & 59,0 & \multirow{2}{*}{0,870} \\
\hline & Grau 3 & 22 & 38,6 & 35 & 61,4 & \\
\hline \multirow{2}{*}{ Grau nuclear } & Graus 1 e 2 & 28 & 41,2 & 40 & 58,8 & \multirow{2}{*}{0,877} \\
\hline & Grau 3 & 44 & 40,0 & 66 & 60,0 & \\
\hline \multirow{2}{*}{ Índice mitótico } & 0 a 9 & 37 & 42,5 & 50 & 57,5 & \multirow{2}{*}{0,637} \\
\hline & 10 ou mais & 20 & 38,5 & 32 & 61,5 & \\
\hline \multirow{2}{*}{ Metástase linfonodal } & Não & 22 & 64,7 & 12 & 35,3 & \multirow{2}{*}{0,002} \\
\hline & Sim & 50 & 35,2 & 92 & 64,8 & \\
\hline
\end{tabular}

* Pacientes vivas e com menos de 60 meses de seguimento foram excluídas da análise.

** Teste de qui-quadrado ou teste exato de Fisher. 
Tabela 18 - Distribuição dos casos de acordo com as variáveis relacionadas ao tratamento e a ocorrência ou não de óbito até 120 meses de seguimento* no grupo de mulheres estadiadas como IIIB $(\mathrm{n}=180)$

\begin{tabular}{|c|c|c|c|c|c|c|}
\hline \multirow{3}{*}{ VARIÁVEL } & \multirow{3}{*}{ CATEGORIAS } & \multicolumn{4}{|c|}{ Óbito até 120 meses } & \multirow{3}{*}{$\mathbf{p}^{* * *}$} \\
\hline & & \multicolumn{2}{|c|}{ Não } & \multicolumn{2}{|c|}{ Sim } & \\
\hline & & $\mathbf{n}$ & $\%$ & $\mathbf{n}$ & $\%$ & \\
\hline \multirow{2}{*}{ Quimioterapia neoadjuvante } & Não & 23 & 34,3 & 44 & 65,7 & \multirow{2}{*}{0,271} \\
\hline & Sim & 42 & 42,9 & 56 & 57,1 & \\
\hline \multirow{2}{*}{ Radioterapia neoadjuvante } & Não & 63 & 39,9 & 95 & 60,1 & \multirow{2}{*}{0,705} \\
\hline & Sim & 2 & 28,6 & 5 & 71,4 & \\
\hline \multirow{2}{*}{ Quimioterapia adjuvante } & Não & 16 & 25,8 & 46 & 74,2 & \multirow{2}{*}{0,005} \\
\hline & Sim & 49 & 48,0 & 53 & 52,0 & \\
\hline \multirow{2}{*}{ Radioterapia adjuvante } & Não & 8 & 29,6 & 19 & 70,4 & \multirow{2}{*}{0,256} \\
\hline & Sim & 57 & 41,3 & 81 & 58,7 & \\
\hline \multirow{2}{*}{ Hormonioterapia } & Não & 42 & 42,0 & 58 & 58,0 & \multirow{2}{*}{0,395} \\
\hline & Sim & 23 & 35,4 & 42 & 64,6 & \\
\hline
\end{tabular}

* Pacientes vivas e com menos de 60 meses de seguimento foram excluídas da análise.

** Teste de qui-quadrado ou teste exato de Fisher. 
Tabela 19 - Distribuição dos casos de acordo com as variáveis biomoleculares e a ocorrência ou não de óbito até 120 meses de seguimento* no grupo de mulheres estadiadas como IIIB $(\mathrm{n}=180)$

\begin{tabular}{|c|c|c|c|c|c|c|}
\hline \multirow{3}{*}{ VARIÁVEL } & \multirow{3}{*}{ CATEGORIAS } & \multicolumn{4}{|c|}{ Óbito até 120 meses } & \multirow{3}{*}{$\mathbf{p}^{* *}$} \\
\hline & & \multicolumn{2}{|c|}{ Não } & \multicolumn{2}{|c|}{ Sim } & \\
\hline & & $\mathbf{n}$ & $\%$ & $\mathrm{n}$ & $\%$ & \\
\hline \multirow{2}{*}{ ER } & Negativo & 31 & 43,1 & 41 & 56,9 & \multirow{2}{*}{0,447} \\
\hline & Positivo & 40 & 37,4 & 67 & 62,9 & \\
\hline \multirow{2}{*}{ PR } & Negativo & 41 & 38,7 & 65 & 61,3 & \multirow{2}{*}{0,830} \\
\hline & Positivo & 29 & 40,3 & 43 & 59,7 & \\
\hline \multirow{2}{*}{ HER2 } & Negativo & 57 & 40,1 & 85 & 59,9 & \multirow{2}{*}{0,941} \\
\hline & Positivo & 15 & 39,5 & 23 & 60,5 & \\
\hline \multirow{2}{*}{ P53 } & Negativo & 6 & 46,2 & 7 & 53,8 & \multirow{2}{*}{0,770} \\
\hline & Positivo & 64 & 39,3 & 99 & 60,7 & \\
\hline \multirow{2}{*}{ CK 5/6 } & Negativo & 61 & 39,9 & 92 & 60,1 & \multirow{2}{*}{0,990} \\
\hline & Positivo & 10 & 40,0 & 15 & 60,0 & \\
\hline \multirow{2}{*}{ CK 14} & Negativo & 66 & 39,1 & 103 & 60,9 & \multirow{2}{*}{0,270} \\
\hline & Positivo & 5 & 62,5 & 3 & 37,5 & \\
\hline \multirow{2}{*}{ CK 8} & Negativo & 1 & 100,0 & 0 & 0,0 & \multirow{2}{*}{ NA } \\
\hline & Positivo & 65 & 38,5 & 104 & 61,5 & \\
\hline \multirow{2}{*}{ CK 18} & Negativo & 13 & 46,4 & 15 & 53,6 & \multirow{2}{*}{0,447} \\
\hline & Positivo & 55 & 38,7 & 87 & 61,3 & \\
\hline \multirow{2}{*}{ P63 n } & Negativo & 64 & 40,0 & 96 & 60,0 & \multirow{2}{*}{0,531} \\
\hline & Positivo & 3 & 27,3 & 8 & 72,7 & \\
\hline \multirow{2}{*}{ NOS-2 } & Negativo & 24 & 40,7 & 35 & 59,3 & \multirow{2}{*}{0,894} \\
\hline & Positivo & 42 & 39,6 & 64 & 60,4 & \\
\hline & Negativo & 25 & 49,0 & 26 & 51,0 & 000 \\
\hline E caderina & Positivo & 37 & 34,9 & 69 & 65,1 & 0,090 \\
\hline & Negativo & 52 & 38,2 & 84 & 61,8 & \\
\hline $\mathrm{N}$ caderina & Positivo & 3 & 60,0 & 2 & 40,0 & 0,378 \\
\hline & Negativo & 46 & 38,7 & 73 & 61,3 & 0788 \\
\hline P caderina & Positivo & 12 & 41,4 & 12 & 58,6 & $0, / 88$ \\
\hline & Negativo & 58 & 39,7 & 88 & 60,3 & \\
\hline Vimentina & Positivo & 4 & 57,1 & 3 & 42,9 & 0,442 \\
\hline & Negativo & 47 & 44,3 & 59 & 55,7 & \\
\hline Twist & Positivo & 10 & 25,0 & 30 & 75,0 & 0,033 \\
\hline & Negativo & 0 & - & 0 & - & \\
\hline Snai 1 & Positivo & 58 & 38,7 & 92 & 61,3 & NA \\
\hline & Negativo & 58 & 38,9 & 91 & 61,1 & \\
\hline EGFR & Positivo & 0 & - & 0 & - & NA \\
\hline & Negativo & 15 & 45,5 & 18 & 54,5 & \\
\hline Slug & Positivo & 43 & 37,7 & 71 & 62,3 & 0,423 \\
\hline
\end{tabular}

* Pacientes vivas e com menos de 60 meses de seguimento foram excluídas da análise.

** Teste de qui-quadrado ou teste exato de Fisher.

NA: Não avaliável em virtude do reduzido número de casos em uma das categorias. 
Quando analisamos a distribuição dos casos de acordo com o perfil fenotípico entre as pacientes que morreram e as que não morreram no estádio IIIB, não observamos diferença estatisticamente significante entre os grupos analisados (Tabela 20).

Tabela 20 - Distribuição dos casos de acordo com o perfil biomolecular fenotípico e a ocorrência ou não de óbito até 120 meses de seguimento* no grupo de mulheres estadiadas como IIIB $(n=180)$

\begin{tabular}{|c|c|c|c|c|c|c|}
\hline \multirow{3}{*}{ VARIÁVEL } & \multirow{3}{*}{ CATEGORIAS } & \multicolumn{4}{|c|}{ Óbito até 120 meses } & \multirow{3}{*}{$\mathbf{p}^{* *}$} \\
\hline & & \multicolumn{2}{|c|}{ Não } & \multicolumn{2}{|c|}{ Sim } & \\
\hline & & $\mathbf{n}$ & $\%$ & $\mathbf{n}$ & $\%$ & \\
\hline \multirow{2}{*}{ Luminal $A^{* * *}$} & Não & 33 & 41,8 & 46 & 58,2 & \multirow{2}{*}{0,551} \\
\hline & Sim & 37 & 37,4 & 62 & 62,6 & \\
\hline \multirow{2}{*}{ Luminal $\mathrm{B} * * *$} & Não & 66 & 40,0 & 99 & 60,0 & \multirow{2}{*}{1,000} \\
\hline & Sim & 6 & 40,0 & 9 & 60,0 & \\
\hline \multirow{2}{*}{$\begin{array}{l}\text { Super-expressor } \\
\text { HER2*** }\end{array}$} & Não & 63 & 40,1 & 94 & 59,9 & \multirow{2}{*}{0,927} \\
\hline & Sim & 9 & 39,1 & 14 & 60,9 & \\
\hline \multirow{2}{*}{ Triplo negativo*** } & Não & 52 & 38,0 & 85 & 62,0 & \multirow{2}{*}{0,494} \\
\hline & Sim & 18 & 43,9 & 23 & 56,1 & \\
\hline \multirow{2}{*}{ Basal*** } & Não & 58 & 38,9 & 91 & 61,1 & \multirow{2}{*}{0,184} \\
\hline & Sim & 8 & 57,1 & 6 & 42,9 & \\
\hline
\end{tabular}

* Pacientes vivas e com menos de 60 meses de seguimento foram excluídas da análise.

** Teste de qui-quadrado ou teste exato de Fisher.

*** Determinação dos grupos:

Luminal A: $\quad($ ER+ ou PR+) e HER-2 -

Luminal B: $\quad($ ER + ou PR + ) e HER-2 +

Super-expressor HER- 2: ER- e PR- e HER-2+

Triplo-negativo: ER- e PR- e HER-2-

Basal: Triplo-negativo e (EGFR+ ou CK5/6+ ou P63n+ ou p-caderina+ ou CK14+) 
Quando avaliamos o risco de óbito em 120 meses de acordo com o padrão fenotípico luminal A em análise multivariada, (modelo ajustado por idade, realização de hormonioterapia e quimioterapia adjuvantes), observamos que no estádio IIIB, o padrão fenotípico luminal A não esteve relacionado com o óbito. O risco de óbito esteve associado com a presença de metástase nos linfonodos e à não realização de quimioterapia adjuvanteModelo 1: Luminal A (metástase linfonodal, $\mathrm{OR}=3,3,95 \% \mathrm{CI}=1,4-8,0, \mathrm{P}=0,007$ ) e (quimioterapia adjuvante, $\mathrm{OR}=2.3,95 \% \mathrm{CI}=1.02-5,2, \mathrm{P}=0,045)$, (Tabela 21).

Tabela 21 - Avaliação do risco de óbito em 120 meses* de acordo com o padrão fenotípico Luminal A em análise multivariada (regressão logística). Modelo 1, ajustado por idade, realização de hormonioterapia, quimioterapia adjuvante, quimioterapia neoadjuvante e status linfonodal (número de óbitos considerados no modelo $=96$ )

\begin{tabular}{|c|c|c|c|c|c|}
\hline VARIÁVEL & CATEGORIA & $\mathbf{N}$ & OR & IC95\% (OR) & $\mathbf{p}$ \\
\hline \multirow{2}{*}{ Luminal A } & Não & 69 & 1,0 & $0,5-2,0$ & \multirow{2}{*}{0,970} \\
\hline & Sim & 90 & 1,0 & Referência & \\
\hline \multirow{2}{*}{ Hormonioterapia } & Não & 94 & 0,8 & $0,4-1,6$ & \multirow{2}{*}{0,477} \\
\hline & Sim & 65 & 1,0 & Referência & \\
\hline \multirow{2}{*}{ Quimioterapia adjuvante } & Não & 60 & 2,3 & $1,02-5,2$ & \multirow{2}{*}{0,045} \\
\hline & Sim & 99 & 1,0 & Referência & \\
\hline \multirow{2}{*}{ Quimioterapia neoadjuvante } & Não & 62 & 0,9 & $0,4-1,9$ & \multirow{2}{*}{0,785} \\
\hline & Sim & 97 & 1,0 & Referência & \\
\hline \multirow{2}{*}{ Metástase linfonodal } & Não & 29 & 1,0 & Referência & \multirow{2}{*}{0,007} \\
\hline & Sim & 130 & 3,3 & $1,4-8,0$ & \\
\hline Idade & (variável contínua) & 159 & 1,0 & $0,98-1,04$ & 0,341 \\
\hline
\end{tabular}

* Pacientes vivas e com menos de 60 meses de seguimento foram excluídas da análise. 
Ao analisarmos o risco de óbito em 120 meses de acordo com o padrão fenotípico luminal $\mathrm{B}$, observamos que no estádio IIIB, o padrão luminal B não esteve relacionado com o óbito. O risco de óbito esteve associado com a presença de metástase nos linfonodos e à não realização de quimioterapia adjuvante - Modelo 2: Luminal B (metástase linfonodal, $\mathrm{OR}=3,8,95 \% \mathrm{CI}=1,6-9,1, \mathrm{P}=0,003)$ e (quimioterapia adjuvante, $\mathrm{OR}=2.3,95 \%$ $\mathrm{CI}=1.03-5.2, \mathrm{P}=0.042)($ Tabela 22).

Tabela 22 - Avaliação do risco de óbito em 120 meses* de acordo com o padrão fenotípico Luminal B em análise multivariada (regressão logística). Modelo 2, ajustado por idade, realização de hormonioterapia, quimioterapia adjuvante, quimioterapia neoadjuvante e status linfonodal (número de óbitos considerados no modelo $=96$ )

\begin{tabular}{|c|c|c|c|c|c|}
\hline VARIÁVEL & CATEGORIA & $\mathbf{N}$ & OR & IC95\% (OR) & $\mathbf{p}$ \\
\hline \multirow{2}{*}{ Luminal B } & Não & 148 & 1,6 & $0,5-5,1$ & \multirow{2}{*}{0,457} \\
\hline & Sim & 13 & 1,0 & Referência & \\
\hline \multirow{2}{*}{ Hormonioterapia } & Não & 94 & 0,8 & $0,4-1,6$ & \multirow{2}{*}{0,464} \\
\hline & Sim & 65 & 1,0 & Referência & \\
\hline \multirow{2}{*}{ Quimioterapia adjuvante } & Não & 60 & 2,3 & $1,03-5,2$ & \multirow{2}{*}{0,042} \\
\hline & Sim & 101 & 1,0 & Referência & \\
\hline \multirow{2}{*}{ Quimioterapia neoadjuvante } & Não & 64 & 0,8 & $0,4-1,8$ & \multirow{2}{*}{0,669} \\
\hline & Sim & 97 & 1,0 & Referência & \\
\hline \multirow{2}{*}{ Metástase linfonodal } & Não & 31 & 1,0 & Referência & \multirow{2}{*}{0,003} \\
\hline & Sim & 130 & 3,8 & $1,6-9,1$ & \\
\hline Idade & (variável contínua) & 161 & 1,0 & $0,99-1,04$ & 0,281 \\
\hline
\end{tabular}

* Pacientes vivas e com menos de 60 meses de seguimento foram excluídas da análise. 
Ao analisarmos o risco de óbito em 120 meses de acordo com o padrão fenotípico super-expressor de HER-2 em análise multivariada, (modelo ajustado por idade, realização de hormonioterapia e quimioterapia adjuvantes), observamos que no estádio IIIB este padrão não esteve relacionado com o óbito. O risco de óbito esteve associado com a presença de metástase nos linfonodos e à não realização de quimioterapia adjuvante, Modelo 3: super-expressor de HER-2 (metástase linfonodal, $\mathrm{OR}=3,6,95 \% \mathrm{CI}=1,5-8,6$, $\mathrm{P}=0,003)$ e (quimioterapia adjuvante, $\mathrm{OR}=2.4,95 \% \mathrm{CI}=1.1-5.3, \mathrm{P}=0.034) \quad($ Tabela 23).

Tabela 23 - Avaliação do risco de óbito em 120 meses* de acordo com o padrão fenotípico Super-expressão de HER-2 em análise multivariada (regressão logística). Modelo 3, ajustado por idade, realização de hormonioterapia, quimioterapia adjuvante, quimioterapia neoadjuvante e status linfonodal (número de óbitos considerados no modelo $=96$ )

\begin{tabular}{|c|c|c|c|c|c|}
\hline VARIÁVEL & CATEGORIA & $\mathbf{N}$ & OR & IC95\% (OR) & $\mathbf{p}$ \\
\hline \multirow{2}{*}{ Super-expressão de HER-2 } & Não & 140 & 0,9 & $0,3-2,4$ & \multirow{2}{*}{0,845} \\
\hline & Sim & 21 & 1,0 & Referência & \\
\hline \multirow{2}{*}{ Hormonioterapia } & Não & 94 & 0,8 & $0,4-1,5$ & \multirow{2}{*}{0,423} \\
\hline & Sim & 65 & 1,0 & Referência & \\
\hline \multirow{2}{*}{ Quimioterapia adjuvante } & Não & 60 & 2,4 & $1,1-5,3$ & \multirow{2}{*}{0,034} \\
\hline & Sim & 101 & 1,0 & Referência & \\
\hline \multirow{2}{*}{ Quimioterapia neoadjuvante } & Não & 64 & 0,8 & $0,4-1,8$ & \multirow{2}{*}{0,661} \\
\hline & Sim & 97 & 1,0 & Referência & \\
\hline \multirow{2}{*}{ Metástase linfonodal } & Não & 31 & 1,0 & Referência & \multirow{2}{*}{0,003} \\
\hline & Sim & 130 & 3,6 & $1,5-8,6$ & \\
\hline Idade & (variável contínua) & 161 & 1,0 & $0,99-1,04$ & 0,315 \\
\hline
\end{tabular}

* Pacientes vivas e com menos de 60 meses de seguimento foram excluídas da análise. 
Já ao analisarmos o risco de óbito de acordo com o padrão triplo negativo, observamos que este padrão não esteve relacionado com o óbito. O risco de óbito esteve associado com a presença de metástase nos linfonodos e à não realização de quimioterapia adjuvante, Modelo 4: triplo-negativo (metástase linfonodal, $\mathrm{OR}=3.4,95 \% \mathrm{CI}=1.4-8.2$, $\mathrm{P}=0,007)$ e (quimioterapia adjuvante, $\mathrm{OR}=2,3,95 \% \mathrm{CI}=1,02-5,2, \mathrm{P}=0,044)$ (Tabela 24).

Tabela 24 - Avaliação do risco de óbito em 120 meses* de acordo com o padrão fenotípico Triplo-negativo em análise multivariada (regressão logística). Modelo 4, ajustado por idade, realização de hormonioterapia, quimioterapia adjuvante, quimioterapia neoadjuvante e status linfonodal (número de óbitos considerados no modelo $=96$ )

\begin{tabular}{|c|c|c|c|c|c|}
\hline VARIÁVEL & CATEGORIA & $\mathbf{N}$ & OR & IC95\% (OR) & $\mathbf{p}$ \\
\hline \multirow{2}{*}{ Triplo-negativo } & Não & 124 & 1,1 & $0,5-2,7$ & \multirow{2}{*}{0,738} \\
\hline & $\operatorname{Sim}$ & 35 & 1,0 & Referência & \\
\hline \multirow{2}{*}{ Hormonioterapia } & Não & 94 & 0,8 & $0,4-1,5$ & \multirow{2}{*}{0,458} \\
\hline & Sim & 65 & 1,0 & Referência & \\
\hline \multirow{2}{*}{ Quimioterapia adjuvante } & Não & 60 & 2,3 & $1,02-5,2$ & \multirow{2}{*}{0,044} \\
\hline & Sim & 99 & 1,0 & Referência & \\
\hline \multirow{2}{*}{ Quimioterapia neoadjuvante } & Não & 62 & 0,9 & $0,4-2,0$ & \multirow{2}{*}{0,798} \\
\hline & Sim & 97 & 1,0 & Referência & \\
\hline \multirow{2}{*}{ Metástase linfonodal } & Não & 29 & 1,0 & Referência & \multirow{2}{*}{0,007} \\
\hline & Sim & 130 & 3,4 & $1,4-8,2$ & \\
\hline Idade & (variável contínua) & 159 & 1,0 & $0,99-1,04$ & 0,322 \\
\hline
\end{tabular}

* Pacientes vivas e com menos de 60 meses de seguimento foram excluídas da análise. 
Com relação à avaliação do risco de óbito no padrão basal, observamos no estádio IIIB, que este padrão não esteve relacionado com o óbito. O único fator risco de óbito foi a presença de metástase nos linfonodos, Modelo 5: $(\mathrm{OR}=3,0$ 95\% CI=1.2-7.3, $\mathrm{P}=0,016)$ (Tabela 25).

Tabela 25 - Avaliação do risco de óbito em 120 meses* de acordo com o padrão fenotípico Basal em análise multivariada (regressão logística). Modelo 5, ajustado por idade, realização de hormonioterapia, quimioterapia adjuvante, quimioterapia neoadjuvante e status linfonodal (número de óbitos considerados no modelo $=86$ )

\begin{tabular}{lccccc}
\hline VARIÁVEL & CATEGORIA & N & OR & $\begin{array}{c}\text { IC95\% } \\
\text { (OR) }\end{array}$ & p \\
\hline \multirow{2}{*}{ Basal } & Não & 135 & 0,7 & $0,2-2,6$ & 0,625 \\
& Sim & 12 & 1,0 & Referência & \\
\hline \multirow{2}{*}{ Hormonioterapia } & Não & 87 & 0,7 & $0,3-1,4$ & 0,300 \\
& Sim & 60 & 1,0 & Referência & \\
\hline \multirow{2}{*}{ Quimioterapia adjuvante } & Não & 55 & 2,0 & $0,9-4,6$ & 0,106 \\
& Sim & 92 & 1,0 & Referência & \\
\hline \multirow{2}{*}{ Quimioterapia neoadjuvante } & Não & 61 & 0,9 & $0,4-2,0$ & 0,854 \\
\hline \multirow{2}{*}{ Metástase linfonodal } & Sim & 86 & 1,0 & Referência & \\
\hline Idade & Não & 29 & 1,0 & Referência & \multirow{2}{*}{0,016} \\
\hline
\end{tabular}

* Pacientes vivas e com menos de 60 meses de seguimento foram excluídas da análise. 


\section{DISCUSSÃ̃}

A importância do câncer de mama se torna clara na medida em que analisamos a incidência do câncer de mama no mundo e no Brasil. Segundo dados do INCA, são estimados para o ano de 2010 aproximadamente 49.240 casos de câncer de mama no Brasil (Ministério da Saúde, 2009).

Não há muitos estudos publicados que tenham analisado quais fatores prognósticos podem influenciar na sobrevida a longo prazo, nos EC IIA e IIIB, fato este que nos motivou a realizar este estudo.

Quando analisamos tanto o estádio IIA quanto o IIIB, separadamente levando-se em conta as variáveis (idade, raça, número de gestações, status hormonal e história familiar), não encontramos nenhuma correlação, estatisticamente significante, com a ocorrência ou não de óbito até um período de 120 meses de seguimento.

Segundo a literatura, um fator importante na determinação da sobrevida a longo prazo é a idade (Arriagada et al., 2006; Carey et al., 2006). As pacientes mais jovens (30/35 anos) apresentam uma pior sobrevida quando comparamos às pacientes com idade superior a 70 anos. Em nossa análise, não encontramos nenhuma correlação estatisticamente significante com a sobrevida em até 120 meses.

Levando-se em conta as variáveis histopatológicas, no EC IIA, observamos que a variável grau nuclear não se mostrou associada à ocorrência de óbito, na análise multivariada. Com relação às variáveis relacionadas ao tratamento e à ocorrência ou não de óbito em 120 meses, não houve nenhuma associação estatisticamente significante. 
Diversos estudos mostram a associação entre a ocorrência de alto grau histológico e uma menor sobrevida livre de doença (Fisher et al., 2001; Warwick et al., 2004, Arriagada et al., 2006; Thomas et al., 2009). O grau histológico também apresenta um impacto significativo na seleção de pacientes que serão submetidas a tratamento sistêmico adjuvante. O grau histológico leva em consideração a formação tubular, o grau nuclear e o índice mitótico (Ellis, Elston, 1998). Porém o valor prognóstico individual de cada um dos seus componentes, em especial do grau nuclear, não apresenta uma representação significativa na literatura.

Ainda analisando o EC IIA, as pacientes que possuíam RE positivo, apresentaram uma menor taxa de óbito em até 120 meses de seguimento $(p=0,021)$. Porém após a regressão logística, o RE não se mostrou fator de risco neste subgrupo de mulheres. Os achados da literatura demonstram que a positividade para o RE confere um melhor prognóstico às pacientes, independente dos subgrupos, permitindo o uso de medicação anti-hormonal específica (EBCTCG, 2005; Soerjomataram et al., 2008).

Os tumores pertencentes ao fenótipo luminal A, se caracterizam por apresentarem expressão de RE +, e/ou RP + e HER-2 (Nielsen et al., 2004). De acordo com o estudo de Zaha et al. (2010), os tumores pertencentes ao subgrupo luminal A, estavam mais associados com a presença de RE +, maior porcentagem de pacientes nos estádios I e II, bem como apresentavam tumores bem e moderadamente diferenciados. No estudo de Fernandes et al. (2009), observa-se claramente que a presença de receptores hormonais define um subgrupo com características morfológicas mais favoráveis.

Em nosso estudo, após a regressão logística, observamos que os fatores que estavam associados a um pior prognóstico, no EC IIA, foram o fato destas pacientes não pertencerem ao luminal A, pertencerem ao padrão fenotípico triplo negativo ou ao padrão 
basal. De maneira geral, a literatura mostra a ocorrência de um pior prognóstico nas pacientes portadoras de tumores de mama de padrão basal ou triplo-negativo (van de Rijn, 2002; Dent, et al., 2007, Reis-Filho, 2008). Haupt et al. (2010), observaram que o fato do tumor pertencer ao subgrupo basal se associou a um pior prognóstico, tanto nos estádios precoces quanto nos estádios avançados, além de se associarem mais frequententemente à disseminação visceral. Recentemente, De Brot et al. (2009), demonstraram que os tumores do subgrupo basal apresentaram uma sobrevida média, livre de doença, de 28 meses e uma sobrevida global de 36 meses, sendo que somente 50\% das pacientes estavam livres de doença. São também, mais comuns no grupo de mulheres jovens, sendo que, em nossa experiência, neste grupo mais de 50\% dos casos, são de fenótipo basal (Dutra et al., 2009).

Esta associação entre pior sobrevida nos tumores não luminais A, também pode ser analisada com relação à expressão dos marcadores IIQ da transição epitélio-mesênquima. A progressão do câncer de mama é o resultado, entre outros, de um processo em que ocorre a perda de características epiteliais e o ganho de propriedades mesenquimais, resultando em um fenótipo tumoral mais agressivo (Logullo et al., 2010). Sarrio et al. (2008), observaram uma correlação entre a TEM e o padrão basal. Em nosso estudo, não observamos relação entre os perfis fenotípicos e a expressão dos marcadores IIQ da TEM nos tumores IIA. Pode-se supor que a expressão destes marcadores da TEM, nos tumores de mama, dependa do grau de transformação de células epiteliais em mesenquimais e que todo este processo tenha uma via de regulação específica e complexa, aonde cada um destes fatores possa atuar de maneira distinta durante a progressão tumoral.

Ainda analisando as pacientes estadiadas como IIA, com relação ao risco de óbito, a análise multivariada mostrou que as pacientes com padrão fenotípico diferente do luminal A, tem risco aumentado (em 6,3 vezes) de morrer em até 120 meses, independentemente do 
efeito da hormonioterapia, quimioterapia e da idade. Também observamos um aumento do risco de óbito, no padrão triplo-negativo (em 11,8 vezes) e no padrão basal (em 18,4 vezes). Apesar da significância estatística, é importante ressaltar que o intervalo de confiança está muito alargado, já que há poucos casos de padrão basal positivo (somente seis casos no modelo). Embora este resultado deva ser interpretado com cautela, o padrão basal representa ser um fator de risco para óbito independente.

Com relação aos tumores no EC IIIB, apesar da melhor definição das imagens ao diagnóstico e o uso adequado de terapias medicamentosas adjuvantes, observamos que ainda são diagnosticados tumores de mama localmente avançados (Morris et al., 2007; Jemal et al., 2009). A melhora da sobrevida destas pacientes nas últimas décadas se deve ao acréscimo do tratamento sistêmico (Wolmark et al., 2001; EBCTCG, 2005; Smigal et al., 2006).

Quando analisamos o estádio IIIB, levando-se em conta as variáveis (idade, raça, número de gestações, status hormonal e história familiar), estas não se mostraram fatores de risco em um período de seguimento de 10 anos.

Em relação aos marcadores de transição epitelio-mesênquina e moléculas de adesão celular analisados, não observamos um aumento do risco de óbito em 120 meses, nos dois estádios analisados. Na análise univariada EC IIIB, observamos que a variável Twist mostrou-se associada à ocorrência de óbito, mas esta associação não se manteve na análise multivariada. Isto pode ter ocorrido pelo número de casos analisados ou pela presença de outra variável explicativa não identificada neste estudo. Sabemos que o twist é um fator transcricional envolvido na TEM. Sabe-se também que a expressão aumentada deste marcador, se correlaciona positivamente com maior agressividade do tumor e pior taxa de sobrevida em pacientes com câncer de mama (Yang et al., 2004; Kwok et al., 2005). Este 
dado estaria de acordo com o encontro de uma pior sobrevida nas pacientes que expressaram o marcador twist, porém este achado não se manteve na análise multivariada.

Já as variáveis metástase linfonodal, assim como a quimioterapia adjuvante, mostraram ser fatores de risco de óbito até um período de 120 meses de seguimento, independentes da idade, do fenótipo, da hormonioterapia e da quimioterapia adjuvante segundo os vários modelos estudados.

$\mathrm{Na}$ literatura, a presença de metástase linfonodal é um dos fatores prognósticos mais importantes descritos (Fisher et al., 2001; Weiss et al., 2003; Arriagada et al., 2006; Soerjomataram et al., 2008). Os pacientes com metástase linfonodal axilar apresentam uma taxa de mortalidade 4 a 8 vezes maior do que os pacientes sem envolvimento linfonodal (Soerjomataram et al., 2008). Segundo o trabalho de Zaha et al.(2010), observou que a presença de linfonodos positivos nos subgrupos diferentes do basal, não reduziu a taxa de sobrevida destas mulheres.

Este achado está de acordo com a literatura, na qual os grandes estudos internacionais mostram uma melhora na sobrevida das pacientes portadoras de tumores localmente avançados, submetidas ao regime quimioterápico (El Saghir et al., 2008). Os tumores IIIB quando tratados com cirurgia e radioterapia apenas, apresentam em média sobrevida em 5 anos de 32\% e aos 10 anos de 20\% (Yetman et al., 1995).

Muito se discute na literatura com relação à melhor indicação e quimioterapia sistêmica: se pré-operatória ou pós-operatória. O que se observa nos tumores do EC IIIB, é que há uma tendência a se oferecer o tratamento sistêmico pré-operatório. As proposições iniciais desta forma de tratamento visavam transformar pacientes inoperáveis em operáveis, pela redução da massa tumoral, beneficiando as pacientes com câncer de mama inflamatório e localmente avançados (Bonadonna et al., 1990). 
Quando realizamos a avaliação do risco de óbito em 120 meses, no estádio IIIB, observamos que o padrão fenotípico luminal A, luminal B, super-expressor de HER-2, triplo-negativo e basal, não estiveram relacionados com óbito, nos modelos estudados.

Muito embora em nosso estudo, não tenhamos obtido nenhuma correlação no estádio IIIB, entre os diferentes subtipos moleculares do câncer de mama, entre os marcadores IIQ da TEM estudados, da NOS 2 e do EGFR, e a sobrevida, ainda há muito que se conhecer sobre a biologia destes tumores. Para tal, estudos populacionais robustos, com casuísticas adequadas são importantes para a definição destes fatores prognósticos. 


\section{CONCLUSÃO}

Com nosso estudo podemos concluir que:

1- No estádio IIA, são fatores de risco para óbito em 120 meses, a presença do padrão fenotípico diferente do luminal $\mathrm{A}$, do padrão triplo-negativo e do padrão basal.

2- No estádio IIIB, o risco de óbito em 120 meses esteve associado com a presença de metástase linfonodal e à não realização de quimioterapia adjuvante.

3- Os padrões fenotípicos não estão relacionados com o prognóstico no grupo de pacientes do estádio IIIB.

4- Em relação aos marcadores de transição epitélio-mesênquima analisados, não observamos um aumento do risco de óbito em 120 meses, nos dois estádios analisados. 


\title{
7. ANEXOS
}

Anexo 1 - Carta de aprovação pela Comissão de Ética em Pesquisa do Centro de Tratamento e Pesquisa do Hospital do Câncer - A. C. Camargo (Processo no 949/07).

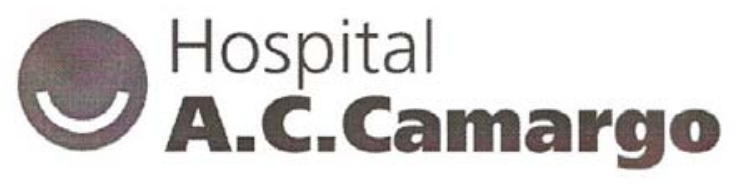

\section{Comitê de Ética em Pesquisa - CEP}

São Paulo, 16 de Julho de 2007.

\author{
Ao \\ Dr. Fernando Augusto Soares
}

Ref.: Projeto de Pesquisa ${ }^{\circ}$ 949/07

"Estudo do perfil fenotípico dos carcinomas ductais de mama com evoluação atípica".

Os membros do Comitê de Ética em Pesquisa (CEP) da Fundação Antonio Prudente - Hospital A.C. Camargo, em sua última reunião de 10/07/2007, aprovaram a realização do estudo e tomaram conhecimento dos seguintes documentos:

Folha de Rosto para pesquisa envolvendo seres humanos;

$>$ Termo de Compromisso do pesquisador com Resoluções CNS;

$>$ Termo de Dispensa do Consentimento Livre e Esclarecido;

Justificativa da não apresentação do orçamento financeiro;

$>$ Declaração de Ciência e Comprometimento do Departamento de Mastologia;

$>$ Declaração de Ciência e Comprometimento do Departamento de Anatomia Patológica.

Informações a respeito do andamento do referido projeto deverão ser encaminhadas à assistente do CEP dentro de 12 meses.

Atenciosamente,

\section{Dr. Gilles Landman}

Vice-Coordenador do Comitê de Ética em Pesquisa 
Anexo 2 - Carta de aprovação da Comissão de Ética da Universidade de São Paulo (Processo $n^{\circ}$ 0763/07).

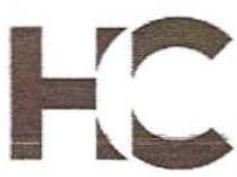

Ao

Departamento de Radiologia

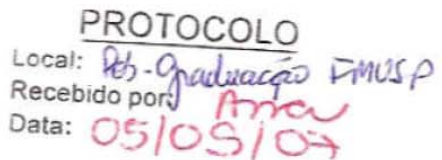

Data: $05 / 05107$

A Comissão de Ética para Análise de Projetos de Pesquisa - CAPPesq da Diretoria Clínica do Hospital das Clínicas e da Faculdade de Medicina da Universidade de São Paulo, em 30.08.07, tomou ciência da execução do Protocolo de Pesquisa n 0763/07, infitulado: "ESTUDO DO PERFIL FENOTíPICO DOS CARCINOMAS DUCTAIS DE MAMA COM EVOLUÇĀO ATÍPICA".

No que tange à sua parte empírica será desenvolvido no Hospital do Câncer A. C. Camargo, tendo seu Comitê de Ética aprovado o estudo em 10.07.07.

Pesquisador (a) Responsável: Prof. Dr. Fernando Augusto Soares

Pesquisador (a) Executante: Dra. Solange Maria Torchia Carvalho

CAPPesq, 30 de agosto de 2007.

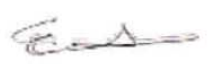

PROF. DR. EDUARDO MASSAD

Presidente

Comissão de Ética para Análise de Projetos de Pesquisa

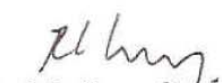

Prof. Dr. Roger Cnammas

Coordenador da Pós-Graduaçao

Area de Oncologia

FMUSP 
Anexo 3 - Ficha de registro de dados epidemiológicos, clínicos, histológicos e terapêuticos

\begin{tabular}{|c|c|c|}
\hline Nome & & $\mathrm{RGH}$ \\
\hline Nascimento & Atendimento em: & Idade: \\
\hline Cor & Menarca & Menopausa \\
\hline Paridade & Hist Fam Ca mama & \\
\hline OBS & & \\
\hline N AP BX & Data & Bloco/Lam \\
\hline N AP MX & Data & Bloco/Lam \\
\hline Outros AP & & \\
\hline ILPC & Data & Bloco/Lam \\
\hline DX: & Tamanho & $\mathrm{G}$ histo \\
\hline G Nuclear & G tubular & Mitoses \\
\hline Necrose & Desmoplasia & Inflamação \\
\hline DCIS assoc & Invasão Venosa & Inv. Linfa \\
\hline Inv Perineural & Margens & $\mathrm{LN}+/ \mathrm{T}$ \\
\hline $\mathrm{RE}$ & $\mathrm{RP}$ & p53 \\
\hline c-erbB-2 & $\mathrm{Ki}-67$ & $\mathrm{CK} 3$ \\
\hline CK $5 / 6$ & CK 6 & $\mathrm{CK} 7$ \\
\hline CK 8 & CK 10 & CK 13 \\
\hline CK 14 & CK 15 & CK 16 \\
\hline CK 17 & CK 18 & CK 19 \\
\hline CK 20 & CK HMW basic & CK LMW acidic \\
\hline CK HMW 34BE12 & CAM 5.2 & Vimentina \\
\hline Desmoplaquina & & \\
\hline QT NEOADJ & DROGAS & CICLOS \\
\hline Início & Término & Resposta \\
\hline Cirurgia & & Data \\
\hline QT ADJ & DROGAS & CICLOS \\
\hline Início & Término & \\
\hline HT & Droga & Tempo (anos) \\
\hline RXT Pré & Data & cGy \\
\hline RXT Pós & Data & cGy \\
\hline QT recidiva & Drogas & Ciclos \\
\hline Início & Término & \\
\hline CTNM & pTNM & Estádio \\
\hline Evolução & & \\
\hline Data Rec Local & Data Rec Sistêmica & Sítio 1 \\
\hline Sítio 2 & Sítio 3 & Sítio 4 \\
\hline Último retorno & Data Revisão RGH & Revisor \\
\hline
\end{tabular}


Anexo 4 - Estadiamento anatomopatológico

\begin{tabular}{|c|c|}
\hline \multicolumn{2}{|c|}{ pT - Tumor primário } \\
\hline pTx & Impossibilidade de avaliação do tamanho do tumor primário* \\
\hline pTO & Sem evidência de tumor primário \\
\hline pTis & $\begin{array}{l}\text { Carcinoma in situ: carcinoma ductal in situ, carcinoma lobular in situ ou doença de Paget }{ }^{\star \star} \text { da papila } \\
\text { sem tumor subjacente }\end{array}$ \\
\hline pT1 & Tumor $\leq 2 \mathrm{~cm}$ em sua maior dimensão \\
\hline pT1mic & 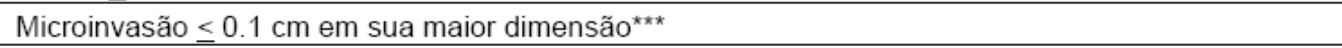 \\
\hline pT1a & Tumor $>0.1 \mathrm{e} \leq 0.5 \mathrm{~cm}$ ou menos em sua maior dimensão \\
\hline pT1b & Tumor $>0.5 \mathrm{~cm}$ e $\leq 1 \mathrm{~cm}$ em sua maior dimensão \\
\hline pT1c & Tumor $>1 \mathrm{~cm} \mathrm{e} \leq 2 \mathrm{~cm}$ em sua maior dimensão \\
\hline pT2 & Tumor $>2.0 \mathrm{~cm} \leq 5 \mathrm{~cm}$ em sua maior dimensão \\
\hline pT3 & Tumor $>5.0 \mathrm{~cm}$ em sua maior dimensão \\
\hline pT4 & Tumor de qualquer tamanho com extensão direta para a parede do tórax ou pele ${ }^{\wedge}$ \\
\hline pT4a & Extensão à parede do tórax, excluindo-se o músculo peitoral ${ }^{\wedge \wedge}$ \\
\hline pT4b & $\begin{array}{l}\text { Edema (incluindo peau d'orange) ou ulceração da pele da mama ou nódulos cutâneos satélites } \\
\text { contíguos na mesma mama }\end{array}$ \\
\hline pT4c & Soma de pTa e pT4b \\
\hline pT4d & Carcinoma inflamatório ${ }^{\wedge \wedge \wedge}$ \\
\hline \multicolumn{2}{|c|}{ pN - Linfonodos regionais ${ }^{\#}$} \\
\hline $\mathrm{pNx}$ & Linfonodos regionais não podem ser avaliados (ex: remoção anterior ou não ressecados) \\
\hline pNO & Ausência de metástases histológicas; pesquisa de células tumorais isoladas (ITC ${ }^{\# \#}$ ) não realizada \\
\hline pNO(i-) & $\begin{array}{l}\text { Ausência de metástases histológicas; pesquisa de ITC negativa por técnicas histológicas - } \\
\text { hematoxilina/eosina e imunoistoquímica. }\end{array}$ \\
\hline $\mathrm{pN} 0(\mathrm{i}+)$ & $\begin{array}{l}\text { Ausência de metástases histológicas; pesquisa de ITC positiva por técnicas histológicas - } \\
\text { hematoxilina/eosina e imunoistoquimica; grupo de ITC } \leq 0,2 \mathrm{~mm}\end{array}$ \\
\hline pNO(mol-) & Ausência de metástases histológicas; pesquisa de ITC negativa por técnicas moleculares (RT-PCR) \\
\hline $\mathrm{pNO}(\mathrm{mol}+)$ & Ausência de metástases histológicas; pesquisa de ITC positiva por técnicas moleculares \\
\hline pN1 & $\begin{array}{l}\text { Metástases para } 1 \text { a } 3 \text { linfonodos (LN) axilares ou mamários internos com doença microscópica } \\
\text { detectada através de dissecção de linfonodos sentinelas (DLS), mas clinicamente inaparente }\end{array}$ \\
\hline pN1mi & Micrometástases $^{\# \# \#}>0,2 \mathrm{~mm} \mathrm{e} \leq 2 \mathrm{~mm}$ \\
\hline pN1a & Metástases para 1 a $3 \mathrm{LN}$ axilares (pelo menos um grupo de células tumorais $>2.0 \mathrm{~mm}$ ) \\
\hline pN1b & Metástases em LN mamários internos detectados por DLS, mas clinicamente inaparentes \\
\hline pN1c & $\begin{array}{l}\text { Metástases para } 1 \text { a } 3 \mathrm{LN} \text { axilares e mamários internos com doença microscópica detectada por DLS } \\
\text { mas clinicamente inaparente. Se associados a mais de } 3 \mathrm{LN} \text { axilares positivos, os LN mamários } \\
\text { internos são classificados como pN3b para refletir a carga tumoral aumentada }\end{array}$ \\
\hline pN2 & $\begin{array}{l}\text { Metástases em } 4 \text { a } 9 \text { LN axilares; ou LN mamários internos clinicamente aparentes na ausência de } \\
\text { metástases em LN axilares }\end{array}$ \\
\hline pN2a & Metástases para 4 a $9 \mathrm{LN}$ axilares (pelo menos um grupo de células tumorais $>2.0 \mathrm{~mm}$ ) \\
\hline $\mathrm{pN} 2 \mathrm{~b}$ & $\begin{array}{l}\text { Metástases para LN mamários internos clinicamente aparentes na ausência de metástases para LN } \\
\text { axilares }\end{array}$ \\
\hline pN3 & $\begin{array}{l}\text { Metástases } 10 \text { ou mais } \mathrm{LN} \text { axilares, ou em LN infraclaviculares, ou em LN mamários internos } \\
\text { ipsilaterais clinicamente aparentes na presença de } 1 \text { ou mais } \mathrm{LN} \text { axilares positivos; ou em mais de } 3 \\
\mathrm{LN} \text { axilares com micrometástases clinicamente inaparentes em LN mamários internos ou LN } \\
\text { supraclaviculares ipsilaterais }\end{array}$ \\
\hline $\mathrm{pN} 3 \mathrm{a}$ & $\begin{array}{l}\text { Metástases em } 10 \text { ou mais LN axilares (pelo menos um grupo de células tumorais }>2.0 \mathrm{~mm} \text { ); ou } \\
\text { metástases para LN infraclaviculares }\end{array}$ \\
\hline pN3b & $\begin{array}{l}\text { Metástases em LN mamários internos clinicamente aparentes na presença de } 1 \text { ou mais LN axilares } \\
\text { positivos; ou em mais de } 3 \mathrm{LN} \text { axilares e } \mathrm{LN} \text { mamários internos com doença microscópica detectada } \\
\text { por DLS mas clinicamente inaparente }\end{array}$ \\
\hline pN3c & Metástases em LN supraclaviculares ipsilaterais \\
\hline \multicolumn{2}{|c|}{ pM - Metástases à distância } \\
\hline $\mathrm{pMx}$ & Não avaliada \\
\hline pMO & Ausência de metástases \\
\hline pM1 & Metástases à distância, incluindo metástases em LN supraclaviculares homolaterais \\
\hline
\end{tabular}




\section{OBSERVAÇŐES:}

* Se houver tumor presente na margem de ressecção macroscópica, o caso é codificado como pTx por impossibilidade de acesso ao tamanho completo do tumor.

** Doença de Paget associada a tumor subjacente é classificada de acordo com o tamanho do tumor ***Microinvasão é a extensão de células neoplásicas além da membrana basal aos tecidos adjacentes, com focos não maiores que $0,1 \mathrm{~cm}$ em sua maior dimensão. Quando há múltiplos focos de microinvasão, o tamanho do maior foco é utilizado para classificar a microinvasão (não deve se usada a soma de todos os focos individuais). A presença de múltiplos focos deve ser quantificada $e$ notificada, bem como a presença de múltiplos focos maiores de carcinomas invasivos.

^ Invasão dérmica isolada (sem ulceração, nódulos satélites ou carcinoma inflamatório) não altera a categoria $\mathrm{T}$. Os casos são classificados como T1, T2 ou T3, dependendo de seu tamanho.

^^ Tumor no músculo peitoral deve ser medido em conjunto com o tumor mamário contíguo para a determinação do tamanho tumoral e a categoria $T$ final.

$\wedge \wedge \wedge$ Carcinoma inflamatório da mama é uma entidade clínico-patológica caracterizada por eritema difuso e edema envolvendo a maior parte da pele da mama, freqüentemente sem massa palpável subjacente. A apresentação clínica é devida a êmbolos tumorais em linfáticos, apesar deles poderem não ser observados numa biópsia da pele. $O$ diagnóstico é estabelecido pela combinação dos achados clínicos com uma biópsia evidenciando o carcinoma no parênquima mamário ou nos linfáticos dérmicos. A presença de êmbolos linfáticos dérmicos sem o quadro clínico típico não é diagnóstica de carcinoma inflamatório. Num caso de carcinoma inflamatório clínico (cT4d) se a biópsia de pele da mama for negativa e não houver carcinoma localizado subjacente mensurável, a categorização patológica deve ser PTx. Retração da pele ou do mamilo, bem como outras alterações cutâneas, exceto aquelas dos estádios $T 4 b$ e $T 4 d$, podem ocorrer em tumores $T 1, T 2$ ou $T 3$ sem afetar sua classificação.

Há situações onde o patologista não pode fazer a avaliação completa dos linfonodos (LN) em decorrência do procedimento cirúrgico realizado para a sua abordagem, ou porque os dados de procedimentos prévios não estão disponiveis ou estão incompletos. Nessas situações, deve-se classificar o estadiamento nodal como "pNx" ao invés do número do TNM.

* A classificação é baseada na dissecção dos LN axilares com ou sem a dissecção dos LN sentinela. Quando a classificação for baseada apenas na dissecção dos linfonodos sentinela sem dissecção axilar subseqüente, deve-se acrescentar a abreviatura (sn) à classificação, por exemplo, pNO(i+)(sn).

\# Células tumorais isoladas (ITC) são definidas como células únicas isoladas ou em pequenos grupos não maiores que $0,2 \mathrm{~mm}$. Elas podem ser detectadas através de exame histoógico de rotina, por imunoistoquimica ou métodos moleculares (RT-PCR). As ITC geralmente não mostram evidências de atividade maligna (ex: proliferação ou reação estromal).

\#\# Doença clinicamente aparente é definida pela detecção de LN através de estudos de imagem (excluindo linfocintilografia) ou através de exame clínico.

\#\#\# Micrometástases podem mostrar evidência histológica de atividade maligna (ex: proliferação ou reação estromal). 
Anexo 5 - Sistema de graduação de Notingham

\begin{tabular}{|c|c|}
\hline Característica & Escore \\
\hline \multicolumn{2}{|l|}{ Formação de túbulos } \\
\hline Presente na maioria do tumor ( $>75 \%$ ) & 1 \\
\hline Moderada: 10 a $75 \%$ do tumor & 2 \\
\hline Mínima: $<10 \%$ do tumor & 3 \\
\hline \multicolumn{2}{|l|}{ Pleomorfismo nuclear } \\
\hline Núcleos pequenos e regulares & 1 \\
\hline Moderada hipertrofia e irregularidade & 2 \\
\hline Acentuada variação de tamanho, nucléolos, cromatina grosseira & 3 \\
\hline \multicolumn{2}{|l|}{ Contagem mitótica* } \\
\hline Até 12 mitoses por $10 \mathrm{CGA}$ & 1 \\
\hline Entre 13 e 24 mitoses por 10 CGA & 2 \\
\hline Mais que 24 mitoses por $10 \mathrm{CGA}$ & 3 \\
\hline Graduação final & Soma dos escores \\
\hline Grau I & $3-5$ \\
\hline Grau II & $6-7$ \\
\hline Grau III & $8-9$ \\
\hline
\end{tabular}

* Valores ajustados para o campo microscópico utilizado neste estudo CGA: campo de grande aumento

Fonte: Adaptado de ELSTON e ELLIS (1991) 


\section{REFERÊNCIAS}

ACS. Cancer facts and figures 2005. Atlanta, 2005.

Agiostratidou G, Hulit J, Phillips GR, Hazan RB. Differential cadherin expression: potential markers for epithelial to mesenchymal transformation during tumor progression. $\mathrm{J}$ Mammary Gland Biol Neoplasia. 2007;12(2-3):127-33. Review.

Allred DC, Harvey JM, Berardo M, Clark GM. Prognostic and predictive factors in breast cancer by immunohistochemical analysis. Mod Pathol. 1998 Feb;11(2):155-68.

Arriagada R, Le MG, Dunant A, Tubiana M, Contesso G. Twenty-five years of follow-up in patients with operable breast carcinoma: correlation between clinicopathologic factors and the risk of death in each 5-year period. Cancer. 2006;15;106(4):743-50.

Baranwal S, Alahari SK. Molecular mechanisms controlling E-cadherin expression in breast cancer. Biochem Biophys Res Commun. 2009;384(1):6-11.

Berx G, Van Roy F. The E-cadherin/catenin complex: an important gatekeeper in breast cancer tumorigenesis and malignant progression. Breast Cancer Res. 2001;3(5):289-93.

Blanco MJ, Moreno-Bueno G, Sarrio D, Locascio A, Cano A, Palacios J, Nieto MA. Correlation of Snail expression with histological grade and lymph node status in breast carcinomas. Oncogene. 2002;21(20):3241-6.

Brenton JD, Carey LA, Ahmed AA, Caldas C. Molecular classification and molecular forecasting of breast cancer: ready for clinical application? J Clin Oncol. 2005 Oct 10;23(29):7350-60.

Calza S, Hall P, Auer G, Bjöhle J, Klaar S, Kronenwett U, Liu ET, Miller L, Ploner A, Smeds J, Bergh J, Pawitan Y. Intrinsic molecular signature of breast cancer in a population-based cohort of 412 patients. Breast Cancer Res. 2006;8(4):R34.

Cano A, Pérez-Moreno MA, Rodrigo I, Locascio A, Blanco MJ, del Barrio MG, Portillo F, Nieto MA. The transcription factor snail controls epithelial-mesenchymal transitions by repressing E-cadherin expression. Nat Cell Biol. 2000;2(2):76-83.

Carey LA, Dees EC, Sawyer L, Gatti L, Moore DT, Collichio F, Ollila DW, Sartor CI, Graham ML, Perou CM. The triple negative paradox: primary tumor chemosensitivity of breast cancer subtypes. Clin Cancer Res. 2007;13(8):2329-34.

Carey LA, Perou CM, Livasy CA, Dressler LG, Cowan D, Conway K, et al. Race, breast cancer subtypes, and survival in the Carolin Breast Cancer Study. JAMA.

2006;295:2492-502.

Carvalho SM, Soares FA, Netto MM, Nonogaki S, Castro RA. Is the Expression of Inducible (iNOS) and Endothelial (eNOS) Nitric Oxide Synthases an Early Event in Breast Carcinogenesis? Breast J. 2010 Jun 10. [Epub ahead of print]. 
Cavallaro U, Christofori G. Cell adhesion and signalling by cadherins and Ig-CAMs in cancer. Nat Rev Cancer. 2004;4(2):118-32.

Cavallaro U, Schaffhauser B, Christofori G. Cadherins and the tumour progression: is it all in a switch? Cancer Lett. 2002;176(2):123-8.

Charafe-Jauffret E, Tarpin C, Bardou VJ, Bertucci F, Ginestier C, Braud AC, Puig B, Geneix J, Hassoun J, Birnbaum D, Jacquemier J, Viens P. Immunophenotypic analysis of inflammatory breast cancers: identification of an 'inflammatory signature'. J Pathol. 2004;202(3):265-73.

Chia SK, Speers CH, Bryce CJ, Hayes MM, Olivotto IA. Ten-year outcomes in a population-based cohort of node-negative, lymphatic, and vascular invasion-negative early breast cancers without adjuvant systemic therapies. J Clin Oncol. 2004;22(9):1630-7.

Côme C, Magnino F, Bibeau F, De Santa Barbara P, Becker KF, Theillet C, Savagner P. Snail and slug play distinct roles during breast carcinoma progression. Clin Cancer Res. 2006;12(18):5395-402.

De Brot M, Soares FA, Stiepcich MM, Cúrcio VS, Gobbi H. Basal-like breast cancers: clínicopathological features and outcome. Rev Assoc Med Bras. 2009;55(5):529-34.

Dent R, Trudeau M, Pritchard KI, Hanna WM, Kahn HK, Sawka CA, Lickley LA, Rawlinson E, Sun P, Narod SA. Triple-negative breast cancer: clinical features and patterns of recurrence. Clin Cancer Res. 2007;13(15 Pt 1):4429-34.

Desprez PY, Sumida T, Coppé JP. Helix-loop-helix proteins in mammary gland development and breast cancer. J Mammary Gland Biol Neoplasia. 2003;8(2):225-39.

Dutra MC, Rezende MA, de Andrade VP, Soares FA, Ribeiro MV, de Paula EC, Gobbi H. Immunophenotype and evolution of breast carcinomas: a comparison between very young and postmenopausal women. Rev Bras Ginecol Obstet. 2009;31(2):54-60.

Early Breast Cancer Trialists' Collaborative Group (EBCTCG). Effects of chemotherapy and hormonal therapy for early breast cancer on recurrence and 15-year survival: an overview of the randomised trials. Lancet. 2005;365(9472):1687-717.

El Saghir NS, Eniu A, Carlson RW, Aziz Z, Vorobiof D, Hortobagyi GN; Breast Health Global Initiative Systemic Therapy Focus Group. Locally advanced breast cancer: treatment guideline implementation with particular attention to low- and middle-income countries. Cancer. 2008;113(8):2315-24.

Ellis IO, Elston CW. Tumors of the breat. In: Fletcher CDM, editor. Diagnostic histopathology of tumors. New York: Churchill Livingstone, 1998; p.635-89.

Elloul S, Elstrand MB, Nesland JM et al. Snail, Slug, and Smad-interacting protein 1 as novel parameters of disease aggressiveness in metastatic ovarian and breast carcinoma. Cancer. 2005;103(8):1631-43. 
Fernandes RC, Bevilacqua JL, Soares IC, Siqueira SA, Pires L, Hegg R, Carvalho FM. Coordinated expression of ER, PR and HER2 define different prognostic subtypes among poorly differentiated breast carcinomas. Histopathology. 2009;55(3):346-52.

Ferrini FS, Rossi MA, Neto MM, Soares FA. Schirrous invasive ductal carcinoma of the breast overexpress p53 oncoprotein. Sao Paulo Med J. 2001;119(1):4-6.

Fisher B, Redmond C, Brown A. Influence of tumor estrogen and progesterone receptor levels on the response to tamoxifen and chemotherapy in primary breast cancer. J Clin Oncol. (1983).

Fisher B, Slack NH, Bross IDJ et al. Cancer of the breast: size of neoplasm and prognosis. Cancer. 1969;24:1071-80.

Fisher ER, Anderson S, Tan-Chiu E, Fisher B, Eaton L, Wolmark N. Fifteen-year prognostic discriminants for invasive breast carcinoma: National Surgical Adjuvant Breast and Bowel Project Protocol-06. Cancer. 2001;91(8):1679-87.

Gilles C, Polette M, Mestdagt M, Nawrocki-Raby B, Ruggeri P, Birembaut P, Foidart JM. Transactivation of vimentin by beta-catenin in human breast cancer cells. Cancer Res. 2003;63(10):2658-64.

Gloeckler Ries LA, Reichman ME, Lewis DR, Hankey BF, Edwards BK. Cancer survival and incidence from the Surveillance, Epidemiology, and End Results (SEER) program. Oncologist. 2003;8(6):541-52.

Greene FL. The American Joint Committee on Cancer: updating the strategies in cancer staging. Bull Am Coll Surg. (2002).

Hajra KM, Chen DY, Fearon ER. The SLUG zinc-finger protein represses E-cadherin in breast cancer. Cancer Res. 2002;62(6):1613-8.

Haupt B, Ro JY, Schwartz MR. Basal-like breast carcinoma: a phenotypically distinct entity. Arch Pathol Lab Med. 2010;134(1):130-3. Review.

Hazan RB, Phillips GR, Qiao RF, Norton L, Aaronson SA. Exogenous expression of Ncadherin in breast cancer cells induces cell migration, invasion, and metastasis. J Cell Biol. 2000;148(4):779-90.

Heimann R, Hellman S. Clinical progression of breast cancer malignant behavior: what to expect and when to expect it. J Clin Oncol. 2000;18(3):591-9.

Hemavathy K, Ashraf SI, Ip YT. Snail/slug family of repressors: slowly going into the fast lane of development and cancer. Gene. 2000;257(1):1-12. Review.

Hevel JM, White KA, Marletta MA. Purification of the inducible murine macrophage nitric oxide synthase. Identification as a flavoprotein. J Biol Chem. 1991;266(34):22789-91.

Hutcheson IR, Knowlden JM, Jones HE et al. Inductive mechanisms limiting response to anti-epidermal growth factor receptor therapy. Endocr Rel Cancer. 2006;13:S89-97. 
Hynes NE, Lane HA. ERBB receptors and cancer: the complexity of targeted inhibitors. Nat Rev Cancer. 2005;5(5):341-54.

Ibrahim EM, Zeeneldin AA, Sadiq BB, Ezzat AA. The present and the future of breast cancer burden in the Kingdom of Saudi Arabia. Med Oncol. 2008;25(4):387-93.

Klus GT, Rokaeus N, Bittner ML, Chen Y, Korz DM, Sukumar S, Schick A, Szallasi Z. Down-regulation of the desmosomal cadherin desmocollin 3 in human breast cancer. Int $\mathrm{J}$ Oncol. 2001;19(1):169-74.

Kokkinos MI, Wafai R, Wong MK, Newgreen DF, Thompson EW, Waltham M. Vimentin and epithelial-mesenchymal transition in human breast cancer--observations in vitro and in vivo. Cells Tissues Organs. 2007;185(1-3):191-203. Review.

Kononen J, Bubendorf L, Kallioniemi A, Bärlund M, Schraml P, Leighton S, Torhorst J, Mihatsch MJ, Sauter G, Kallioniemi OP. Tissue microarrays for high-throughput molecular profiling of tumor specimens. Nat Med. 1998;4(7):844-7.

Korsching E, Packeisen J, Liedtke C, Hungermann D, Wülfing P, van Diest PJ, Brandt B, Boecker W, Buerger $\mathrm{H}$. The origin of vimentin expression in invasive breast cancer: epithelial-mesenchymal transition, myoepithelial histogenesis or histogenesis from progenitor cells with bilinear differentiation potential? J Pathol. 2005;206(4):451-7.

Kowalski PJ, Rubin MA, Kleer CG. E-cadherin expression in primary carcinomas of the breast and its distant metastases. Breast Cancer Res. 2003;5(6):R217-22.

Kurrey NK, K A, Bapat SA. Snail and Slug are major determinants of ovarian cancer invasiveness at the transcription level. Gynecol Oncol. 2005;97(1):155-65.

Kwok WK, Ling MT, Lee TW, Lau TC, Zhou C, Zhang X, et al. Up-regulation of twist in prostate cancer and its implication as a therapeutic target. Cancer Res. 2005;65(12):5153-62.

Larue L, Ohsugi M, Hirchenhain J, Kemler R. E-cadherin null mutant embryos fail to form a trophectoderm epithelium. Proc Natl Acad Sci USA. 1994;91(17):8263-7.

Lo HW, Hsu SC, Xia W, Cao X, Shih JY, Wei Y, Abbruzzese JL, Hortobagyi GN, Hung MC. Epidermal growth factor receptor cooperates with signal transducer and activator of transcription 3 to induce epithelial-mesenchymal transition in cancer cells via upregulation of TWIST gene expression. Cancer Res. 2007;67(19):9066-76.

Logullo AF, Nonogaki S, Pasini FS, Osório CA, Soares FA, Brentani MM.Concomitant expression of epithelial-mesenchymal transition biomarkers in breast ductal carcinoma: association with progression. Oncol Rep. 2010;23(2):313-20.

Louwman WJ, van Beek MW, Schapers RF, Nolthenius-Puylaert MB, van Diest PJ, Roumen RM, Coebergh JW. Long-term survival of T1 and T2 lymph node-negative breast cancer patients according to Mitotic Activity Index: a population-based study. Int J Cancer. 2006;118(9):2310-4. 
Mani SA, Guo W, Liao MJ, Eaton EN, Ayyanan A, Zhou AY, Brooks M, Reinhard F, Zhang CC, Shipitsin M, Campbell LL, Polyak K, Brisken C, Yang J, Weinberg RA. The epithelial-mesenchymal transition generates cells with properties of stem cells. Cell. 2008;133(4):704-15.

Matos I, Dufloth R, Alvarenga M, Zeferino LC, Schmitt F. p63, cytokeratin 5, and Pcadherin: three molecular markers to distinguish basal phenotype in breast carcinomas. Virchows Arch. 2005;447(4):688-94.

Ministério da Saúde. Instituto Nacional do Câncer. Câncer de mama. Disponível em: <URL:http://www1.inca.gov.br/estimativa/2009/index.asp?link=mapa.asp\&ID=13.

Mironchik Y, Winnard PT Jr, Vesuna F, Kato Y, Wildes F, Pathak AP, Kominsky S, Artemov D, Bhujwalla Z, Van Diest P, Burger H, Glackin C, Raman V. Twist overexpression induces in vivo angiogenesis and correlates with chromosomal instability in breast cancer. Cancer Res. 2005;65(23):10801-9.

Nelson WJ. Regulation of cell-cell adhesion by the cadherin-catenin complex. Biochem Soc Trans. 2008;36(Pt 2):149-55. Review.

Nielsen TO, Hsu FD, Jensen K, Cheang M, Karaca G, Hu Z, Hernandez-Boussard T, Livasy C, Cowan D, Dressler L, Akslen LA, Ragaz J, Gown AM, Gilks CB, van de Rijn M, Perou CM. Immunohistochemical and clinical characterization of the basal-like subtype of invasive breast carcinoma. Clin Cancer Res. 2004;10(16):5367-74.

Nieman MT, Prudoff RS, Johnson KR, Wheelock MJ. N-cadherin promotes motility in human breast cancer cells regardless of their E-cadherin expression. J Cell Biol. 1999;147(3):631-44.

Nieto MA. The snail superfamily of zinc-finger transcription factors. Nat Rev Mol Cell Biol. 2002;3(3):155-66. Review.

Palacios J, Benito N, Berraquero R, Pizarro A, Cano A, Gamallo C. Differential spatiotemporal expression of E- and P-cadherin during mouse tooth development. Int J Dev Biol. 1995;39(4):663-6.

Paredes J, Correia AL, Ribeiro AS, Albergaria A, Milanezi F, Schmitt FC. P-cadherin expression in breast cancer: a review. Breast Cancer Res. 2007;9(5):214. Review.

Perou CM, Sørlie T, Eisen MB, van de Rijn M, Jeffrey SS, Rees CA, Pollack JR, Ross DT, Johnsen H, Akslen LA, Fluge O, Pergamenschikov A, Williams C, Zhu SX, Lønning PE, Børresen-Dale AL, Brown PO, Botstein D. Molecular portraits of human breast tumours. Nature. 2000;406(6797):747-52.

Prasad CP, Rath G, Mathur S, Bhatnagar D, Parshad R, Ralhan R. Expression analysis of E-cadherin, Slug and GSK3beta in invasive ductal carcinoma of breast. BMC Cancer. 2009;9:325. 
Radice GL, Ferreira-Cornwell MC, Robinson SD, Rayburn H, Chodosh LA, Takeichi M, Hynes RO. Precocious mammary gland development in P-cadherin-deficient mice. J Cell Biol. 1997;139(4):1025-32.

Radice GL, Sauer CL, Kostetskii I, Peralta Soler A, Knudsen KA. Inappropriate Pcadherin expression in the mouse mammary epithelium is compatible with normal mammary gland function. Differentiation. 2003;71(6):361-73.

Rakha EA, Elsheikh SE, Aleskandarany MA, Habashi HO, Green AR, Powe DG, El-Sayed ME, Benhasouna A, Brunet JS, Akslen LA, Evans AJ, Blamey R, Reis-Filho JS, Foulkes WD, Ellis IO. Triple-negative breast cancer: distinguishing between basal and nonbasal subtypes. Clin Cancer Res. 2009;15(7):2302-10.

Reis-Filho JS, Milanezi F, Carvalho S, Simpson PT, Steele D, Savage K, Lambros MB, Pereira EM, Nesland JM, Lakhani SR, Schmitt FC. Metaplastic breast carcinomas exhibit EGFR, but not HER2, gene amplification and overexpression: immunohistochemical and chromogenic in situ hybridization analysis. Breast Cancer Res. 2005;7(6):R1028-35.

Reis-Filho JS, Milanezi F, Steele D, Savage K, Simpson PT, Nesland JM, Pereira EM, Lakhani SR, Schmitt FC. Metaplastic breast carcinomas are basal-like tumours. Histopathology. 2006;49(1):10-21.

Reis-Filho JS, Tutt AN. Triple negative tumours: a critical review. Histopathology. 2008;52(1):108-18.

Romond EH, Perez EA, Bryant J et al. Trastuzumab plus adjuvant chemotherapy for operable HER2-positive breast cancer. N Engl J Med. 2005;353(16):1673-84.

Rouzier R, Perou CM, Symmans WF, Ibrahim N, Cristofanilli M, Anderson K, Hess KR, Stec J, Ayers M, Wagner P, Morandi P, Fan C, Rabiul I, Ross JS, Hortobagyi GN, Pusztai $\mathrm{L}$. Breast cancer molecular subtypes respond differently to preoperative chemotherapy. Clin Cancer Res. 2005;11(16):5678-85.

Sarrió D, Rodriguez-Pinilla SM, Hardisson D, Cano A, Moreno-Bueno G, Palacios J. Epithelial-mesenchymal transition in breast cancer relates to the basal-like phenotype. Cancer Res. 2008;68(4):989-97.

Shih JY, Tsai MF, Chang TH et al. Transcription repressor slug promotes carcinoma invasion and predicts outcome of patients with lung adenocarcinoma. Clin Cancer Res. 2005;11(22):8070-8.

Shioiri M, Shida T, Koda K, Oda K, Seike K, Nishimura M, Takano S, Miyazaki M. Slug expression is an independent prognostic parameter for poor survival in colorectal carcinoma patients.Br J Cancer. 2006;94(12):1816-22.

Shiozaki H, Oka H, Inoue M, Tamura S, Monden M. E-cadherin mediated adhesion system in cancer cells. Cancer. 1996;77(8):1605-13. Review.

Singletary SE, Connoly JL. Breast cancer staging: working with the sixth edition of the AJCC Cancer staging Manual. CA Cancer J Clin. 2006; 56:37-47. 
Slamon DJ, Clark GM, Wong SG, Levin WJ, Ullrich A, McGuire WL. Human breast cancer: correlation of relapse and survival with amplification of the HER-2/neu oncogene. Science. 1987;235(4785):177-82.

Smigal C, Jemal A, Ward E, Cokkinides V, Smith R, Howe HL, Thun M. Trends in breast cancer by race and ethnicity: update 2006. CA Cancer J Clin. 2006;56(3):168-83.

Sobin LH, Wittenkind CH. TNM classificação de tumors malignos. $6^{\text {ath }}$ ed. Rio de Janeiro: INCA; 2006. Tumores de mama; p.137-48.

Soerjomataram I, Louwman MW, Ribot JG, Roukema JA, Coebergh JW. An overview of prognostic factors for long-term survivors of breast cancer. Breast Cancer Res Treat. 2008 Feb;107(3):309-30.

Sorlie T, Perou CM, Tibshirani R, Aas T, et al. Gene expression patterns of breast carcinomas distinguish tumor subclasses with clinical implications. Proc Natl Acad Sci U S A. 2001;98(19):10869-74.

Sorlie T, Tibshirani R, Parker J, Hastie T, Marron JS, Nobel A, Deng S, Johnsen H, Pesich R, Geisler S, Demeter J, Perou CM, Lønning PE, Brown PO, Børresen-Dale AL, Botstein D. Repeated observation of breast tumor subtypes in independent gene expression data sets. Proc Natl Acad Sci U S A. 2003;100(14):8418-23.

Sotiriou C, Neo SY, McShane LM, Korn EL, Long PM, Jazaeri A, Martiat P, Fox SB, Harris AL, Liu ET. Breast cancer classification and prognosis based on gene expression profiles from a population-based study. Proc Natl Acad Sci USA. 2003;100(18):10393-8.

Stiepich, MMA. Perfil das citoceratinas e sua relação com diferenciação e fatores clínicomorfológicos em carcinomas ductais SOE de mama estudados em "array de tecido" (tissue microarray - TMA). São Paulo; 2007. [Doutorado]. Fundação Antônio Prudente.

Storci G, Sansone P, Trere D et al. The basal-like breast carcinoma phenotype is regulated by SLUG gene expression. J Pathol. 2008;214(1):25-37.

Takeichi M, Hatta K, Nose A, Nagafuchi A. Identification of a gene family of cadherin cell adhesion molecules. Cell Differ Dev. 1988;25 Suppl:91-4. Review.

Thiery JP, Sleeman JP. Complex networks orchestrate epithelial-mesenchymal transitions. Nat Rev Mol Cell Biol. 2006;7(2):131-42. Review.

Thiery JP. Epithelial-mesenchymal transitions in tumour progression. Nat Rev Cancer. 2002;2(6):442-54. Review.

Thomas JS, Kerr GR, Jack WJ, Campbell F, McKay L, Pedersen HC, Kunkler IH, Cameron DA, Chetty U, Bartlett JM. Histological grading of invasive breast carcinoma--a simplification of existing methods in a large conservation series with long-term follow-up. Histopathology. 2009;55(6):724-31. 
Thompson EW, Newgreen DF, Tarin D. Carcinoma invasion and metastasis: a role for epithelial-mesenchymal transition? Cancer Res. 2005;65(14):5991-5.

Thomsen LL, Lawton FG, Knowles RG, Beesley JE, Riveros-Moreno V, Moncada S. Nitric oxide synthase activity in human gynecological cancer. Cancer Res. 1994;54(5):1352-4.

Tschugguel W, Schneeberger C, Unfried G, Czerwenka K, Weninger W, Mildner M, Gruber DM, Sator MO, Waldhör T, Huber JC. Expression of inducible nitric oxide synthase in human breast cancer depends on tumor grade. Breast Cancer Res Treat. 1999;56(2):145-51.

van de Rijn M, Perou CM, Tibshirani R, Haas P, Kallioniemi O, Kononen J, Torhorst J, Sauter G, Zuber M, Köchli OR, Mross F, Dieterich H, Seitz R, Ross D, Botstein D, Brown P. Am J Pathol. 2002; 161:1991-6. Expression of cytokeratins 17 and 5 identifies a group of breast carcinomas with poor clinical outcome. Am J Pathol. 2002;161(6):1991-6.

Vialle G, Bottiglieri L. Pathological definition of triple negative breast cancer. Eur J Cancer. 2009;45(1):5-10.

Warwick J, Tabàr L, Vitak B, Duffy SW. Time-dependent effects on survival in breast carcinoma: results of 20 years of follow-up from the Swedish Two-County Study. Cancer. 2004;100(7):1331-6.

Watanabe O, Imamura H, Shimizu T, Kinoshita J, Okabe T, Hirano A, Yoshimatsu K, Konno S, Aiba M, Ogawa K. Expression of twist and wnt in human breast cancer. Anticancer Res. 2004;24(6):3851-6.

Weiss RB, Woolf SH, Demakos E, Holland JF, Berry DA, Falkson G, Cirrincione CT, Robbins A, Bothun S, Henderson IC, Norton L. Cancer and Leukemia Group B. Natural history of more than 20 years of node-positive primary breast carcinoma treated with cyclophosphamide, methotrexate, and fluorouracil-based adjuvant chemotherapy: a study by the Cancer and Leukemia Group B. J Clin Oncol. 2003;21(9):1825-35.

Wheelock MJ, Shintani Y, Maeda M, Fukumoto Y, Johnson KR. Cadherin switching. J Cell Sci. 2008;121(Pt 6):727-35. Review.

Yang J, Mani SA, Donaher JL, Ramaswamy S, Itzykson RA, Come C, Savagner P, Gitelman I, Richardson A, Weinberg RA. Twist, a master regulator of morphogenesis, plays an essential role in tumor metastasis. Cell. 2004;117(7):927-39.

Zaha DC, Lazăr E, Lăzureanu C. Clinicopathologic features and five years survival analysis in molecular subtypes of breast cancer. Rom J Morphol Embryol. 2010;51(1):85-9.

Zajchowski DA, Bartholdi MF, Gong Y, Webster L, Liu HL, Munishkin A, Beauheim C, Harvey S, Ethier SP, Johnson PH. Identification of gene expression profiles that predict the aggressive behavior of breast cancer cells. Cancer Res. 2001;61(13):5168-78. 
Apêndice 1 - Banco de dados (Parte 1)

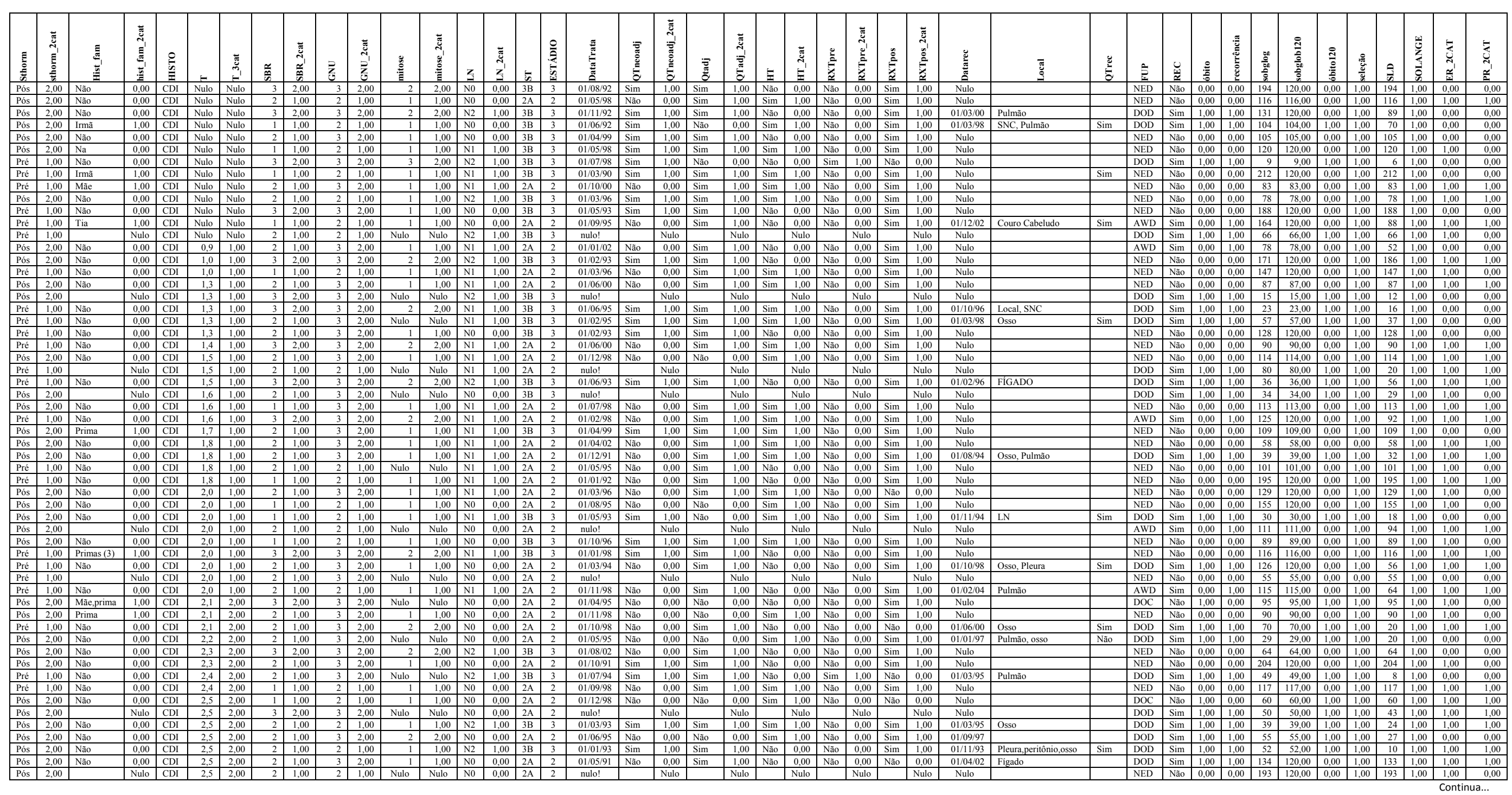




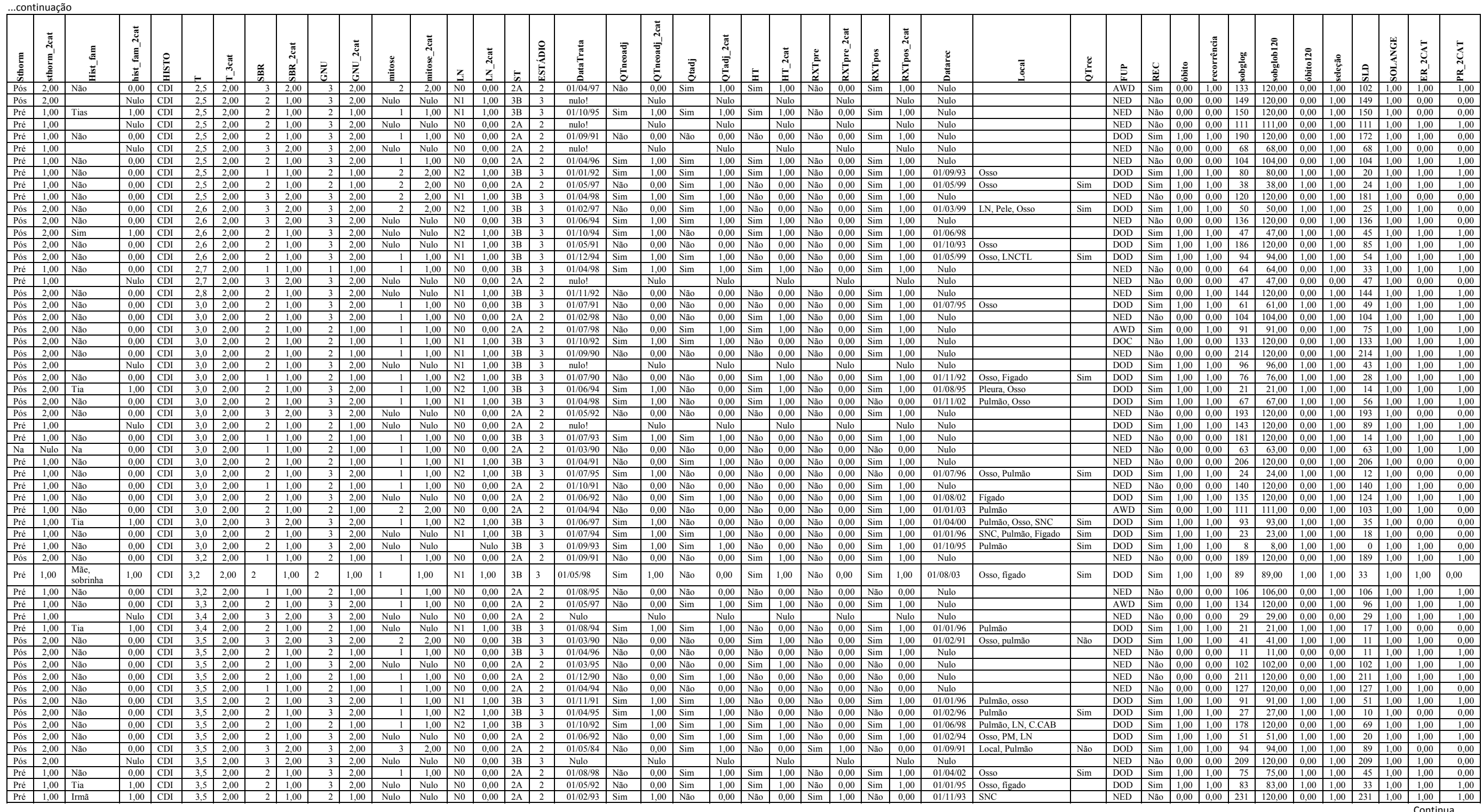




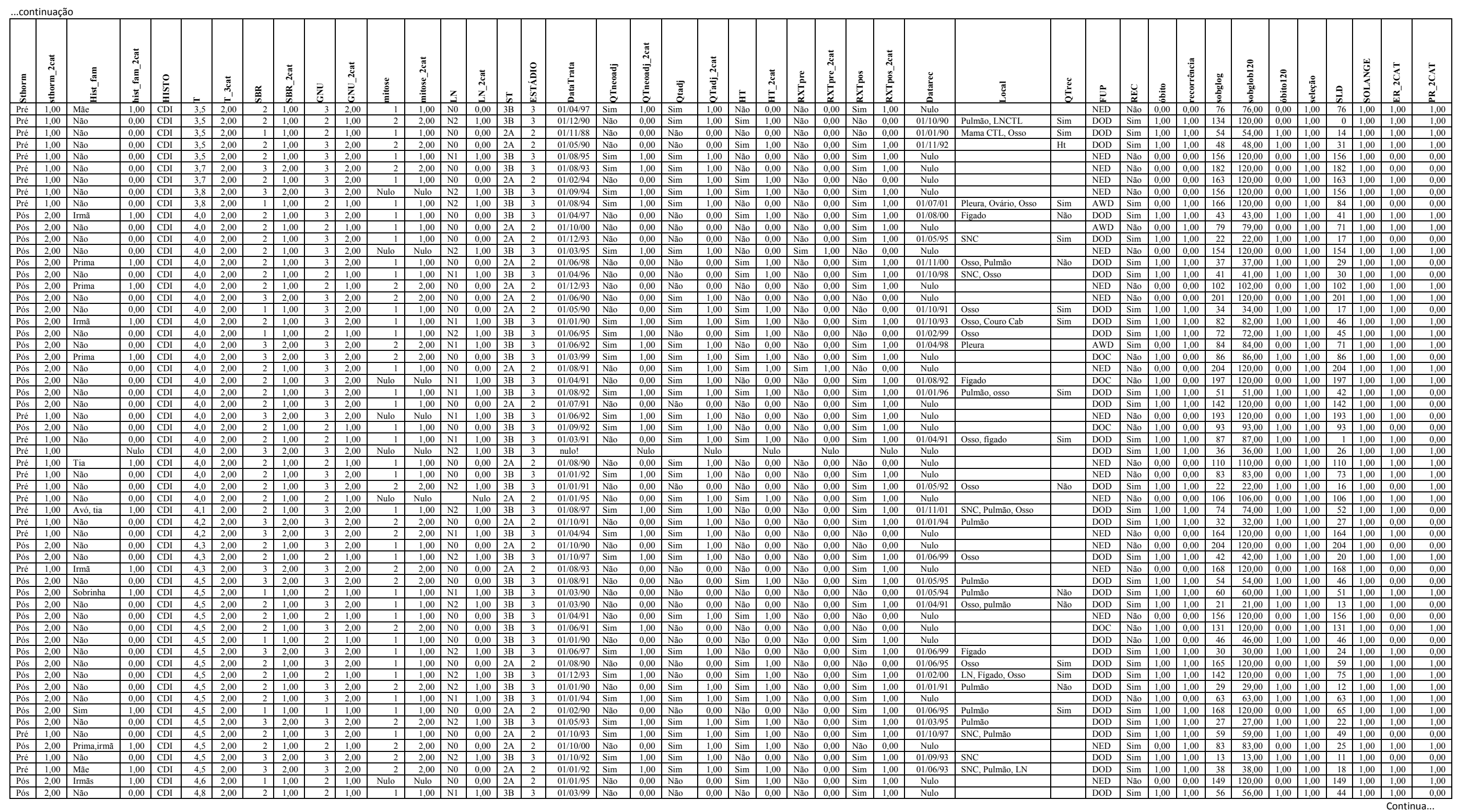




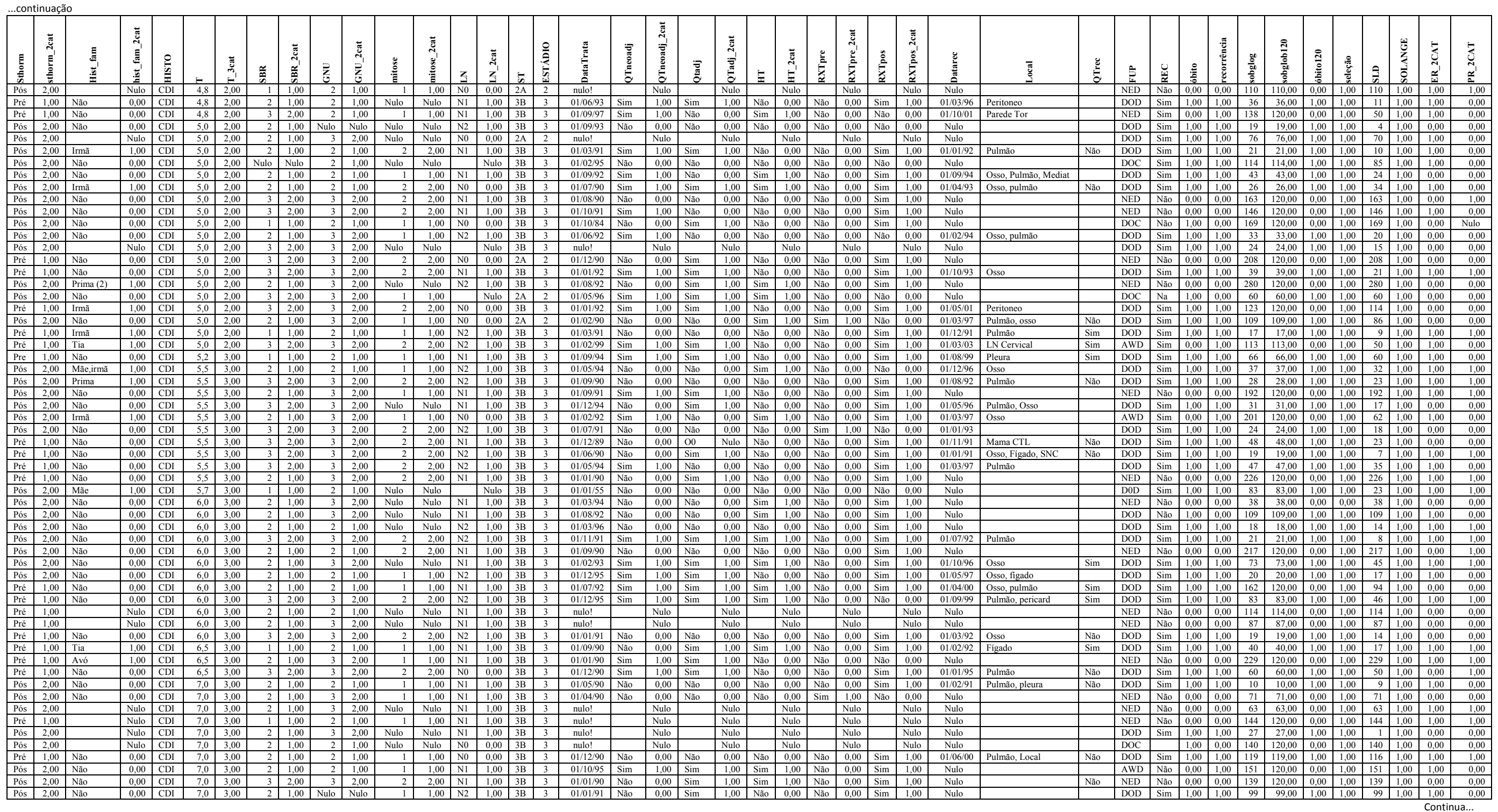




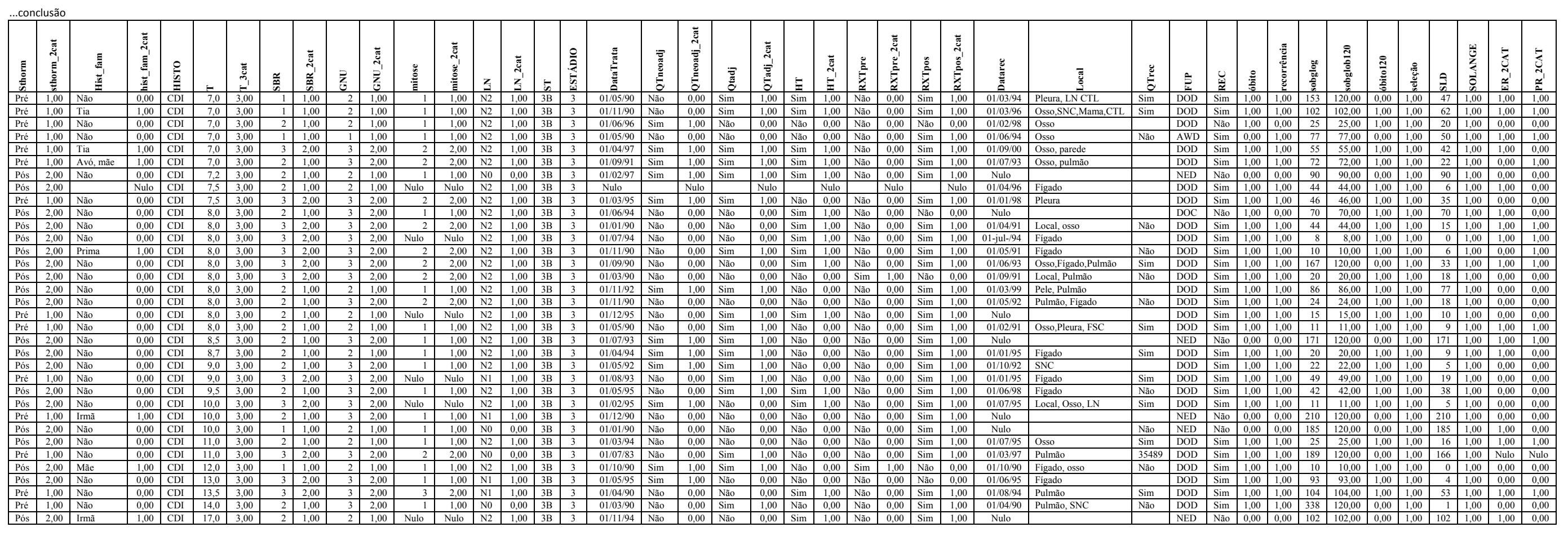


Apêndice 1 - Banco de dados (Parte 2)

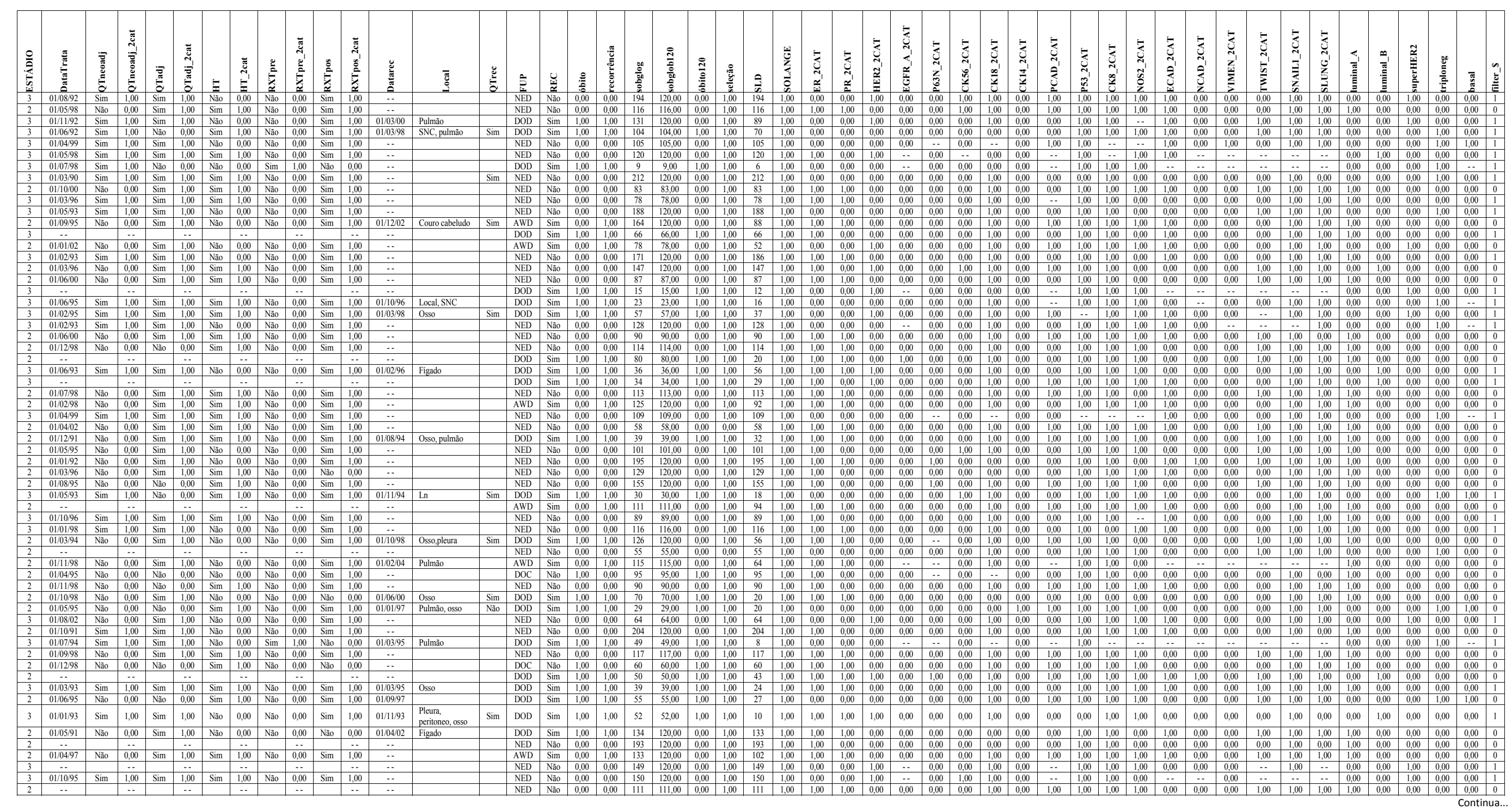




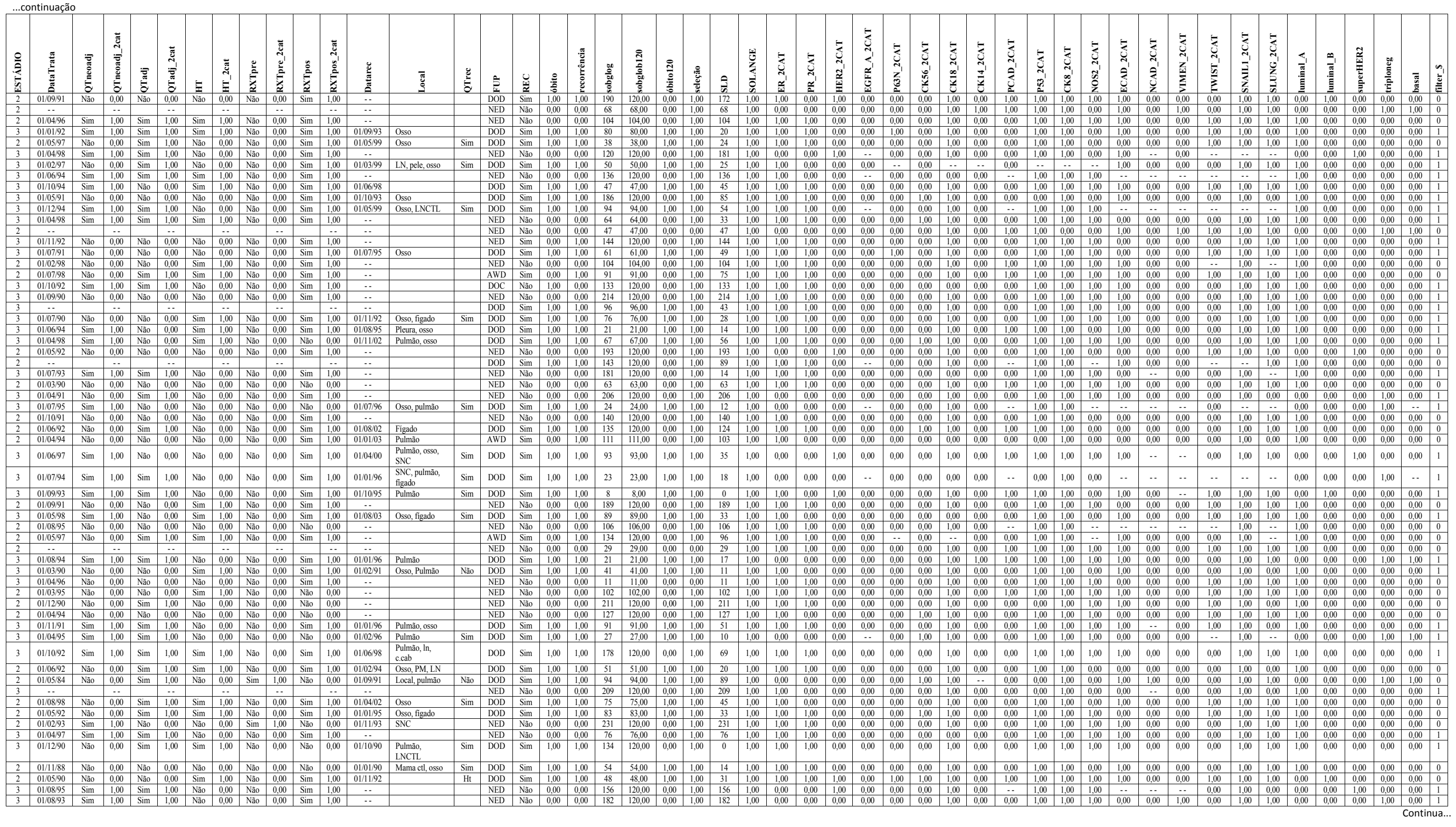




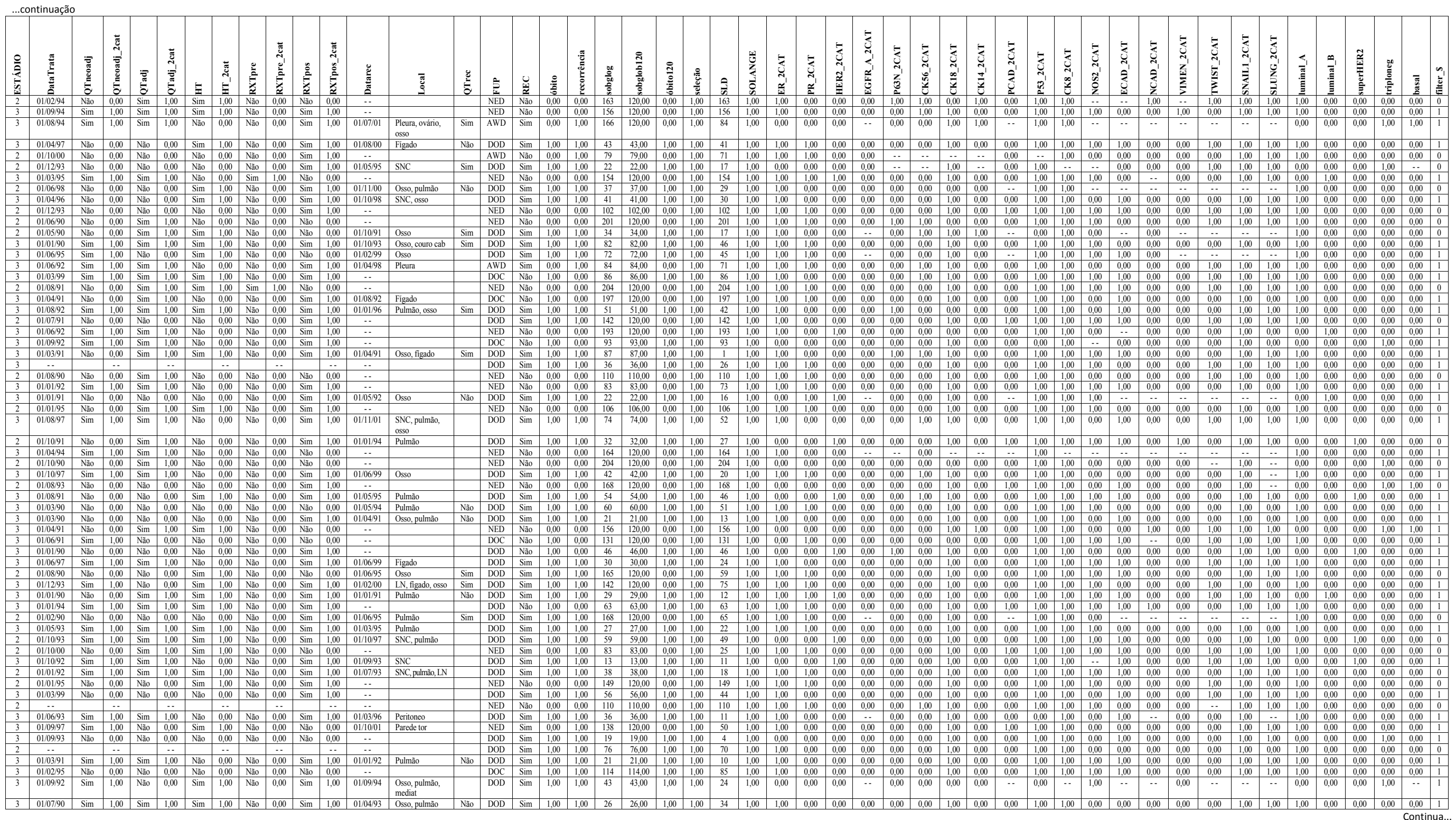




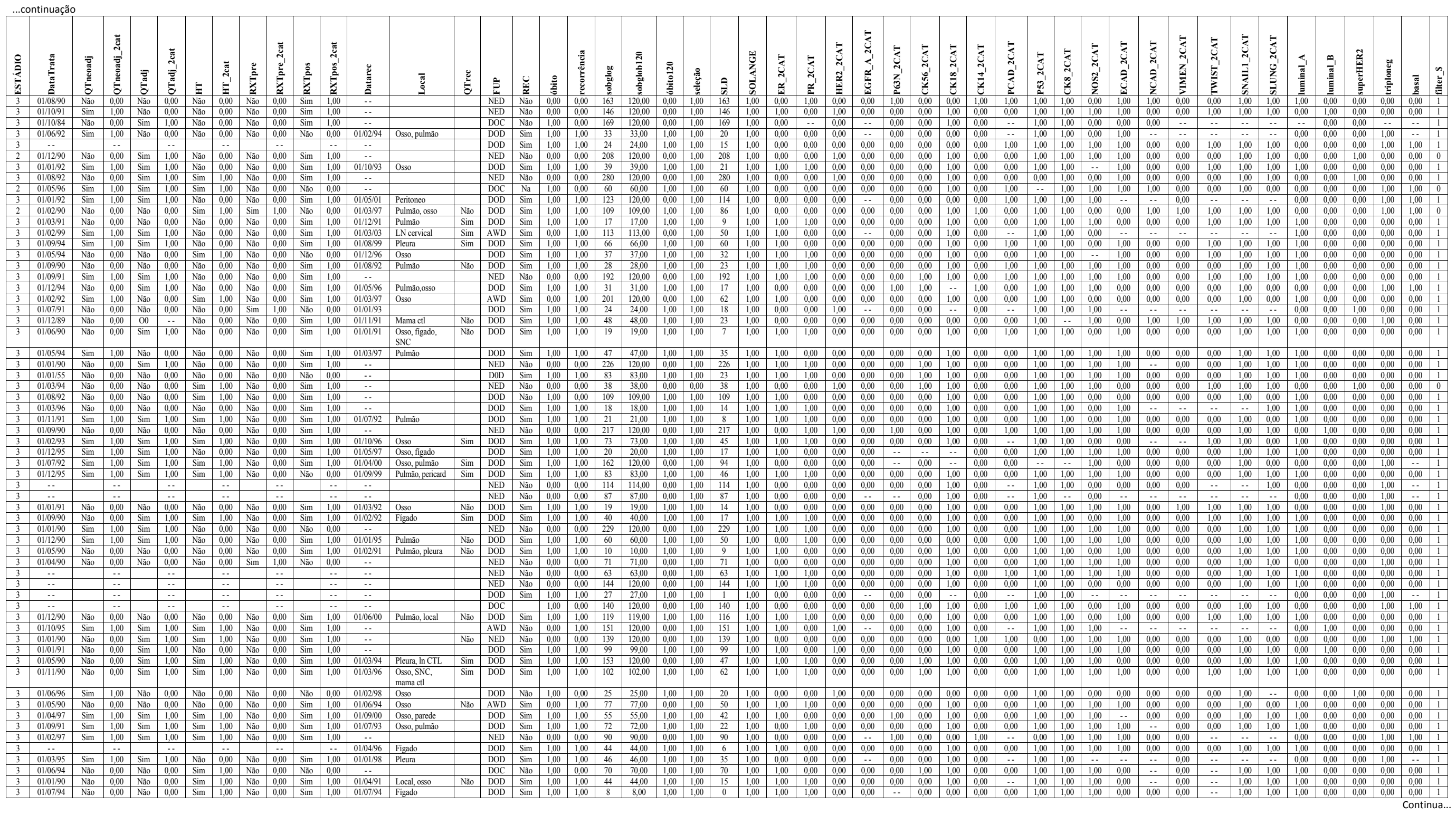




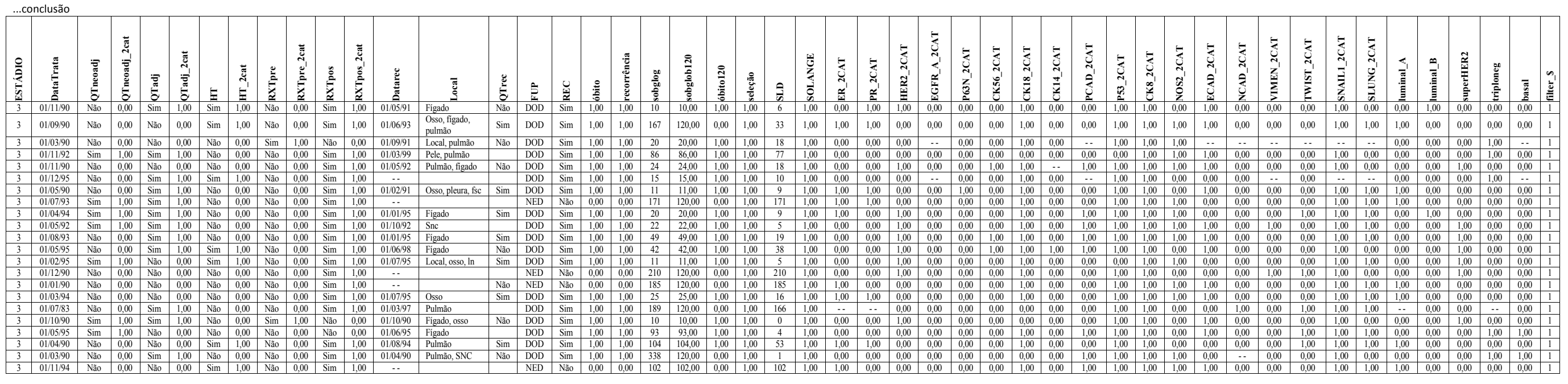

